\title{
Computer Simulations of Deep Eutectic Solvents. Challenges, solutions, and perspectives
}

\author{
Dmitry Tolmachev ${ }^{1 *}$, Natalia Lukasheva ${ }^{1}$, Ruslan Ramazanov ${ }^{1}$, Victor Nazarychev ${ }^{1}$, Natalia Borzdun ${ }^{1}$, Igor Volgin ${ }^{1}$, \\ Maria Andreeva ${ }^{1}$, Artyom Glova ${ }^{1}$, Sofia Melnikova ${ }^{1}$, Alexey Dobrovskiy ${ }^{1}$, Steven A. Silber ${ }^{2,3}$, Sergey Larin ${ }^{1}$, Rafael \\ Maglia de Souza ${ }^{4}$, Mauro Carlos Costa Ribeiro' ${ }^{4}$, Sergey Lyulin ${ }^{1}$ and Mikko Karttunen ${ }^{1,2,3,5 *}$
}

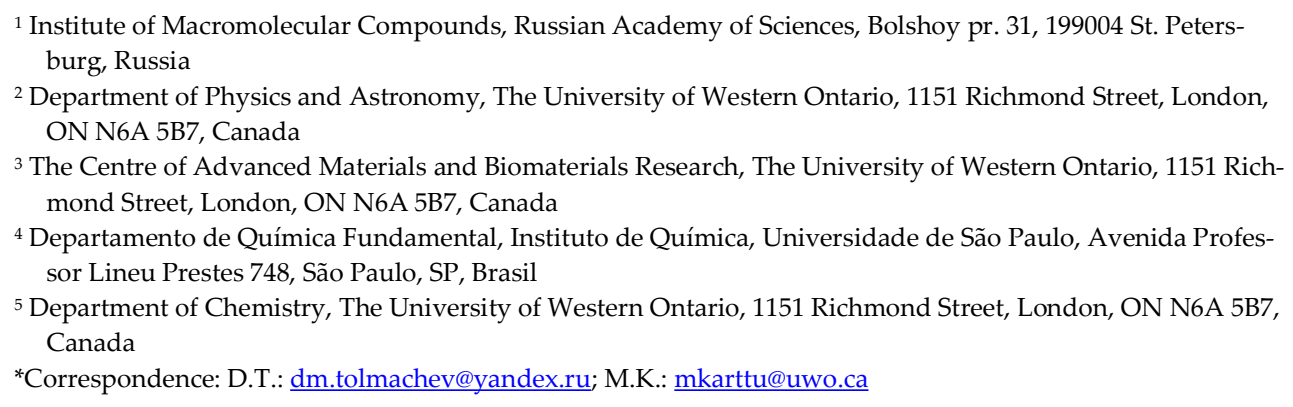

\begin{abstract}
Deep eutectic solvents (DESs) are one of the most rapidly evolving types of solvents, appearing in a broad range of applications such as nanotechnology, electrochemistry, biomass transformation, pharmaceuticals, membrane technology, biocomposite development, modern 3D-printing, and many others. The range of their applicability continues to expand, which demands the development of new DESs with improved properties. To do so requires an understanding of the fundamental relationship between the structure and properties of DESs. Computer simulation and machine learning techniques provide a fruitful approach as they can provide predictions, reveal physical mechanisms and readily be linked to experiments. This review is devoted to the computational research of DESs and describes technical features of DES simulations and the corresponding perspectives on various DES applications. The aim is to demonstrate the current frontiers of computational research of DESs and discuss future perspectives.
\end{abstract}

Keywords: deep eutectic solvents; computer simulation; quantum mechanics; molecular dynamics; machine leaning.

\section{Introduction}

Over the past two decades, deep eutectic solvents (DESs) have become increasingly sought after for a wide range of applications [1,2]. A DES is generally considered to be a multicompound solvent consisting of Lewis or Brønsted acids forming a eutectic mixture. The defining characteristic of a DES is that its melting temperature is substantially lower than the melting temperatures of its individual compounds, that is, the melting point is much deeper than typical melting point depressions of other eutectics. This was first discovered by Abbott et al. [3] using a mixture of choline chloride $(\mathrm{ChCl})$ and urea (in the molar ratio 1:2), which is so-called reline, currently one of the most studied DESs. A mixture of $\mathrm{ChCl}$ and urea at a molar ratio of $1: 2$ melts at $30^{\circ} \mathrm{C}$ [4] and the corresponding ideal solution melts at $100{ }^{\circ} \mathrm{C}$. 
Since the first publications in 2001 [3], the number of articles devoted to DESs has increased exponentially and to-date there are over six thousand publications on this topic, according to Web of Science. This great interest in DESs is due to their unique properties. DESs are often classified as cheap, non-toxic and environmentally friendly analogues of ionic liquids (ILs); see, e.g. Amde, Liu and Pang [5] for a review regarding environmental aspects of ILs. DESs have indeed shown great potential for nanotechnology [6], electrochemistry [7], extraction processes [8], biomass transformation [9], additive technology $[10,11]$, pharmaceuticals [12,13], biosensor development [14], membrane technology $[15,16]$, and many other applications.

Despite the fact that DESs have similar physical properties to ILs, they differ significantly in their chemical structures. DESs are mixtures of at least two compounds that have different types of interactions, which are the underlying reason for the strikingly deep melting points.

Table 1. Types of DESs, their compositions and examples.

\begin{tabular}{|c|c|c|}
\hline Type & Composition & Example \\
\hline Type I & Organic and metal salts & $\begin{array}{l}\text { Choline chloride }+ \text { Metal halide }\left(\mathrm{SnCl}_{2} \text {, }\right. \\
\left.\qquad \mathrm{ZnCl}_{2} \text {, etc. }\right)\end{array}$ \\
\hline Type II & Organic and metal salt hydrate & $\begin{array}{l}\text { Choline chloride }+ \text { Metal salt hydrate } \\
\left(\mathrm{CrCl}_{3}{ }^{*} 6 \mathrm{H}_{2} \mathrm{O} \text {, etc. }\right)\end{array}$ \\
\hline Type III & $\begin{array}{l}\text { Organic salt and H-bond do- } \\
\text { nor }\end{array}$ & $\begin{array}{l}\text { Choline chloride }+ \text { organic compound } \\
\text { (urea, carboxylic acids, alcohols, etc.) }\end{array}$ \\
\hline Type IV & Metal salt and H-bond donor & $\begin{array}{l}\text { Metal halide }\left(\mathrm{ZnCl}_{2}\right)+\text { organic compound } \\
\text { (urea, carboxylic acids, alcohols, etc.) }\end{array}$ \\
\hline
\end{tabular}

DESs are typically classified into four types depending on their chemical nature, as listed in Table 1. Type III deserves special attention since it includes a subclass of natural DESs (NADESs). NADESs are special in the sense that their components are derived from natural resources. The term "natural DES" was first proposed by Choi et al. in 2011 [17]. NADESs are biocompatible and biodegradable which expands their potential applications to the medical field. It is important to point out that DESs are multi-component systems and consist of various types of compounds (salts, acids, alcohol, etc.). The versatility of the components opens up broad opportunities for DES development with highly tunable properties.

One of the proven approaches to targeted material development is combined experimental and theoretical research $[18,19]$. Theory is used to determine the relationship between the structure and properties and can serve as a guide for further experiments. Computer simulations have their own methodological and practical issues, but they are unique in that they allow for direct observations of intermolecular interactions and processes at the nanoscale $[20,21]$. According to Web of Science, the number of studies devoted to computer simulations of DESs has been increasing exponentially since 2013 (Figure 1). In addition, the development of artificial intelligence (AI)-based approaches offers a new way to establish links between the structure and material properties. 


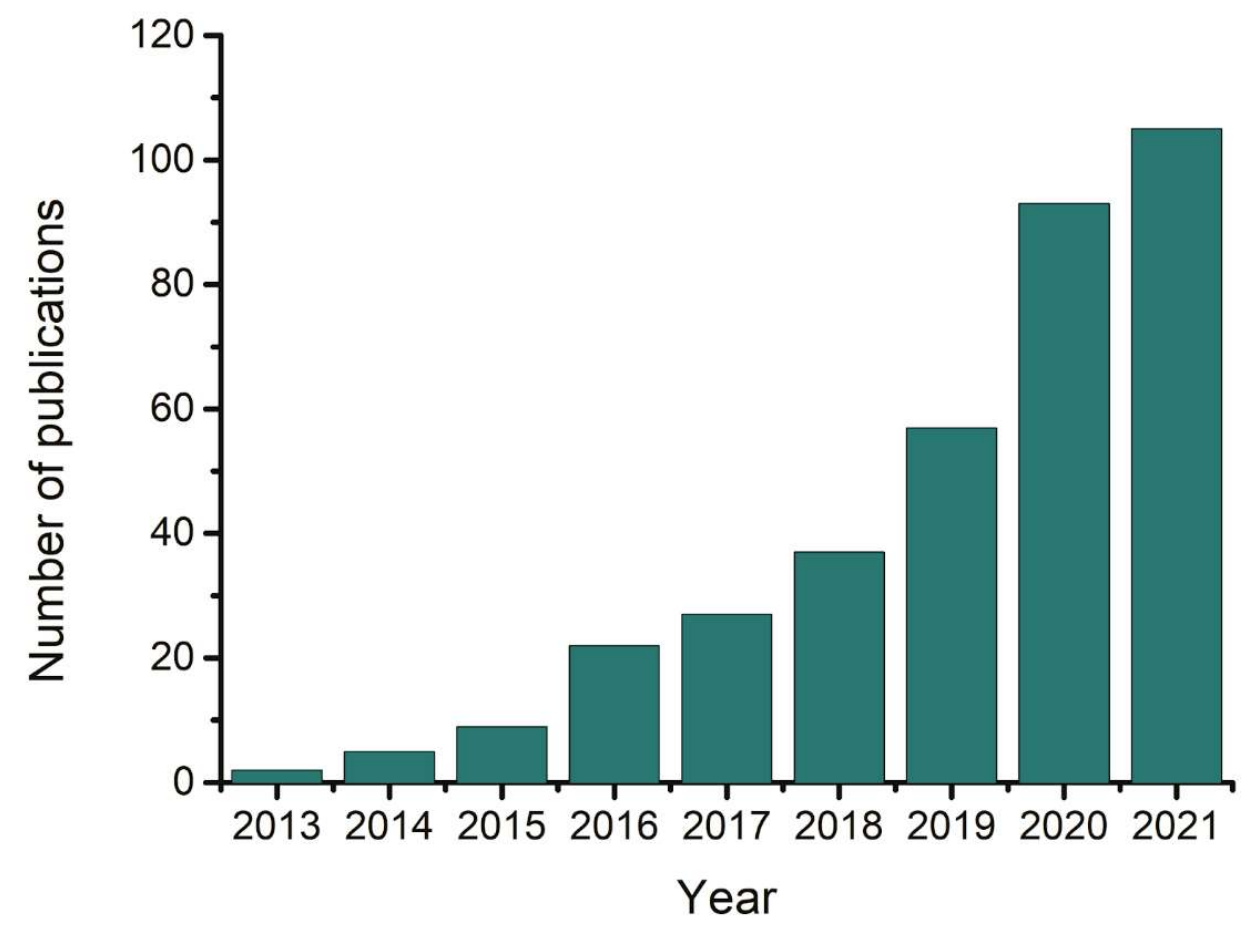

Figure 1. Number of publications per year with keywords "DESs + simulation" in the Web of Science.

Computer simulations that are directly related to DESs can be divided into different groups. Most of the works are devoted to the structure and dynamical properties of DESs to understand how those relate to the composition. Another important direction is low molecular weight compounds in DESs with a main focus on the development of separation membranes for $\mathrm{CO}_{2}$ and $\mathrm{SO}_{2}$ removal, as well as biofuel purification. In nanotechnology, DESs are applied as solvents for the development of nanoparticles. In this context, knowledge about the interactions of the nanoparticle surfaces with DES molecules, and their influence on DES structure and dynamics, are fruitful targets for simulations. Since DESs are used as electrolytes in power systems and battery technology [22], interactions of DESs with electrode surfaces is an important subject. Recent studies have also suggested the potential of DESs as storage media for biomolecules [23], and even as solvents for drugs [24] and pharmaceutical agents [25,26]. In all of the above cases, it is extremely important to understand how DESs affect the molecular conformations, which can be revealed by computer simulation techniques such as atomistic molecular dynamics (MD) simulations. The last but not least popular DES application is biomass formation, where a DES serves as a solvent for carbohydrates. In this case, simulation techniques can be used to reveal the molecular mechanisms and interactions responsible for the solvation of carbohydrates. The most important area of study is perhaps the influence of water molecules on the properties of DESs. Since in practice, it is almost impossible to remove water from DESs, and the water molecules dramatically affect the H-bonding network in it [27-29], understanding the influence of water is of critical importance.

In this review, we focus on simulations of DESs. Currently, there are only two reviews in which simulations of DESs are the central topic: Kovács et al. [30] reviewed the modeling of NADESs and Alkhatib et al. [31] devoted much attention to simulations of DESs in their review on thermodynamic modeling of DESs. These reviews were published at the end of 2019. Since then, the number of articles devoted to simulations of DESs has almost doubled (Figure 1). Some computational studies have been discussed in reviews devoted to current DES applications. For example, Kaur et al. [32] reviewed the research 
on microstructure and devoted part of the review to simulations of DES structures. Pelaquim et al. [16], Liu et al. [15], and Shama et al. [33] have provided overviews of studies devoted to modeling gas solubility in DESs. De Castilla et al. [34] discussed research on simulating thermodynamic and transport properties of DESs in their review. Ma et al. [28] analyzed the effect of water on DESs and provided a review of related simulations.

In this article, we review the status of computer simulations devoted to DESs. We discuss simulations of DES at different scales (quantum chemistry calculations, atomistic modeling and coarse-grained simulations) and also address machine learning techniques.

\section{Simulation methods for DESs}

\subsection{Quantum mechanical methods}

Interactions between molecules in DESs are more diverse than in regular liquids and understanding them is more difficult. Namely, the nature of the H-bond network and charge delocalization between solvent components are some of the key matters of interest. The first general consideration about the physical mechanisms in reline was the suggestion that when urea interacts with chloride anions, they disrupt the choline chloride's lattice, which leads to charge delocalization and prevents crystallization [35]. Later, it was shown by Altamash et al. using electronic structure calculations that the greatest charge transfer occurs from the anion to the choline cation [36]. Matters are more complex, however, and it has also been shown that the interactions between urea and chloride do not necessarily lead to a decrease in the melting point $[37,38]$.

\subsubsection{DFT-derived peculiarities of the local DES structure}

Since electronic structure methods are very demanding when it comes to computational resources, it is necessary to select a small but sufficient fragment of a DES for the simulation. As a good compromise between accuracy and efficiency at the quantum level, density functional theory (DFT) is typically the preferred method as it can provide a good description of geometry and electronic structure with reasonable calculation times. For example, DFT functionals are commonly used to calculate equilibrium geometries of single molecules or complexes of molecules bound by networks of various interactions in the gas phase or by applying continuum solvation models [39] to simulate the effects of a solution [39-41].

The conformational space of mutual arrangements of molecules in a DES can be studied using, e.g., semi-empirical methods (SE) such as the PM6 approximation [42,43] or the SE tight-binding DFT method GFN2-xTB [44]. DFT can also be used to study the details of the type and intensity of the interactions as well as to quantify the short-range interactions. Methods to study such properties include Bader's quantum theory of atoms in a molecule (QTAIM) [45], electrostatic potentials (ESP) and reduced density gradients (RDG). Classification of H-bonds, the corresponding bond strengths and covalency can be done by analyzing bond critical points (BCP) in the QTAIM representation (as an example of a simple system, see Ref. [46]). Based on electron density and its derivatives, RDG analysis can characterize noncovalent interactions such as H-bonds, van der Waals interactions, and steric effects [47].

As for functionals, a lot of studies of systems containing no more than several dozen atoms have been performed using the hybrid B3LYP functional with $20 \%$ HF exchange in conjunction with the family of Pople's split-valence basis sets with the addition of a different number of diffuse and polarization functions (6-31G(d), 6-31G(d,p), 6-31+G(d,p)) [44,47-57], and correlation-consistent basis sets with augmented diffuse functions aug-ccPVDZ [58]. Some organic cations contain alkyl side chains and/or aromatic moieties with important contributions from dispersion forces and hence require a proper description. This can be done by amending the density functionals with dispersion corrections such as Grimme's D2 [55,59], D3 [47,60-62] and D3BJ [63]. Another popular alternative is to use the meta-hybrid functional M06-2X with 54\% HF exchange. It has been shown to have 
excellent performance and accuracy in systems where dispersion interactions contribute significantly to conformer energetics [50,64-70]. Other functionals, for example hybrid long-range corrected CAM-B3LYP [50], hybrid PBE0 [50], hybrid PW91 [71] have also been used, albeit rarely.

DFT approaches have not only been fruitful for studies of distribution patterns of DES components, but also in studies of interactions of DESs with various functional substances in gas separation. In particular, free energy changes and structural analyses have been used to develop new solutions towards desulfurization of liquid fuels $[56,61,68,69,72]$, capturing greenhouse gases such as $\mathrm{CO}_{2}$ or $\mathrm{SO}_{2}[55,62,73,74]$, metronidazole extraction from plasma [75], developing efficient mercury removal strategies from different gases [76], extractive detoxification of feedstocks for the production of biofuels using new hydrophobic DESs [57], capturing $\mathrm{NH}_{3}$ [77] and for separating phenolic compounds from oil mixtures [78].

Even more complex problems have been investigated in the context of nanoobjects. Lawal et al. [79] provided a molecular-level description of the interactions controlling a DES composed of a mixture of methyltriphenylphosphonium bromide with glycerol and carbon nanotubes and revealed physisorption through hydrophobic and $\pi-\pi$ interactions. Shakourian-Fard et al. [70] used the M06-2X functional to analyze the electronic structure of noble metal nanoparticles ( $\mathrm{Mn}, \mathrm{M}=\mathrm{Cu}, \mathrm{Ag}$, and $\mathrm{Au} ; \mathrm{n}=1-4)$ and their complexes with $\mathrm{ChCl}$ :Urea DES. The study revealed two major bonding factors that govern the interactions: the $[\mathrm{Cl}]^{-} . . . M_{n}$ interaction and unconventional H-bonds (C-H...Mn and N-H...Mn). Shakourian-Fard et al. [70] used the M06-2X/cc-pVDZ level to characterize adsorption of DESs on different graphene surfaces and showed that it is noncovalent and dominated by dispersion energies.

\subsubsection{Relations between DFT and NMR \& FTIR experiments of DESs}

It is imperative to compare computational predictions with experiments, for example, Fourier-transform infrared spectroscopy (FTIR) or nuclear magnetic resonance (NMR). NMR enables studies of structure-property relationships and interactions in DESs by probing both cations and anions through several nuclei $\left({ }^{1} \mathrm{H},{ }^{13} \mathrm{C},{ }^{19} \mathrm{~F},{ }^{35} \mathrm{Cl},{ }^{11} \mathrm{~B},{ }^{15} \mathrm{~N}\right.$, and 31P) [80]. The use of NMR chemical shift deviations, relaxation, nuclear Overhauser effect, and diffusion experiments allows for advanced studies of cation-anion-solute interactions, and consequently, facilitates the molecular design of DESs. Li et al. [72] used the B3LYP/6-311+G(2d,p) level with the self-consistent reaction field solvation model to study the solvation effects of dimethylsulfoxide (DMSO). They calculated the NMR shielding constants of hydrogen atoms by the gauge-including atomic orbitals (GIAO) method [81] for different $\mathrm{SO}_{2}$-anion adducts of DESs and revealed molecular details of sorption.

FTIR is a reliable technique for analyzing not only liquids but also solid samples. Vibrational modes from DFT calculations may be matched against FTIR absorption spectra. The presence of hydrogen bonds can be deduced from FTIR spectra after vibration assignments. The accuracy is determined by the system size and how well the range of internal vibrational frequencies inherent in the system is covered. As an example, Araujo et al. [53] used a combination of computational and vibrational spectroscopy tools, including inelastic neutron scattering (INS), to probe intermolecular interactions in a eutectic mixture of reline. Their analyses showed that reaching an agreement between calculations and experiments requires expanding the models to include a greater variety of molecular contacts. They performed comparative calculations of a discrete model of a single cluster by utilizing the B3LYP functional and calculations of a periodic model of the aggregate by using the plane-wave pseudopotential method with the Perdew-Burke-Ernzerhof (PBE) [82]. The eigenvalues and eigenvectors from the Gaussian's frequency calculation of a single cluster were then used to estimate the intensities of the INS spectrum. The phonon frequencies for the aggregate were obtained by diagonalization of the dynamical matrices computed using density-functional perturbation theory [83]. As a result, the region above 
$200 \mathrm{~cm}^{-1}$ in reline's INS spectrum is satisfactorily described by the discrete cluster approximation. The simulations, however, failed in the lowest frequency region, which, as mentioned by the authors, may only be adequately represented by a three-dimensional lattice.

The phonon modes of the "shock-frozen" reline in an amorphous phase representing a 3D array of extended clusters also did not perfectly succeed in replicating reline's lowfrequency modes. Araujo et al. [53] noted that while discrete ab initio calculations of internal vibrational modes satisfactory match to INS experiments, a little improvement is achieved by running periodic calculations of the aggregate. The authors also noted that the advantage of the periodic over the cheaper discrete calculation is a better representation of the pure solvent components, whose details of crystal lattice packing is impossible to reproduce using a small cluster. Hence, when going from pure solvent components to their eutectic mixture, it requires a certain model of the pure crystal lattices for a realistic comparison of calculated and experimental frequency shifts.

\subsubsection{Periodic DFT in studies of the condensed phase of DESs}

Periodic ab initio calculations have become a popular tool allowing the study of hundreds of atoms. This method serves as a powerful instrument to investigate the electronic structure of the condensed phase of DES, but the system sizes are still limited. Usually, periodic ab initio calculations use the DFT in the hybrid Gaussian and plane waves (GPW) approach [84].

Korotkevich et al. [85] used this approach to study $\mathrm{SO}_{2}$ absorption by $\mathrm{ChCl} /$ glycerol DES. The molecularly optimized double-z basis set (MOLOPT-DZVP-SR-GTH) [86] was applied to all atoms together with the generalized gradient approximation (GGA) utilizing the Becke-Lee-Yang-Parr (BLYP) $[87,88]$ functional and the corresponding BLYP Goedecker-Teter-Hutter (GTH) [89] pseudopotentials for core electrons. The deficiency of the dispersion interactions for the GGA functional was corrected using Grimme's D3 scheme with Becke-Johnson damping [90,91]. The authors identified hydrogen bonding and other specific interactions between all components. Fetisov et al. [92] used the same approach to conduct $a b$ initio MD (AIMD) simulations in the canonical ensemble at temperatures of 333 and $363 \mathrm{~K}$ to investigate the behavior of reline and its equimolar mixture with water. It was shown that in hydrous reline, water competes for the anions, and the hydrogen atoms of urea have similar propensities to bond to the chloride $\left(\mathrm{Cl}^{-}\right)$ions and the oxygen atoms of urea and water. The same level of theory was used by Malik et al. [73] to elucidate the solvation structure around $\mathrm{CO}_{2}$ and $\mathrm{SO}_{2}$ in $\mathrm{ChCl}$-based DESs, namely, reline and ethaline. Zahn et al. [93] revealed significantly reduced ion charges in several choline-based DESs by using ab initio molecular dynamics in the GPW representation.

\subsection{Molecular dynamics simulations}

MD simulations have become the most popular computational technique for studies of nanostructures and dynamic properties of materials [94]. MD provides direct information about the molecular processes, and can explain and predict molecular interaction mechanisms. More than half of the computational papers devoted to studies of DESs (more than 150 articles in the Web of Science by the end of 2021) use MD simulations. Most commonly, MD simulations are used to obtain information about the nanoscale structure. Another frequent goal is to study properties directly related to applications such as gas separation and fuel purification, i.e., simulations of low molecular weight compounds in DESs. The accessible length scales, typically on the order of about $10 \mathrm{~nm}$, allow simulations of nano-sized objects and surfaces of larger objects. Importantly, MD simulations are also a useful tool for investigations of rheological properties. The MD technique has, however, its own limitations, see e.g. Refs. [95-97]

The main challenge in MD simulations is the development of force fields (FFs) capable of reproducing the structural and dynamic properties of DESs. The history of FF development for DESs is inextricably linked to the development of FFs for ionic liquids, since 
the interactions in these solutions are very similar. However, due to the differences in compositions and specific interactions in them, the FFs for DESs have their own peculiarities. The main problems are related to the presence of strong ionic interactions and highly polarizable atoms and molecules, and thus neglecting polarization may lead to an overestimation of the ion-ion interactions [98] and potentially unreliable results, such as a reduction of the diffusion coefficient by several orders of magnitude [98]. However, non-polarizable FFs are often able to correctly reproduce the structural properties of DESs [99].

There are two main directions currently being pursued to solve the problem regarding polarization effects. The first is based on adding correction(s) to the noncovalent interactions in existing FFs. This approach has the advantage that it uses existing FFs and no additional parameterization is needed. Moreover, this approach does not require more computational resources than the usual MD. As a result, this has been the most common approach used in simulations of ionic liquids [100]. The second approach is the explicit inclusion of polarization effects in force fields, based on formulations that model the electronic degrees of freedom and thus requires more computational resources. This second approach is described in the next section.

The first approach is based on charge rescaling. Since the atomic charges in DESs have a significant impact on macroscopic properties [101], rescaling of the electrostatic interactions is an effective way to reparametrize FFs for DESs. The magnitude of rescaling has varied from 0.78 to 0.9 (e.g. Refs. [102-104]). Rescaling charges helps to reduce overbinding and achieve agreement with experimental values regarding dynamic properties [105]. However, this approach has its drawbacks. Since the magnitude of rescaling could depend on particular details of the system, a change in composition should be accompanied by new validation of the FF. A common approach for FF validation is to select the scaling parameter such that it reproduces experimental data, usually density, viscosity, and diffusion coefficients (e.g. Refs. $[106,107])$. Although charge scaling helps, at least in some cases, to achieve agreement with experiments, it can also lead to artificial structural and dielectric properties such as an excessive decrease in density [108], less intense peaks in the radial distribution functions, and an artificial dielectric response [109]. In addition, changes in the atomic charges can affect the parameterization of intermolecular interactions leading to artificial structural characteristics $[105,110]$. One particular problem is the incapacity of the scaled-charge models to fix the artificially enhanced long-range ion-ion correlations present in non-polarizable models, as discussed by McDaniel and Yethiraj [111]. Besides that, Son et al. [112] have shown that mixtures of compounds are not well reproduced with scaled-charge models, since these models underestimate the cohesive energy and lead to poor predictions of phase behavior.

As the above indicates, finding new approaches to develop transferable FFs is of critical importance. For example, Chaumont et al. [113] proposed a reparametrization of the van der Waals potentials for atoms involved in H-bonding as an alternative to charge rescaling. Another fruitful approach is explicit inclusion of polarization. Compared to fixed-charge FFs, polarizable FFs are significantly more demanding on computational resources but are more accurate and help to reproduce both structural and dynamic properties. Polarizable FFs are discussed in detail in the next section. The main advantage of fixed-charge FFs is their high transferability, which allows for easy changes of DES compositions and simulations of diverse compounds. However, despite their ability to model and predict structural characteristics, their lack of accounting of polarization is a major drawback. Corrections to existing fixed charge FFs allow to achieve correct results on dynamic properties, but that often comes at the expense of transferability and can lead to unexpected artificial results.

\subsection{Polarization and Polarizable Force Fields for Deep Eutectic Solvents}

There are several ways to introduce polarization effects such as fluctuating charges $[114,115]$, induced point dipoles [116], or Drude oscillators [117,118]. Fluctuating charges allow mimicking polarizability with a respectively low computational cost. However, in 
some cases, it might overestimate the polarizability of the molecule [119] and cannot simulate induction of the out-of-plane dipole moment in planar molecules. The induced point and Drude-induced dipoles are based on using additional particles, either as massless points (induced point dipoles) or as positive and negative charges connected to the atoms by a spring. Schmollngruber et al. have shown that there are no quantitative differences between these two methods in simulations of molecular IL of 1-ethyl-3-methyl-imidazolium triflate [120].

The high concentration of ions in DESs results in non-negligible local electric fields that polarize the components of the eutectic solution. So far, almost all MD simulations of DES have been done with nonpolarizable models only. However, efforts are emerging towards simulations with polarizable FFs [121-124]. They are all based on the classical Drude oscillator model, which will be briefly described next. For a deeper understanding of this method, as well as other polarization methods, see the review of Bedrov et al. [98]

The Drude oscillator model consists of adding an additional particle, the Drude particle (DP), bonded to the nucleus, also called the Drude core (DC), by a harmonic potential. In this arrangement, the DP receives a negative charge $\left(-q_{D}\right)$, while the DC receives a positive charge $\left(q_{D}\right)$, which is summed onto the initial charge of that nuclei, forming a Drude induced dipole. This dipole is intended to capture the distortion of the electron cloud, since the DPs are free to move around the nucleus. The pair of charges $\left( \pm q_{D}\right)$ assigned to the DP and DC of a polarizable atom are determined by the atomic polarizability of that atom and the force constant of the harmonic potential that connects the DP to the DC. Besides that, the polarizability of the hydrogen atoms is usually added onto the polarizabilities of the heavy atoms that own them; hydrogens themselves are treated as non-polarizable because of their small atomic mass. The relation between the polarizability $(\alpha)$, force constant $\left(k_{D}\right)$, and Drude charges $\left( \pm q_{D}\right)$ is given by

$$
\alpha=\frac{q_{D}^{2}}{k_{D}} .
$$

\subsubsection{The polarizable CL\&Pol force field}

Besides the high computational cost, another main problem with polarizable FFs is their poor transferability. Recently, using the CL\&P fixed-charge FF [125] as the basis, Goloviznina et al. developed a transferable polarizable FF for ionic liquids [126] and extended it to DESs $[122,125]$. In order to increase transferability, they applied a fragment approach, which was validated by calculating density, ion diffusion coefficients and viscosity for a range of ionic liquids and their mixtures [126]. In DESs, the strong combination of H-bonds and Drude-induced dipoles causes stability problems, which were also addressed by Goloviznina et al. [122].

When converting the non-polarizable CL\&P model to the polarizable CL\&Pol, the first step is the addition of the Drude induced dipoles in the heavy atoms based on Equation (1). Atomic polarizabilities are determined by first principle calculations. In CL\&Pol $[121,122]$, the force constants of all of the harmonic bonds between the DCs and the DPs are assigned to be $k_{D}=4184 \mathrm{~kJ} \cdot \mathrm{mol}^{-1}$ and the masses of all DPs to $m_{D P}=\mathrm{DP}=0.4 \mathrm{u}$. It is also necessary to scale down the Lennard-Jones energy parameter $\varepsilon$ to avoid double counting the polarization effects, since induction effects are implicitly included in the CL\&P parameter set [125].

In principle, this scaling can be rigorously performed based on symmetry-adapted perturbation theory [127] (SAPT) calculations, a quantum chemistry method that allows decomposing the interaction energies into electrostatic, induction, dispersion, and repulsive terms. However, SAPT calculations are computationally intensive, especially if applied to a broad range of compounds. In this context, an alternative predictive scheme was devised by Goloviznina et al. [121,122,126] to obtain the scaling factor $(k i j)$ for the interaction between fragments $i$ and $j$, 


$$
k_{i j}=\left(1+c_{0} r_{i j}^{2} \frac{Q_{i}^{2} \alpha_{j}+Q_{j}^{2} \alpha_{i}}{\alpha_{i} \alpha_{j}}+c_{i} \frac{Q_{i}^{2} \mu_{j}+Q_{j}^{2} \mu_{i}}{\alpha_{i} \alpha_{j}}\right)^{-1} .
$$

This scheme only needs basic molecular properties of the target fragments: net charges $(Q)$ dipole moments $(\mu)$, and polarizabilities $(\alpha)$. In addition, $r_{i j}$ is the equilibrium distance of the fragments, and $c_{0}=0.25$ and $c_{1}=0.11$ are coefficients that were adjusted to a set of reference $k_{i j}$ values, obtained from SAPT calculations that covered charged and neutral key-fragments. These key-fragments are common molecular structures present in a broad range of DESs components, which allow to achieve a good transferability. For instance, triethylammonium cations are represented by trimethylammonium and butane as fragments.

All of the intramolecular bonded parameters and initial atomic partial charge distributions are simply taken from the CL\&P FF [125]. In addition, for modeling DESs with CL\&Pol, two new potentials are present. These are the Tang-Toennies [128] and Thole [129] damping functions,

$f_{n}\left(B_{i j}, r_{i j}\right)=1-c e^{-B_{i j} r_{i j}} \sum_{k=0}^{n} \frac{\left(B_{i j} r_{i j}\right)^{k}}{k !}$,

$T\left(r_{i j}\right)=1\left(1+\frac{p r_{i j}}{2\left(\alpha_{i} \alpha_{j}\right)^{1 / 6}}\right) e^{-p r_{i j} /\left(\alpha_{i} \alpha_{j}\right)^{1 / 6}}$,

where $k=4$ is the order of the sum, $B=4.5$ determines the spatial extension of the damping, $c=1, r_{i j}$ is the distance between the sites, $i$ is the polarizability of atom $i$, and $p=2.6$ is the Thole Parameter.

The Thole function is used to dampen, at short distances, the Coulomb interactions originating from the induced dipoles. The Tang-Toennis function dampens short-range charge-dipole interactions, avoiding instabilities in the MD simulations. These functions avoid the "polarization catastrophe" [98,122], that is, excessive correlations between nearby dipoles and also events in which the DPs are captured by neighboring DCs.

An important aspect when using the CL\&Pol FF is the absence of Lennard-Jones parameters in some of the hydrogen atoms, especially those involved in H-bonds, such as the hydroxyls group of choline cations and polyol molecules. These hydrogen atoms are referred to as "naked" hydrogens [121,122]. This particular aspect may lead to unrealistically strong interactions after the addition of the Drude particles. This can be circumvented by increasing the atomic diameter ( $\sigma$-parameter) of the heavy atom to which such as a hydrogen is bound [121,122]. Recently, de Souza et al. [130] showed that using the values of the $\sigma$-parameter of the CL\&Pol FF leads to an artificial phase separation between the components of the DES ethaline. This can be fixed by carefully adjusting the $\sigma$-values of the hydroxyl groups to reproduce $a b$ initio radial distribution functions.

There is emerging evidence about the so-called "chloride's overpolarization" that may be present in polarizable MD simulations. This was first noted by Szabadi et al. [131], who performed aqueous chloride-based ionic liquid simulations, and subsequently reported by de Souza et al. [130] in DES ethaline. This issue has its physical origin in the high polarizability of chloride, $\mathrm{Cl}=4.4 \AA^{3}$. In the work of Szabadi et al. [131], they noted an artificial alignment of chlorides with water molecules. In turn, de Souza [130] found that this overpolarization leads to an overestimated spatial nano-heterogeneity, as indicated by peaks and antipeaks at very low q-vector values in all self- and cross-correlations of the partial X-ray structure factors. Szabadi et al. [131] tried to reduce the chloride's polarizability, while de Souza et al. [130] extended the application of the Tang-Toennis damping function for chloride's induced dipole interactions. In both cases, the behavior of the polarizable MD simulations improved.

The aforementioned aspects of the CL\&Pol FF ("naked" hydrogens and chloride's overpolarization) may make it difficult to apply in simulations of DESs. Nonetheless, following the guidelines of the original CL\&Pol FF [121,122] and the contributions from de 
Souza et al. [130] facilitate its reliable use. In addition, the CL\&Pol FF has parameters available for a broad range of components of DESs, such as alkylammonium-based and alkylphosphonium-based cations, urea, ethylene glycol, and so on. Besides that, the CL\&Pol model is relatively easy to extend to other components, since it shares the functional form and parameterization strategy of the OPLS FF.

\subsubsection{The polarizable SAPT force field}

The second available polarizable FF for DESs is the model from Jeong et al. [124], which we will refer to as SAPT-FF since it is completely obtained from scratch based on a SAPT protocol [132]. In this approach, the atomic point charges are obtained using a distributed multipole analysis (DMA) on the electron density of a single molecule. Then, the intermolecular parameters from distinguished FF terms are individually fitted to the components of the total non-bonded energy, composed of electrostatics, induction, exchange, dispersion, and delta Hartree-Fock, all obtained from SAPT calculations. The functional form of these energy components are given as

$$
\begin{aligned}
& E_{\text {elec }} \approx \sum_{i j} \frac{q_{i} q_{j}}{r_{i j} q_{j}}+\sum_{i j} A_{i j}^{e l e c} e^{\left(-B_{i j} r_{i j}\right)}, \\
& E_{\text {pol }} \approx U_{\text {shell }}^{(2)}+\sum_{i j} A_{i j}^{\text {ind }} e^{\left(-B_{i j} r_{i j}\right)}, \\
& E_{\text {exch }} \approx \sum_{i j} A_{i j}^{\text {exch }} e^{\left(-B_{i j} r_{i j}\right)}, \\
& E_{\text {disp }} \approx \sum_{n=6,8,10,12} \sum_{i, j} f_{n}\left(B_{i j}, r_{i j}\right) \frac{c_{n}^{i j}}{r_{i j}^{n},} \\
& E_{\text {pol }} \approx U_{\text {shell }}^{(\Delta S C F)}+\sum_{i j} A_{i j}^{\delta h f} e^{\left(-B_{i j} r_{i j}\right)} .
\end{aligned}
$$

The electrostatic energy $\left(E_{\text {elec }}\right)$ is composed of a Coulomb potential and a short-range term describing charge penetration effects. The induction energy $\left(E_{p o l}\right)$ is the contribution from the polarizable Drude oscillator (the second-order Drude oscillator energy) plus a short-range charge penetration component. The exchange energy $\left(E_{\text {exch }}\right)$ describes the short-range repulsion with an exponential Born-Mayer function. The dispersion energy $\left(E_{\text {disp }}\right)$ is represented with a series of $\mathrm{r}-\mathrm{n}$ power functions $(\mathrm{n}=6,8,10,12)$ and it is dampened by $f_{n}, B_{i j}, r_{i j}$, the Tang-Toennis function of Equation 3. The delta Hartree-Fock energy is composed of the Drude oscillator energy above second-order and the penetration component of the $\delta$ Hartree-Fock energy. Furthermore, for each pair of atoms, the preexponential coefficients $A_{i j}^{\text {elec }}, A_{i j}^{\text {ind }}, A_{i j}^{\text {exch }}$, and $A_{i j}^{\delta h f}$ determined based on the SAPT energy benchmark. In addition, the exponents $B_{i j}$ and the dispersion coefficients $C_{n}^{i j}$ are assigned with specific mixing rules [124].

The sum of all terms yields the total non-bonded energy expression,

$E_{\text {total }} \approx \sum_{i j} \frac{q_{i} q_{j}}{r_{i j} q_{j}}+U_{\text {shell }}+\sum_{i j}\left(A_{i j}^{t o t} e^{\left(-B_{i j} r_{i j}\right)}-\sum_{n=6,8,10,12} f_{n}\left(B_{i j}, r_{i j}\right) \frac{c_{n}^{i j}}{r_{i j}^{n}}\right)$,

where $U_{\text {shell }}=U_{\text {shell }}^{(2)}+U_{\text {shell }}^{(\triangle \mathrm{SCF})}$ is the total Drude oscillator polarization energy and it considers all the intramolecular DP-DP interactions. Those atom pairs at 1-4 or closer distances are screened using the Thole function of Equation 4 with $p=2.0$.

The costly case-by-case SAPT-based parameterization combined with the incompatibility of the specific functional form of the SAPT-FF with commonly used FFs are challenging aspects to achieving transferability. In fact, reline is the only available DES within 
the SAPT-FF [124]. However, this "physically motivated" SAPT-FF presents some advantages. In principle, any DES can be simulated in this formalism, considering that the FF is fitted to $a b$ initio data and no prior experimental data is needed in advance. Furthermore, due to the explicit separation of energy components, improvements in the quality of individual parameters are possible without the need for complete reparameterization. In addition, the molecular interactions present in MD simulations of any DESs can be accurately rationalized in terms of the different energy contributions.

\subsection{Combinations of quantum mechanics and molecular dynamics techniques}

The previous sections highlighted the advantages and disadvantages of different computational approaches to studying DESs. One way to unite the strengths of these methods and overcome their weaknesses is to use them in combination. In this regard, there are two fundamentally different approaches. The first one implies the simultaneous application of MD and QM methods within a single study. The second approach involves the use of advanced $a b$ initio MD (AIMD) simulations, also known as first-principles MD. As quantum effects are not directly included in classical MD, several characteristics of the systems can be probed only with the use of QM approaches. Conversely, due to the complexity of QM calculations, the time and length scales accessible in classical MD are well beyond those available in QM.

Aparicio's group has used a combination of QM and MD to investigate the properties of a number of DESs, including ones based on $\mathrm{ChCl}$ [35-38], ammonium [133], arginine [134-136], betaine [137], and cineole [138] for applications such as gas capture, drug delivery, oil desulfurization, and the development of task-specific solvents. In particular, the strength and localization of H-bonds, the binding energy of the ionic pairs, as well as energetically favored positions of solvated molecules with respect to DES molecules were obtained from DFT. Their MD simulations allowed the estimation of properties such as intermolecular interaction energies, the extension of $\mathrm{H}$-bonds, their number, residence times, as well as prediction of the physicochemical properties of the fluids.

The QM and MD methods are not always applied independently. For example, Ali et al. [139] used MD simulations to obtain the energetically most favorable cluster conformers of menthol-based DESs, which required sufficient simulation time, and then DFT calculations were utilized to optimize the isolated structures and calculate their structural and thermochemical properties. In a study on $\mathrm{ChCl}$ /acetylsalicylic acid (ASA) therapeutic DESs by Saha et al. [139], radial distribution functions obtained from MD simulations demonstrated the presence of several H-bonds between the components and DFT calculations allowed demonstrating that $\mathrm{Cl}^{-}$is acting as a charge transfer bridge between choline and ASA. Finally, a combination of QM and MD methods is often not an independent research method, but an auxiliary way to confirm a hypothesis formulated on the basis of experimental findings, which is no exception in the case of DES studies [140,141].

Similar to classical MD, in AIMD, Newton's equations of motion are solved at each simulation step. However, instead of using a prescribed potential, DFT calculations are employed to calculate the energy, which is then considered a function of nuclear coordinates. Thus, AIMD directly treats many-body effects and polarizability. Moreover, compared to classical MD, AIMD does not struggle with the problem of poor transferability. The drawbacks of AIMD are small system sizes ( up to few 100 atoms) and short simulation times (picoseconds), as well as the need to apply corrections due to the lack of van der Waals interactions, similarly to DFT.

Although AIMD methods have long been used to study ILs, to date, only about a dozen papers are devoted to the studies of DESs utilizing this method. The first investigation of DESs by AIMD was reported by Zahn et al. in 2016 [93]. The authors examined several choline-based DESs, including the widely studied mixture of $\mathrm{ChCl}$ and urea. As the negative charge transferred from the halide anion to the organic compound was found to be negligible, the authors questioned whether the deep eutectic melting point is due to charge delocalization occurring through this hydrogen bonding. 
Among the subsequent AIMD simulations of DESs, a number of papers have focused on gas capture $[73,85,142]$. Since many-body effects and polarizability are directly included in AIMD, it is excellent for elucidating the local solvation structure around the gas molecules. For example, Malik et al. [73] demonstrated for $\mathrm{CO}_{2}$ and $\mathrm{SO}_{2}$ in reline and ethaline that charge transfer between the solute and the chloride anion determines the shapes of the solvation shells, while the nature of the H-bond donor (HBD) is responsible for its organization around the solute. AIMD allows one to investigate the solvation of not only small gas molecules in DES, but also, for example, mercury solvation, as its capture represents a major challenge in natural gas processing [143]. In addition to structural factors, AIMD has also been used successfully to probe charge transfer and chemical reactions in DES, as shown by Carrasco-Busturia et al. [144] and Warrag et al. [143].

AIMD can also be applied to validate FFs for classical MD simulations [145]. For example, Jeong et al. [124] utilized AIMD to develop atomistic polarizable FF for reline. The authors reported that the resulting FF is in good agreement with both AIMD simulations and experimental data on the static structure factor and diffusion coefficient.

The final remark concerns the significant limitation of the AIMD method, namely its resource intensity. Typical simulation times are of the order of hundred of picoseconds, while the available sizes of the systems reach only some hundreds of atoms [92]. For example, Carrasco-Busturia et al. [144] have studied the speciation and reactivity in $\mathrm{AlCl}_{3}$ :urea DES using AIMD. Estimated time scales required for direct AIMD simulation of reactants, $\mathrm{AlCl}_{3}$ and urea, were found to be well beyond nanoseconds, which is not feasible using AIMD. To overcome this technical limitation, the authors devised an approach based on the simulations of the products they hypothesized to be observed in this DES, such as chloroaluminate anions and [ $\mathrm{AlCl}_{\mathrm{x}}(\text { urea })_{\mathrm{y}}$ ] cations, which allowed them to determine the possible paths for aluminium electrodeposition in the battery anode with reasonable simulation times.

\subsection{Coarse-grained models}

Despite its strengths, all-atom MD is limited by its characteristic time and length scales and computational resources [146,147]. One of the possibilities to overcome the limitations imposed on the simulation times and system sizes is multiscale simulations. One of the critical steps in these schemes is the correct transfer of data between different levels of the representation. This data should contain both structural and thermodynamic properties.

Coarse-grained (CG) models are often built using structure reduction [146,148-151]. This requires the definition of a scheme to transform the atomic structure of the investigated system into a coarse-grained representation (mapping scheme) and the determination of the interaction parameters between individual types of CG particles, i.e., a FF.

Typically, each CG bead represents a group of atoms. Therefore, the transition from atomistic models to CG ones can significantly reduce the number of particles in a system and, consequently, the number of degrees of freedom but simultaneously may also lead to inaccuracies when computing properties via fluctuation-dissipation relations [152]. The other main disadvantage is the loss of essential chemical details. CG does, however, enable a significant expansion in system sizes and simulation times.

As in the case of all-atom MD, the choice of the FF is of critical importance. In general, the determination of interaction parameters is carried out individually for each calculated system, taking into account the specifics of the mapping scheme to convert an all-atom representation into a coarse-grained one [146,153-156].

It should be noted that one of the main drawbacks of CG models is the lack of general applicability (MARTINI [151] being the notable exception) since, as mentioned earlier, the choice of a mapping scheme and model parameters should be made taking into account the studied system and the problem that is being addressed. With an increase in the number of atoms included in each CG bead (i.e., with a decrease in the number of CG beads in a system), one obtains a greater gain in the speed and efficiency of modeling due to a 
decrease in accuracy. Another important problem in CG modeling is the issue of the transferability [157] of models and FF parameters between different thermodynamic states (for example, for modeling at different temperatures), as well as the relationship between the CG timescale and the actual timescale. Coarse-grained FFs from ILs [158] may offer alternatives that can be applied to DESs as well.

The well-established Dissipative Particle Dynamics (DPD) $[159,160]$ method has been used in a few DES simulations. Hu et al. [161] and Fan et al. [162] used DPD to study the self-assembly process of the zeolitic imidazole framework (ZIF) based on sodium dodecyl sulfate and zinc nitrate complex with 2-methilimidazole in reline with water. The simulation results made it possible to describe the structure of the hierarchical porous structure of ZIF-8 and the mechanism of its formation. Fan et al. [163] used DPD to study microemulsions based on DES ( $\mathrm{ChCl} /$ urea), tetrahydrofurfuryl alcohol (THFA), and diethyl adipate (DA). The simulations were used to calculate the phase diagram, which was found to be in good agreement with experimental data. The simulations also showed that the main driving force behind the formation of a microemulsion is the interaction between DA and amphiphilic THFA molecules associated with a change in surface tension. However, the main restriction of the DPD approach is related to the highly coarse-grained nature of the potentials, which enable only qualitative comparison with experimental data and all atom simulations.

\subsection{Machine learning methods}

Designing new DESs usually relies on an intuitive understanding of the relationship between the chemical composition of a DES and its properties. This can make molecular design time-consuming and costly. Machine learning (ML) has become an increasingly popular approach to alleviate such problems. ML is based on statistical processing of large datasets and detecting correlations between input and output data (for example between structure and property) and using them to predict properties of new compounds $[1,164,165]$. One of the most common applications of ML is prediction of the quantitative structure-property relationship (QSPR) [1,166]. For this purpose, the most frequently used mathematical models are Artificial Neural Networks (ANNs) and methods of regression analysis $[1,164,166]$.

\subsubsection{Working principles of ANNs}

ANN models consist of a set of nodes connected to each other and distributed over several layers, similar to the neuron cells in a human brain [164]. The data analysis typically begins with translating the structure from a chemical to mathematical language by coding it with molecular descriptors, or features [166]. There are a number of different types of descriptors; they can originate, for example, from properties with a clear physical meaning (e.g. molecular mass, the number of carbons in the structure, HOMO or LUMO energies and other characteristics obtained through the quantum chemical calculations) or from any type of topological indices [167].

After a translation of the structure to a set of its features has been performed, it can be regarded as an input layer of an ANN. The next step is transferring the initial data from one layer to another by applying a transformation function to the input data using appropriate weights at each node. The final layer consists of nodes that represent the properties of interest, for example, density or viscosity. As a result, the model can recognize some unknown non-linear correlations between the different features of the investigated material, although it does not explain the reasons for the existence of such correlations. In most cases, the ANN can be taught using training datasets, containing structures with already known properties. This training involves minimization of an error function and adjusting the weights [164]. A scheme of a simple commonly used model of ANN called "multilayer perceptron" is presented in Figure 2. 
There are many methods to estimate the accuracy of the model, for example the mean absolute percent error, the relative error, the mean square error (MSE), the root mean square error and so on. One of the most important and commonly used indicators of the model "goodness" is $\mathrm{R}^{2}$, defined as the ratio between the sum of squares regression and sum of squares total. In physical terms, $\mathrm{R}^{2}$ represents the proportion of dispersion in the dependent variable that can be explained by the independent variable, the closer its value to unity, the better the model describes the data.

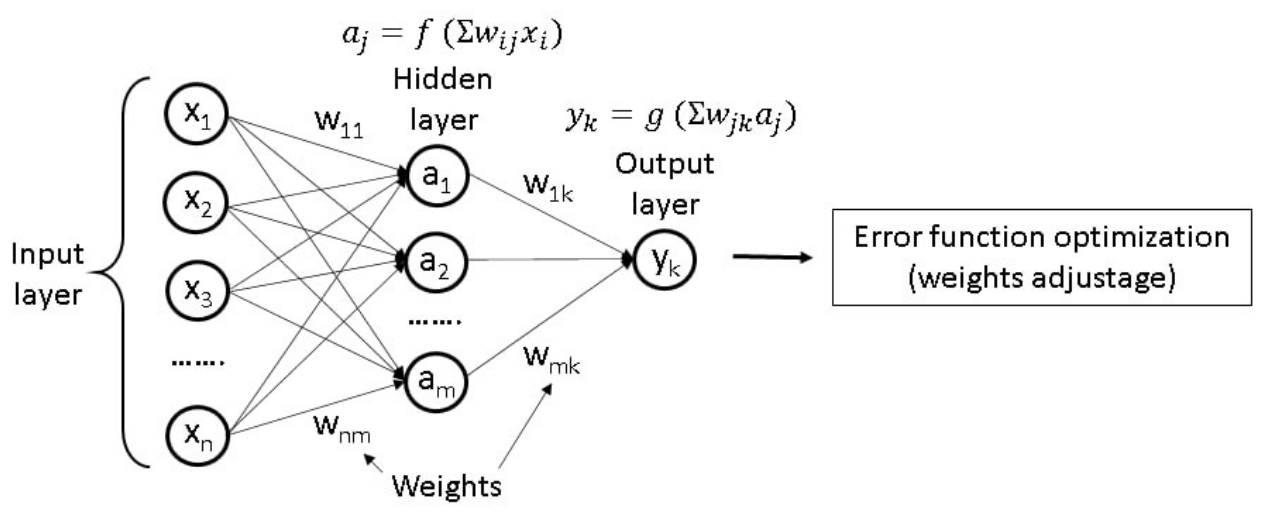

Figure 2. The scheme of a multilayer perceptron (a primitive model of ANN). Here $w_{\mathrm{ij}}$ and $\mathrm{w}_{\mathrm{jk}}$ are the connection weights, $f$ and $g$ are the activation functions.

\subsubsection{DES property prediction}

There are many works dedicated to the prediction and estimation of the different properties of DESs by means of ANNs. For example, Shahbaz et al. used an ANN with three layers (6-9-1 architecture, namely the input, hidden, and output layer has 8, 4, and 1 neurons respectively) to predict densities of three different ammonium- and phosphonium-based DESs across a range of temperatures and compositions [168]. The mole fraction of DES components and the temperature were used as inputs. They achieved an average absolute error of $0.14 \%$. The same year, the authors published another study in which they applied an ANN model with an 8-4-1 structure for the prediction of glycerol removal from palm-oil-based biodiesel using DESs [169]. The results were in good agreement with the experimentally measured data with an absolute average deviation of $6.46 \%$.

In another work by Benguerba et al., multilinear regression (MLR) and ANN methods were utilized for the prediction of DESs' viscosities [170]. The authors used the $\sigma-$ profile surface area descriptors derived from DFT and a temperature descriptor as inputs for their ML models and 108 experimental measurements of five amine-based DESs to build their mathematical model. As a result, both the MLR and ANN models were able to predict viscosity with high accuracy (with an $\mathrm{R}^{2}$ value of 0.9305 for the MLR model and an $\mathrm{R}^{2}$ value of 0.9863 for the ANN model). Alrugaibah et al. [171] compared the usage of ANN and response surface methodology (RSM) models while investigating the efficiency of NADESs for extraction of procyanidins and anthocyanins from cranberry pomace. For extraction of anthocyanins using 8 NADESs under various conditions, the ANN models performed better than the RSM model ( $\mathrm{R}^{2}=0.95$ for $\mathrm{ANN}$ versus 0.88 for $\left.\mathrm{RSM}\right)$. Fiyadh et al. compared two types of ANNs, namely feed-forward back-propagation (FFBP) and the layer recurrent $(\mathrm{LR})$ networks for the prediction of lead $\left(\mathrm{Pb}^{2+}\right)$ removal from water by DESfunctionalized CNTs [172]. Through the utilization of the experimental data and implementation of the types of ANN models mentioned above, the authors established the influence of adsorbent dosage, the concentration of $\mathrm{Pb}^{2+}, \mathrm{pH}$, and contact time (the input features) on the adsorption capacity of the DES-CNT adsorbent (the models' output feature). After the optimization of the inner architecture of ANNs, the best prediction of lead removal was achieved by applying a feed forward back propagation (FFBP) ANN that 
gave a MSE of $1.66 \times 10^{-4}$ and $\mathrm{R}^{2}=0.9956$. In another paper, Fiyadh et al. applied a NARX neural network (non-linear autoregressive network with exogenous inputs) for the prediction of arsenic removal from water using N,N-diethylethanolammonium chloridebased DES functionalized CNTs [173]. As in their previous work, they studied the effect of the same factors on the adsorption capacity of DES-CNTs. Using a NARX neural network with an optimized structure gave an MSE of $4.75 \times 10^{-4}$ for the testing set (20 experimental data points) with $\mathrm{R}^{2}=0.9922$. In similar work, Fiyadh et al. explored the removal of the $\mathrm{As}^{3+}$ ions from water with benzyltriphenylphosphonium chloride based DES-CNTs by implementing a NARX-based approach [174]. The results showed that this model is suitable for the prediction of the adsorption of $\mathrm{As}^{3+}$ ions from water $\left(\mathrm{R}^{2}=0.9818\right)$. Finally, in a separate work, Fiyadh et al. investigated removal of mercury ions from water using multi-walled CNTs functionalized with an allyl triphenylphosphonium bromide and glycerol-based DES [175]. After comparison of the NARX network, feedforward neural network and LR network models with optimized structures, it was discovered that the NARX model provides the best prediction of $\mathrm{Hg}^{2+}$ adsorption capacity with the $\mathrm{R}^{2}=0.9701$.

Dashti et al. used four ML models, namely particle optimization swarm (PSO-ANN), adaptive network-based fuzzy inference system (PSO-ANFIS), least-squares support-vector machine (LSSVM), and multivariate polynomial regression (MPR). The models were trained and tested using a set of 333 experimental data to demonstrate their efficiency in the prediction of the $\mathrm{CO}_{2}$ solubility in different DESs [176]. It was shown that the LSSVM model can provide better performance and the highest accuracy with $\mathrm{R}^{2}=0.993$. In the work of Bagh et al., an ANN model was utilized for the prediction of electrical conductivity of ammonium and phosphonium-based DESs [177]. The ANN with 8 hidden neurons showed the best performance and gave the smallest $\mathrm{R}^{2}$ coefficient of 0.9988 .

\subsubsection{Optimization of experiments using ML}

Besides prediction of materials properties, ANN models can be used to design experiments, that is, they can identify optimal experimental conditions by analyzing the datasets containing information about how different factors (for example, temperature or humidity) influence the experimental outcome. As an example of such an application, Sharma and Dash utilized a combined ANN and genetic algorithm (ANN-GA) approach for how to establish parameters for a DES-based microwave-assisted extraction process (microwave power, extraction time, liquid-solid ratio, and water percentage in DES) that allowed achieving a high extraction efficiency of phytochemical compounds from black jamun pulp [178]. Stupar et al. applied the RSM and ANN model for the development of an optimized procedure for $\beta$-carotene ultrasound-assisted extraction from pumpkin using natural DESs [179]. Ghaedi et al. described the development of linear and quadratic regression models for the prediction of $\mathrm{CO}_{2}$ solubility in DESs and their aqueous solutions [180]. The authors used the designed quadratic regression model for investigating the influence of pressure, temperature, molar ratio, and water/DES concentration on the $\mathrm{CO}_{2}$ mole fraction and establishing the experimental conditions under which $\mathrm{CO}_{2}$ solubility in DESs and their aqueous mixtures reaches its maximum.

In the study by $\mathrm{Xu}$ et al., 42 key factors of DES pretreatment of lignocellulosic biomass procedure were handled by principal component analysis (PCA) and partial least squares analysis methods to raise the possible efficiency of this industrial procedure [181]. Another case where PCA and regression analysis were used synergistically is the work of Kollau et al. [182]. In this study, the authors used a combination of experimental, theoretical, and computed properties as input for their linear and non-linear models to predict the nonideality of the DES mixtures and thus the eutectic temperatures. As a result, the nonlinear model with singular descriptors appeared to be significantly more accurate with $\mathrm{R}^{2}=0.93$. 


\subsubsection{Different aspects regarding application of ML methods}

One of the greatest benefits of the ML approach is that it can be combined with MD simulations. ML algorithms can be used not only for the construction of $\mathrm{FFs}$, but also in post-processing of simulation data or/and their interpretation [183-185]. Moreover, the results of the MD simulation can be used as an input for ML models [166]. Although some works exist where MD and ML methods have been applied synergistically, to the best of our knowledge, there are currently no examples of the implementation of these two approaches in combination with DES research.

Despite the vast number of possibilities that ML methods offer, they have their own limitations. For example, during iterations, the algorithm can converge to a local minimum of the error function [164,176]. Moreover, in order to avoid the common problem of overfitting, some advanced ML models use the molar structure (e.g. graph-convolutional neural networks [186]) as their direct input. As a result, the number of parameters may be so large that they require a substantial amount of data to properly estimate the weights [166]. Thus, gathering a sufficient amount of experimental data is a major obstacle for developing advanced ML models, since training of these models may require thousands and even hundreds of thousands of entries on molecular properties that may not be available. A promising solution to this problem may be developing advanced ML models by applying the so-called "transfer learning" approach [187]. It implies a two-stage protocol of ML model learning: 1) pre-training using data on proxy-properties and 2) fine-tuning using data on the target property(ies). Passing the first stage of the protocol typically requires large "synthetic" (computationally obtained) databases (for example, QM9 [188], Open Quantum Materials Database [189], etc.). For this reason enlarging and developing "synthetic" databases specifically for DES is among the most vital tasks.

\section{Main directions of investigations}

\subsection{DES Structure}

One of the main aims is determining the DES structure-property relationship. Considering the huge number of conceivable combinations of possible DESs, insights into the properties of DESs at the nanoscopic level are critical.

In this section, we summarize the structural characteristics of different DESs obtained by different simulation methods. Most of the work has been devoted to the third type of DES (see Table 1 in Introduction). It consists of a HBD and an organic salt. To control the structure and properties of DES, each component can be varied. We first overview the role of each component in DES structure formation based on existing simulation studies. Figure 3 and Figure 4 illustrate the chemical structures discussed in this section.

\subsubsection{Role of the hydrogen bond donor}

Most of the works on the structures of classical DESs are based on $\mathrm{ChCl}$ such as reline $[47,53,59,106,190-194]$ (HBD is urea), ethaline $[145,192,195,196]$ (HBD is ethylene glycol), glyceline [65,192,197] (HBD is glycerol), and propoline [198,199] (HBD is propylene glycol). Over the last five years, their structures and properties have been investigated intensively and the main interactions have been determined. In particular, the interplay of soft and strong interactions confers flexibility to the hydrogen-bond network formed in DESs and allows the ensemble to remain liquid at room temperature.

Celebi et al. [106] used MD simulations to accurately describe the influence of the fraction of urea in DESs based on $\mathrm{ChCl}$ and urea. They showed that the $\mathrm{H}$-bond network between ions and urea molecules disappears as the mole fraction of urea increases. In addition, they demonstrated a non-monotonic behavior between the urea fraction and ionic conductivity: the latter increases with increasing urea concentration and reaches a plateau at reline composition. Shayestehpour et al. also recently highlighted the main mo- 
lecular features responsible for the properties of $\mathrm{ChCl} /$ urea mixtures using MD simulations [102]. In particular, they demonstrated the key role of urea in the formation of the $\mathrm{H}$-bond network in reline.

Instead of urea, Bonomo et al. [197] investigated DESs based on $\mathrm{ChCl}$ and glycerol (which has three hydroxyl groups). They showed that in the case of glycerol 1:2 composition, the coordination is probably defective, and chloride stabilization is ensured both by H-bonding with the choline hydroxyl group and electrostatic interactions with the tetramethylammonium group. At 1:3 composition, the excess of glycerol was sufficient to stabilize chloride anions due to the high amount of hydroxyl group in them.

\section{Hydrogen bond donors}<smiles>CC(O)CO</smiles><smiles>CCCCO</smiles><smiles>C=CC(=O)OCCC(=O)O</smiles><smiles>CC(=O)Oc1ccccc1C(=O)O</smiles>
acetylsalicylic acid<smiles>O=C(O)CC(O)C(=O)O</smiles><smiles>O=C(O)C(O)C(O)C(=O)O</smiles><smiles>O=C(O)CC(=O)O</smiles>

malic acid

tartaric acid<smiles>O=C(O)CO</smiles>

glycolic acid<smiles>CC(C)(C)CC(C)(C)C(=O)O</smiles><smiles>CC1CCCC(O)C1</smiles>

malonic acid<smiles>CCN(CC)CC(=O)Nc1c(C)cccc1C</smiles>
decanoic acid menthol<smiles>Cc1ccc(C(C)C)c(O)c1</smiles><smiles>O=C(O)CCC(=O)O</smiles>

Figure 3. Chemical structures of H-bond donors of DESs discussed in this section. 


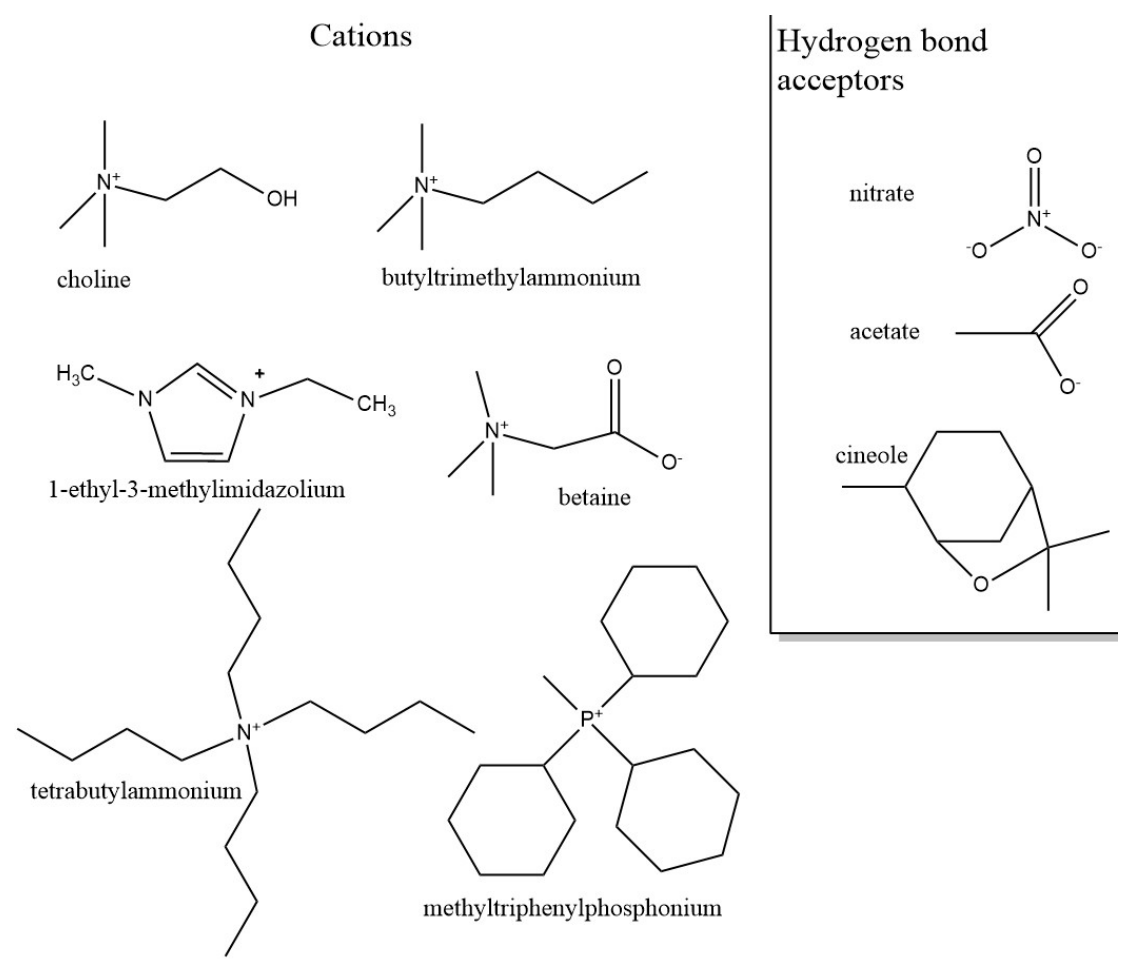

Figure 4. Chemical structures of cations and H-bond acceptors discussed in this section.

Stefanovic et al. compared three DESs based on $\mathrm{ChCl}$, ethaline, glyceline and reline by AIMD simulations [192]. They showed that the structure of the bulk HBDs is largely preserved for glyceline and ethaline, which can explain a smaller melting point depression. In contrast, reline exhibits a well-established hydrogen-bond network between the salt and HBD, leading to a larger melting point depression. The extensive hydrogen-bond network in reline also results in higher viscosity compared to ethaline and glyceline. Glyceline also exhibits over-saturation of HBD groups, which leads to higher cohesive forces within the bulk liquid and to a higher viscosity than ethaline due to more extensive interactions between HBDs. Another comparison of the choline-based DESs was performed by Ferreira et al. [198,199]. In their first work [198], they developed a non-polarizable OPLS-based FF for propeline. The results showed that the HBDs in propeline have a preference to interact with the salt rather than with itself, which explains its relatively high viscosity. In the follow-up work Ferreira et al. [199] compared four DESs, namely, ethaline, propeline, propaneline (based on propanediol), and glyceline. Glyceline, which has a higher number of hydroxyl groups, demonstrated a higher degree of H-bonding formation with the anion. Despite the number of HBD groups, an important factor determining the DES properties is the size of the HBD molecule. Thus, the smaller molecular size of ethaline compared to propeline and propaneline, allows these molecules to get closer to choline leading to a higher density of DES based on diatomic alcohols. The critical role of the H-bond network in DES formation was also recently demonstrated using MD simulations by Panda et al. [200] who compared DESs based on tetrabutylammonium chloride and two different HBDs glycerol and ethylene glycol.

Role of HBD can be played by acids, which can endow a DES with unique properties [51,201], [202], [203-205]. Fu et al. [201] developed a DES based on acrylic acid and estimated the stability of the $\mathrm{ChCl}$-acrylic acid complexes by $\mathrm{QM}$ calculations. The authors demonstrated a strong interaction between $\mathrm{ChCl}$ and acrylic acid, which is more stable than interactions between individual components. This is an important result because acrylic acid is able to polymerize, and a DES containing it has the potential to function as an ink for 3D printing. Gautam et al. [51] used DFT to compare the structure of clusters 
formed in DESs based on acetic acid and formic acids. The authors detected the formation of strong H-bonds between the hydroxyl groups of choline, chlorine ions, and doublebonded oxygens in carboxylic acids. It is important to note that the viscosity of DESs based on formic acid is two times lower due to its smaller size and faster movement in the liquid structure. The importance of the size of HBD was also shown by Rozas et al. [138] who used MD simulations and revealed the mechanism of $\mathrm{H}$-bond network formation in saltfree cineole-based DES based on different acid HBDs: the interaction between cineole and HBD are highly dependent on the size of the HBD. Access to the ester group of cineole is sterically hindered, and only small molecules can form the most favorable interactions with it.

As discussed in Introduction, components of DESs could act as active pharmaceutical ingredients forming so-called therapeutic DESs. These DESs can be used to enhance the solubility of active ingredients, membrane transport, drug delivery, and bioavailability [206,207]. Saha et al. [203] used combined DFT/MD simulations to study the possibility of developing DESs based on acetylsalicylic acid (aspirin), and Bonab et al. [204,205] simulated DESs based on $\mathrm{ChCl}$ and phenyl propionic acid, which have a wide variety of uses including cosmetics, food additives, and pharmaceuticals [208]. The authors aimed to understand the physical mechanisms occurring at the eutectic composition point.

Polyols and acids have also received attention [50,209]. Naseem et al. [50] used MD simulations to compare DESs based on polyols (ethylene glycol and glycerol) and acids (malic acid, tartaric acid and oxalic acid). The DES based on tartaric acid was found to be more stable due to the larger number of HBD groups in tartaric acid compared to other HBDs. The H-bond network, as revealed by QM simulations, showed a three-dimensional structure via cross-linking through carboxyl groups of tartaric acid and choline's hydroxyl group. Similar results have been obtained by Perkins et al. [209] and Bruinhorst et al. [210]. Perkins et al. [209] showed that a DES based on malonic acid is much more stable than ethaline and glyceline. Bruinhorst et al. [210] simulated DESs based on heterocyclic amino acid proline as HBA and glycolic acid or malic acid as HBD and showed that malic acid with the largest number of HBD sites forms the most stable DES.

\subsubsection{Role of hydrogen bond acceptor (anion)}

Another way to control the properties of a DES is to change the H-bond acceptor (HBA). Because HBA is involved in both interactions (with cation and HBD), its replacement will cause changes in both interactions. This makes property and structure prediction a nontrivial task. Migliorati et al. [211] recently discussed the role of an anion in Hbond network formation. They compared the structure and properties of DESs based on four different anions: chloride, fluoride, nitrate, and acetate. The results showed that there is no one-to-one correspondence between the order of DES melting points and the strength of the H-bonds between urea and anion; a complex network of interactions is formed in which the anions try to maximize their H-bond interactions with the other components of the system. The specific way in which each anion achieves this goal depends on the nature of the anion. It was shown that unlike monatomic anions, polyatomic anions such as nitrate and acetate are able to simultaneously bind two hydrogens of urea.

\subsubsection{Role of cation}

Most of the studies regarding cations have focused on DESs based on $\mathrm{ChCl}$. Migliorati et al. [193] compared structures of DESs based on choline (reline) and butyltrimethylammonium (UBTMAC). H-bonds between chloride ions and urea molecules are more favored in DESs based on UBTMAC due to absence of competition from the anion. This result suggests that the formation of anion-urea H-bonds is not the only reason for the large melting point depression observed in DESs, so a more complex picture has to be considered in which a variety of different H-bonds exists. In this context, it is worth mentioning the work of Gutiérrez et al. [137] in which a DES based on amino acid betaine and 
lactic acid was developed. Betaine has a close similarity in chemical structure to choline, where the hydroxyl group of choline is instead replaced by a carboxyl group. This produces a stronger H-bond network in DESs based on betaine and makes such DESs promising for future applications.

The role of another cation, 1-ethyl-3-methylimidazolium ([EMIm]), for ([EMIm][Cl]):urea DES structure formation was investigated by Cerajewski et al. [212]. Their MD simulations revealed nanoscale segregation of DES into two regions: EMIm and urea-enriched regions. The properties of the DES are determined by the interface between these regions, which depends on the interaction of chloride anions with urea and EMIm. Another example is the fact that one can control the structure of DES and its intramolecular interactions by varying cation types is the work of Naik et al. [213]. They demonstrated the difference in structure and formation of the H-bond network of DESs based on methyltriphenylphosphonium bromide (MTPPBr) and tetrabutylammonium bromide with ethylene glycol or glycerol as HBD [213]. It is worth mentioning that a DES based on MTPPBr is highly required for $\mathrm{CO}_{2}$ adsorption and its structure has been studied using MD simulations by Kussainova et al. [214].

\subsubsection{Hydrophobic deep eutectic solvents}

One of the actively developed types of DESs are hydrophobic DESs. Hydrophobic DESs were presented as solvents for liquid-liquid extractions in 2015 [215,216]. Since then, the field of hydrophobic DESs has grown extensively. The development of hydrophobic DESs is well described in the review by van Osch et al. [217].

Several authors have reported that the structure of hydrophobic DES could be heterogeneous. Because the structure of a DES is mostly determined by the H-bond network, the investigation of the influence and diversity of $\mathrm{H}$-bonds on the structure is one of the common tasks. Thus, Salehi et al. [218] investigated the effect of the hydrophobicity of the cation on the structure and properties of the DESs. They performed MD simulations of DESs based on tetraalkylammonium chloride and decanoic acid with varying lengths of the alkyl side chain of the cation. The increase in cation chain length decreases the density and slows down diffusion. However, no significant influence was observed on the intermolecular characteristic distances and the H-bonds. Abbas et al. [219] investigated the structure and dynamics of H-bonds in hydrophobic salt-free DESs formed by the composition of decanoic acid, menthol, thymol, and lidocaine by MD simulations. They demonstrated the critical role of H-bonding on the structure and dynamics of DES and revealed a high diversity of $\mathrm{H}$-bonds. The strength of the dominating $\mathrm{H}$-bonds determines the diffusion of components in DES and the character of the H-bond network.

Control of heterogeneity is an important task for the development of DESs for extraction and other separation applications [219,220]. Alizadeh et al. [220] studied heterogeneity in DESs based on $\mathrm{ChCl}$ and its depravities with different lengths of the alkyl chain. MD simulations revealed strong heterogeneity caused by the segregation of polar and nonpolar parts of molecules in DESs based on the cations with the long alkyl chains. A similar result was observed by Cui et al. [221], who compared the structures of DESs based on tetramethylammonium and tetraethylammonium, and Migliorati et al. [193] butyltrimethylammonium in the simulations discussed above.

\subsubsection{Electrolyte-based DESs}

Heterogeneity in structure has also been observed in electrolyte-based DESs (the first and fourth type of DES). Direct evidence of nanoscale spatial heterogeneity in electrolytebased DES $\mathrm{Li}^{+} / \mathrm{ClO}^{4-:}$ :alkylamides (acetamide and propionamide) was reported by Kashyap et al. [222,223]. The authors demonstrated that nanoscale spatial heterogeneity is exhibited by the segregated domains of the constituent electrolyte; elongation of the tail of alkylamide enhances the extent of nanoscale morphology and the strength of ion-pairing. Moreover, they found that the degree of heterogeneity increases with temperature 
and explained this by the enhanced correlations between the ionic species that overpower the decrease of ionic species-alkylamide cross-correlations.

Biswas et al. [224,225] performed MD microstructure simulations for a number of $\mathrm{Li}$ salts $\left(\mathrm{Li}^{+}, \mathrm{Br}^{-}, \mathrm{NO}^{-3}, \mathrm{ClO}^{-4}\right)$ and acetamide to identify the solution-phase microstructures in these media, and investigated the anion and temperature dependence of these microstructures. The authors showed that the presence of heterogeneity arises from the balance of the interactions between the various species. Ionic clusters were found to be most stable in the presence of $\mathrm{NO}^{-3}$. It was also revealed that the perchlorate DES is the most heterogeneous among the three systems studied.

New DESs based on lithium salts are promising electrolytes for lithium-ion batteries operated in low-temperature environments. In this context, the phenomenon of the decrease of melting temperature in metal salt-based DESs is relevant. Ogawa and Mori [226] combined MD and DFT methods to study four representative DESs based on LiCl or Lithium bis(trifluoromethanesulfonyl)imide (LiTFSI) and urea or tetramethylurea as HBDs. They compared directly the coordination states between Li salts and amides with or without $\mathrm{NH}$ groups, such as urea (with $\mathrm{NH}$ ) or tetramethylurea (without $\mathrm{NH}$ ), and revealed the eutectic mechanism of DESs. It was established that if the cation in the DES is bulky, such as in reline, the $\mathrm{NH}$ group coordinated with $\mathrm{Cl}^{-}$causes the melting point to decrease. In contrast, in the case of high Lewis acidity of the cation (such as $\mathrm{Li}^{+}$), the $\mathrm{CO}$ group in amide coordinates preferentially with cation. In the case of DESs based on LiTFSI and an amide, the presence of an NH group may not lead to a decrease of the electrolyte melting point. Furthermore, the HOMO-LUMO calculated from DFT to estimate electrochemical stability showed that Li-salt:amide-based electrolytes with $\mathrm{NH}$ group are unstable on the reduction side. So, in contrast to $\mathrm{ChCl}$-based DES, for lithium-ion batteries it is preferable to use compounds without any $\mathrm{NH}$ groups.

\subsubsection{Ternary DES}

Recently, the possibility of the formation of ternary DESs (TDESs) has been put forth which offer lower viscosity and melting points than binary DESs.

The ternary DES choline chloride ( $\mathrm{ChCl}$ ):resorcinol (Res):glycerol (Gly) mixture was simulated using MD by Li et al. [227]. It was concluded that $\mathrm{ChCl}$, resorcinol, and glycerol form numerous $\mathrm{H}$-bonds that lead to the destruction of the intrinsic microstructure of each component. As a result, $\mathrm{ChCl} / \mathrm{Res} / \mathrm{Gly}$ are strongly associated through supramolecular $\mathrm{H}$ bond network and form a DES.

The influence of alcohols as ternary components (n-butanol, iso-butanol, and butandiol) as an additional HBD in a binary DES composed of $\mathrm{ChCl}$ and malonic acid in equimolar ratio (1:1), also called as maline, was examined in Ref. [42] to understand the $\mathrm{H}$-bonding interactions. The calculations focused on the molecular orbital (MO) energy levels. It was concluded that the $\mathrm{H}$-bond network formed between maline and butandiol results in a larger melting point depression in comparison to n-butanol and iso-butanol. The interpretation was that maline and butandiol (in contrast to n-butanol and iso-butanol) form stable and homogeneous systems. These findings were further supported and significantly validated by the evaluation of the total energy. Maline:butandiol makes a homogeneous mixture to form a TDES with a less negative value, while n-butanol and iso-butanol with more negative value show prominent phase separation. The conclusion was also supported by the recent work of the same authors [228] where they calculated the MO energy levels for the molecular structures formed in TDES maline/butandiole. The results indicate that maline molecule more easily donates electrons accepted by the unoccupied orbitals of the two hydroxyl groups of the HBD.

Jangir et al. [43] studied the effects of alcohols such as ethanol and ethylene glycol as additional HBD (cosolvents) on DESs formed using $\mathrm{ChCl}$ as the $\mathrm{HBA}$ and L-lactic acid as the HBD at 1:2 molar ratio. The calculations of the MO energy levels revealed that the 
ethanol-based DESs showed more favorable hydrogen bonding than the ethylene glycolbased DESs leading to a thermodynamically stable binary system.

\subsection{Dynamic properties}

Transport properties, namely diffusion coefficients and viscosity, are important parameters characterizing the potential of DESs practical applications. Significant attention has been dedicated to the investigation of mechanisms of motion of DES components, dynamical heterogeneities, as well as their dependence on different factors (such as ion identity, chain length, polarity, etc.). MD simulations could provide valuable insights into the dynamics of different components of DESs, which is not easily possible in experiments. For example, quasielastic neutron scattering (QENS) experiments provide only ensemble-averaged results for the system [229]. Moreover, MD simulations allow access to smaller time and length scales, thus giving more information about dynamic properties and underlying mechanisms of motions in DESs.

Srinivasan et al. used MD simulations in addition to QENS to examine nanoscale dynamics in DESs comprised of acetamide $\left(\mathrm{C}_{2} \mathrm{H}_{5} \mathrm{ON}\right)$ with lithium nitrate $\left(\mathrm{LiNO}_{3}\right)$ or lithium perchlorate $\left(\mathrm{LiClO}_{4}\right)$ to investigate mechanisms of motion of their molecular components [229-231]. In particular, it was observed that movement of acetamide within the temperature range of $300-365 \mathrm{~K}$ consists of localized motions in transient cages formed by the neighboring molecules (both ions and acetamide) and cage-to-cage jumps. Thus, there are two types of acetamide molecules: (i) H-bonded to lithium ions (slow diffusion) and (ii) completely free of any H-bonds (fast diffusion). Interestingly, for the first type of acetamide molecules, jump diffusivity is at least 3 times lower and the mean residence time between jumps is twice larger than those for the molten acetamide. Also, it was found that almost all lithium ions (90\%) are moving between the cages by a vehicular motion between solvation shells formed by 3-4 acetamide molecules. Only a small number of ions (10\%) are diffusive due to the structural relaxation of cages. At the same time, no correlation was observed in the movement of ions, implying a system of dissociated anions and cations.

MD simulations were extensively used by Biswas' group to prove the existence of dynamic heterogeneity in DESs [232-237]. Das et al. [232] applied MD simulations to provide support for the fractional viscosity dependence of rotation rates of fluorescence probes observed in experiments for DESs based on acetamide $\left(\mathrm{C}_{2} \mathrm{H}_{5} \mathrm{ON}\right)$ and lithium bromide ( $\mathrm{LiBr}$ ) with an acetamide mole fraction of 0.78 . Analysis of the wavenumber-dependent incoherent and coherent scattering functions for acetamide molecules calculated at 303 $\mathrm{K}$ and corresponding to four different length scales of density fluctuations showed stretched exponential behavior. This provided evidence for temporal heterogeneity, thus explaining the experimentally observed fractional viscosity.

Guchhait et al. [233] simulated acetamide-based DESs with lithium perchlorate $\left(\mathrm{LiClO}_{4}\right)$, lithium bromide $(\mathrm{LiBr})$, and lithium nitrate $\left(\mathrm{LiNO}_{3}\right)$ as electrolytes. Three systems with different mole fractions of acetamide $\left(\mathrm{C}_{2} \mathrm{H}_{5} \mathrm{ON}\right)$ and electrolytes were studied $\left(0.81 \mathrm{C}_{2} \mathrm{H}_{5} \mathrm{ON}+0.19 \mathrm{LiClO}_{4}, 0.78 \mathrm{C}_{2} \mathrm{H}_{5} \mathrm{ON}+0.22 \mathrm{LiNO}_{3}\right.$, and $\left.0.78 \mathrm{C}_{2} \mathrm{H}_{5} \mathrm{ON}+0.22 \mathrm{LiBr}\right)$. The observed stretched exponential relaxation of the dynamic structure factors (even at $\sim 150 \mathrm{~K}$ above Tg) allowed explanation of viscosity decoupling in terms of the temporal heterogeneity of the DES medium controlled by anion identity.

A more comprehensive molecular view regarding the influence of anion identity on orientational jumps was given by Das et al. [234] who carried out MD simulations of DESs composed of acetamide and different lithium salts (bromide $\left(\mathrm{Br}^{-}\right)$, nitrate $\left(\mathrm{NO}^{3-}\right)$ and perchlorate $\left.\left(\mathrm{ClO}^{4-}\right)\right)$ with 78:22 mole ratio of the components at $303 \mathrm{~K}$. Orientational jumps involve a bifurcation of a H-bond, switching of a binding partner followed by a largeangle rotation of the molecule. This mechanism was first suggested (using MD simulations) by Laage and Hynes [238] for water and has since been shown to be an important mechanism in solvation especially in the presence of hydrophobes [239]. To study the orientational jumps of DES components, Das et al. analyzed both acetamide-acetamide and acetamide-ion pairs. Their analysis of the MD data showed that: 1) Compared to the other 
two anions, the presence of $\mathrm{NO}_{3}$ - leads to less frequent large-angle jumps, 2) compared to $\mathrm{NO}_{3}{ }^{-}$and $\mathrm{ClO}_{4}^{-}$, the presence of $\mathrm{Br}-$ anion has a different impact on the jump angle distribution, resulting in a bimodal form, 3) the energy barriers of orientational jumps of acetamides $\mathrm{H}$-bonded to $\mathrm{NO}_{3}{ }^{-}$and to $\mathrm{ClO}_{4}{ }^{-}$differ almost by a factor of two, 4) viscosity of DESs has an opposite trend compared to the relative reorientational jumps displacements (both radial and angular) of sequence $\mathrm{ClO}_{4}^{-}>\mathrm{NO}_{3}^{-}>\mathrm{Br}$, and 5) there is almost no difference between the free energy barriers of orientational jumps for acetamide-acetamide in systems with different anions, the value being also close to thatfor molten acetamide. Additionally, the presence of dynamic heterogeneity in the systems was supported by the fact that jump time distributions exhibit a power-law dependence for all the anions studied.

Interestingly, the opposite conclusions about dynamic heterogeneity of DESs were made by Das et al. [235] while studying systems composed of acetamide $\left(\mathrm{C}_{2} \mathrm{H}_{5} \mathrm{ON}\right)+$ urea $\left(\mathrm{CH}_{4} \mathrm{ON}_{2}\right)$ at $338 \mathrm{~K}$ with acetamide mole fractions of 0.6 and 0.7 . These systems are nonionic DESs composed of dipolar molecules and amphiphiles. Examining the mean squared displacement profiles, heterogeneity parameters, displacement distributions, and relaxation of dynamic structure factors showed that acetamide + urea is both a spatially and dynamically homogeneous system.

Mukherjee et al. [236] examined systems based on acetamide + urea. Pure systems containing only urea molecules were also simulated for reference. By analyzing various correlation functions, the authors proposed an explanation for the physical origin of the three slowest time scales in dielectric relaxation. They suggested that they are dominated by structural H-bond relaxation that involves center-of-mass translation. Particularly, they proposed that the origin of the fastest time scale in dielectric relaxation that lies in the sub-10 ps regime could be fast reorientational dynamics of the components (acetamide and urea). Additional conclusions were made about the time and length scales of dynamical and spatial heterogeneity in DESs, which were estimated to be on the order of $\sim 10$ ps and $\sim 10 \AA$, respectively.

Reorientation dynamics was also studied by Rajbangshi et al. [237] using $\mathrm{MD}$ in $\mathrm{ChCl}$ + urea DES. They simulated systems at 0.33 mol fraction of urea at six different temperatures between 293 and $333 \mathrm{~K}$. Their results suggested evidence for strong temporal heterogeneity in DESs based on, e.g., displacement distributions and dynamic susceptibilities. The comparison of a rank-dependent average reorientation relaxation time and translational diffusion also provided support for translation-rotation decoupling.

The above works use a single FF in MD simulations, the most popular ones being OPLS-DES [99] (in Ref. [237]), CHARMM [240-242] (in Refs. [229-232]) and its modified versions [242-244] (in Refs. [229-231,233,234]) and combined versions (CHARMM [240242] + GROMOS [245]) (in Refs. [235,236]). The atomistic models in these works were mostly validated by measuring density [233-237] and good agreement was found. The situation is different for dynamic properties. Despite partial agreement with experiments regarding viscosity $[230,236]$ and ionic conductivity [230] at a single state point, the temperature transferability of dynamical properties suffers from a lack of quantitative agreement. For, example Rajbangshi et al. [237] have shown that the ratio of diffusion coefficients measured with pulsed-field gradient nuclear magnetic resonance to those estimated in MD simulations lay in the range of 0.58-4.82 for choline and 0.63-4.76 for urea in the temperature range 293 to $333 \mathrm{~K}$, despite using a specific OPLS-DES FF [99]. This result emphasizes the importance of FF development and inclusion of polarizability.

Perkins et al. [209] examined the influence of different FF parameters on various properties of the most commonly investigated DESs based on $\mathrm{ChCl}$ and urea using a single molar ratio 1:2. The authors showed that using the default values of GAFF and charges reduced by a factor of $0.8\left(\mathrm{HF} / 6-31 \mathrm{G}^{*}\right.$ level calculation) provides a better agreement with experimental data for density, thermal expansion coefficients, and heat capacity compared to other FFs. They found the self-diffusivities of the DES components at $298 \mathrm{~K}$ are underestimated between $25-51 \%$ compared to experimental data. On the other hand, good agreement with experimental values was observed at $330 \mathrm{~K}$. 
In their follow-up work, Perkins et al. [107] found that better agreement with experimental values of diffusion coefficients could be achieved by reducing the partial charges by a factor of 0.9 in the ionic species. This result was shown for three ChCl-based DESs: $\mathrm{ChCl}+$ ethylene glycol 1:2 (ethaline), $\mathrm{ChCl}+$ glycerol 1:2 (glyceline). They found that at $298 \mathrm{~K}$ the diffusion coefficients were underestimated only by $20-30 \%$ (for ethaline) and by $14-20 \%$ (for glyceline). At $330 \mathrm{~K}$ the discrepancy was 5-25\% (for ethaline) and $17-27 \%$ (for glyceline).

The above shows the complexity of finding universal charge scaling and parameterization for different DES systems. For a more comprehensive discussion on simulations of DES transport properties, we refer the reader to the excellent review by the group of Smirnova [34].

To conclude, an alternative way to achieve more accurate predictions could be via the use of polarizable FFs. A recent example is given by Goloviznina et al. [121], who used the polarizable CL\&Pol FF to simulate transport properties of $\mathrm{ChCl}+$ ethylene glycol (1:2 molar ratio). Their results show good agreement with experimental data at $298 \mathrm{~K}(2.18 \times$ $10^{-11} \mathrm{~m}^{2} \mathrm{~s}^{-1}$ in MD vs. $2.62 \times 10^{-11} \mathrm{~m}^{2} \mathrm{~s}^{-1}$ in the experiment) and viscosity (35 $\pm 5 \mathrm{mPa} \cdot \mathrm{s}$ in $\mathrm{MD}$ vs $37 \mathrm{mPa} \cdot \mathrm{s}$ in the experiment). However, the $\mathrm{H}$-bond donor diffusion coefficient was significantly overestimated $\left(13 \times 10^{-11} \mathrm{~m}^{2} \mathrm{~s}^{-1}\right.$ in MD vs $4.77 \times 10^{-11} \mathrm{~m}^{2} \mathrm{~s}^{-1}$ in the experiment). Improved performance of CL\&Pol compared to its non-polarizable version (CL\&P) was demonstrated for the diffusion coefficient of ethylene glycol in DESs based on $\mathrm{ChCl}(1: 2)$, as shown by de Souza et al. [130]. Interestingly, a better agreement between MD and experimental results was achieved when using temperature-grouped Nosé-Hoover thermostats rather than traditional ones [121]. According to the authors, the reason for that is a better treatment of translational, intramolecular, and polarization degrees of freedom.

\subsection{DES for Separations and Gas Capture}

One of the world's major challenges is the reduction of greenhouse gases. Acid gas emissions, especially $\mathrm{CO}_{2}$, are one of the most pressing technical challenges of this century, given their role in driving climate change and ocean acidification. The world's $\mathrm{CO}_{2}$ emissions are emitted in a number of ways, such as burning of oil, coal, natural gas, or liquid gas in power plants, or for instance by aluminum or petrochemical industries. Despite recent advances and developments in renewable energy sources, it is likely that at least for the next few years, fossil fuels will continue to play a key role in energy production. This means that $\mathrm{CO}_{2}$ emissions will inevitably continue to increase [246-248]. Thus, developing more sustainable and environmentally friendly ways to capture $\mathrm{CO}_{2}$ (before, during, or after processing) from fossil fuels is a major challenge today.

A wide range of $\mathrm{CO}_{2}$ capture technologies have been proposed over the past few years, including solid and liquid sorbents and sorption through membranes [249]. Selective membrane separation technology is one of the most promising methods and it is considered to be a cost-effective method to mitigate the emission of $\mathrm{CO}_{2}$. It is necessary to use materials that can effectively separate and capture gases on industrial scales. Membranes based on DESs are highly promising due to their unique properties and relative cheapness [250].

Another challenge is the removal of carbon dioxide from natural gas. Natural gas exists in deep underground reservoirs as a shale gas with non-hydrocarbon components such as $\mathrm{CO}_{2}$. The presence of $\mathrm{CO}_{2}$ in natural gas is undesirable due to corrosion and low heating value; one of the difficulties in using natural gas is the removal of $\mathrm{CO}_{2}$ from it $[251,252]$.

García et al. [249] used MD simulations to study the intermolecular interactions of different DESs (reline, glycine and maline) in contact with gas phases consisting of pure $\mathrm{CO}_{2}$, pure $\mathrm{SO}_{2}$, and a model flue gas (containing $\mathrm{N}_{2}, \mathrm{CO}_{2}, \mathrm{O}_{2}$, and water). It has been established that their intermolecular interactions depend on the nature of H-bonding sites available in the HBDs. Mechanisms of $\mathrm{CO}_{2}$ absorption were also investigated on methyltriphenylphosphonium (MEA) bromide and mono ethanol amine-based DESs using MD 
simulations by Kussainova et al. [253]. The authors found that interactions between the $\mathrm{CO}_{2}$ molecules decreased significantly in the presence of the DESs, while interactions between $\mathrm{CO}_{2}$ and MEA became enhanced. In addition, strong interactions between $\mathrm{Br}^{-} / \mathrm{CO}_{2}$ and $\mathrm{MEA} / \mathrm{CO}_{2}$ were shown, which suggests the predominant sorption of $\mathrm{CO}_{2}$ by these components. Haider et al. [254] investigated the $\mathrm{CO}_{2}$ removal process from model shale gas using two DESs, reline and ethaline. They found that the process of $\mathrm{CO}_{2}$ recovery from shale gas with a DES is better than the conventional methyl diethanolamine (MDEA)based acid gas removal process.

Investigation of highly $\mathrm{CO}_{2}$-philic DES-based separation membrane was carried out by Lin et al. [255]. The membrane was developed by nanoconfining $\mathrm{ChCl} /$ ethylene glycol $(\mathrm{ChCl} / \mathrm{EG}) \mathrm{DES}$ into graphene oxide nanoslits. Their MD simulations revealed that the confinement affects the structure of the nanosized $\mathrm{ChCl} / \mathrm{EG}$ liquid, which greatly facilitates $\mathrm{CO}_{2}$ transfer. It has been shown that by adjusting the $\mathrm{ChCl} / \mathrm{EG}$ molar ratio and membrane thickness, it is possible to create materials with desired properties, which makes it a promising membrane for the selective separation of $\mathrm{CO}_{2}$. Similar studies were carried out by Shen et al. [256]. This study was aimed to understand how slit-like nanopores of graphite and titania (rutile) walls containing different amounts of DESs would perform in the gas binary mixture of $\mathrm{CO}_{2}$ and $\mathrm{CH}_{4}$ separation. Such a system is relevant for the separation of carbon dioxide from methane in natural gas. Lin et al. proposed a new kind of supported liquid membrane by incorporating a DES (1ChCl-4EG eutectic liquid) into the nanoslits of titanium carbide $\left(\mathrm{Ti}_{3} \mathrm{C}_{2} \mathrm{~T}_{\mathrm{x}}\right)$ membrane [257]. Their MD simulations were applied to the resulting $\mathrm{Ti}_{3} \mathrm{C}_{2} \mathrm{~T}_{\mathrm{x}}$-based deep eutectic liquid membrane, which showed a good preference for $\mathrm{CO}_{2}$ in permeability, selectivity (over other light gases), high heat resistance, and durability.

Alioui et al. [258] used MD simulations and a theoretical approach to study the molecular interaction between $\mathrm{CO}_{2}$ and different DESs. A relationship between the solubility of gas molecules and the energy of their interaction with DESs was established: The solubility of $\mathrm{CO}_{2}$ in DESs becomes greater when the energy of attraction is higher and vice versa [258]. Wang et al. [259] studied phosphonium-based DESs and found good agreement with experimentally determined solubility coefficients.

Besides the problems described above associated with capturing carbon dioxide from the processing of fossil fuels or removing $\mathrm{CO}_{2}$ from natural gas combustion, desulfurization is a critical process for producing quality fuel. This required researchers to develop new and environmentally friendly methods for fuel desulfurization. Research shows that DESs have provided a new route for fuel desulfurization due to the cheapness and availability of raw materials, higher desulfurization efficiency and environmentally friendly properties [260]. Hydrodesulfurization and Extractive Desulfurization (EDS) are among the most promising desulfurization methods due to their simple operation, low-cost and high efficiency when using low-quality fuels [260,261].

MD simulations could be used for the theoretical investigation of these desulfurization processes by DESs: in the study by El-hoshoudy et al., [261] it was shown that DESs can be used to capture and remove thiophene compounds. Li et al. [260], proposed metal ion-based DESs (MDESs), which have even higher sulfur extraction efficiency, and Shah et al. [262] used MD simulations to investigate them. The authors showed that an MDES based on tetrabutyl ammonium chloride (TBAC), polyethylene glycol (PEG) and ferric chloride $\left(\mathrm{FeCl}_{3}\right)$ could be useful in desulfurization of diesel and capable of rapidly removing thiophenic compounds such as benzothiophenes and thiophenes. It was also shown that PEG-free systems can have higher extraction abilities than TBAC + PEG + FeCl 3 systems.

Besides the absorption of $\mathrm{CO}_{2}$ and $\mathrm{SO}_{2}$, and natural gas purification, DESs could also be used for extraction of pure components (aromatic and aliphatic) from naphtha streams. This is of great significance for the petrochemical industry due to the high economic value of its components [263]. Kumar et al. [263] investigated the molecular mechanisms of benzene extraction from hydrocarbon mixture using a phosphonium-based DES using MD 
simulations. They found that the van der Waals interactions prevailed over electrostatic ones and enabled the extraction of benzene from a DES-benzene-hexane mixture. In this ternary system, the DES-benzene pair had a higher interaction energy than DES-hexane. The self-diffusion value suggested a higher miscibility with DESs and benzene compared to hexane.

It should be noted that fossil fuels also contain a variety of nitrogen-based polyaromatic compounds in various forms. The presence of nitrogen-based polyaromatic hydrocarbons (PAHs) in fuels, which emit NOx into the environment during fuel combustion in engines and industrial plants, have a large negative impact on the environment and ecosystem. Recent studies have shown that DESs based on phosphonium have a very high ability to remove PAHs from fuel oils. Naik et al. [264] studied the extraction of polyaromatic hydrocarbons from fuel oils using the DES-quinoline-heptane ternary system. The results of their MD simulations, similar to results obtained by Kumar et al. [263], showed that the van der Waals interactions were the controlling interactions. Thus, the low-cost DES could be used for extraction of PAH from fuel oils.

Oxygen-containing additives are widely used in the production of gasoline to reduce lead content and thereby minimize the severe engine knocking induced by hydrocarbon mixtures in gasoline. For the production of these oxygenated additives, more and more processes are being developed for the coexistence of alkanes resulting in many azeotropic mixtures (such as n-hexane-ethanol and n-heptane-1-butanol). However, these azeotropic mixtures are difficult to separate by conventional distillation. Liquid-liquid extraction (LLE) can be applied to solve this problem. In this case, DESs can be used as an extractant. The study by Zhang et al. [265] explored a choline-based DES for extracting 1-butanol (a renewable high-energy biofuel) from an alkanol azeotrope system. Simulations of the LLE process were performed using the MD method to explain the azeotropic separation extraction mechanism at the molecular level. The results showed that a $\mathrm{ChCl}+$ urea DES had the best extraction effect. Moreover, the results showed that the extraction of different DESs depended on the HBD in DESs, and urea had the best performance among HBDs. It was also found that among the three components of DESs, $\mathrm{Cl}$ - ion played a dominant role in the extraction process.

Thus, today there are significant hurdles to face in the purification of various energy sources (fuel, gas) from different substances, such as acid gases, organic compounds and others. Their presence can have a disastrous effect on the environment, polluting the atmosphere and on the quality of the fuel itself, from which these impurities were extracted. DESs can be used as separating membranes in the processes of gas (liquid) purification. In addition to pure DESs, some nano-confining (nanoparticles such as graphene oxide or the nanoslits of titanium carbide) or additives of the $\mathrm{MoO}_{3}$ type can also be used for changing the properties of the gas separation membrane. Each method allows one to improve certain characteristics that are necessary for a specific industrial task. However, the processes occurring at the nanoscale are often completely inaccessible by experimental methods. In this regard, computer simulations are an excellent tool that allows studies of the molecular mechanisms.

\subsection{Water effect on DES}

One of the important questions is the interactions of water with DESs. The effect of water on DESs and ILs has been reviewed by Ma et al. [28] In practice, the presence of trace amounts of water in DESs is unavoidable in most cases [27-29]. However, even trace amounts of water can affect the H-bond network and significantly change the properties of a DES [28,29]. Water molecules have the ability to be both HBDs and HBAs and can therefore significantly modify the arrangement of DES at the molecular level $[27,266]$.

Water can also be used to change many of the crucial properties of DES such as viscosity, density and ionic conductivity, to lower the financial cost and to preserve the environmental friendliness of the solvent $[28,266]$. For example, high viscosity is considered as one of the drawbacks of DESs that may impede their wider application, $[28,267,268]$ 
and increasing water content leads to a decrease in DES solution viscosity that is often a desirable effect $[269,270]$.

\subsubsection{Water effect on DES micro- and nanostructure}

Much effort has been put into understanding the influence of water on the microand nanostructures of DESs [27,49,92,267,271-276]. Using MD simulations along with NMR spectroscopy, Di Pietro et al. investigated ChCl:urea and ChCl:glycolic acid DESs upon aqueous dilution [27]. The addition of water caused the displacement of DES components and asymmetric hydration around the $\mathrm{Cl}^{-}$ions until water became the main ligand. Busato et al. analyzed the effect of water on the structure of $\mathrm{ChCl} / \mathrm{sesamol}$ 1:3 DES [276]. It was shown that for water/DES molar ratios greater than 6 , water segregates from sesamol and captures the majority of $\mathrm{ChCl}$ in the aqueous area. Weng et al. described the dual effect of water on DESs made of 1:2 ChCl/glycerol using MD simulations [267]. With the addition of water, the number of $\mathrm{ChCl}$-glycerol supramolecular complexes in DES and the number of $\mathrm{H}$-bonds between choline and glycerol decreased significantly. Water can also link choline to glycerol instead of chloride. Alizadeh et al. performed AIMD simulations to study $\mathrm{ChCl}$ :ethylene glycol DES structure with the addition of water (1:2:1 [Ch]Cl:EG:water) [274]. The results showed that water molecules compete for association with $\mathrm{Cl}^{-}$anions. At the same time, some charge transfer occurs from the anion and the hydroxyl group of the cation to water.

QM calculations can also be used to complement experimental data for water-DES systems $[49,273,277]$. For instance, Faraji et al. compared molecular interactions in aqueous solutions of NADESs based on different amino acids [49]. It was shown that NADES containing lactic acid/histidine have the highest interaction energy compared with those NADESs based on alanine and glycine.

\subsubsection{Effects of water on reline}

A large number of studies have focused on the structure and properties of reline in the presence of water $[92,266,272,275,278,279]$. Kumari et al. demonstrated that increasing hydration levels leads to the reduction of interactions between the components of reline while water preferentially solvates $\mathrm{Cl}^{-}$anions as well as hydroxyl and ammonium groups of choline cations [266]. Above $41 \mathrm{wt} \%$ of water content, the structure of reline changes dramatically and a transition from reline to an aqueous solution of reline components occurs. Below this point, the DES structure is qualitatively retained. More recently, Sapir et al. analyzed the effect of water on the nanostructure of reline using MD simulations [272]. The results showed that the nanostructure changed even at very low water content. Moreover, hydrated DES can be deconvoluted into two dominant nanostructures that prevail up to $30 \mathrm{wt} \%$ water: water-in-DES with preserved structural characteristics of pure DES, and DES-in-water where aqueous solvation of chloride and formation of water-chloride aggregates occurs. Thus, DESs in the presence of water are mostly heterogeneous, i.e., composed of a few structures. However, when water content is $>50 \mathrm{wt} \%$, a dilute aqueous solution of DES with solvation of the choline-chloride ion pairs is observed. The quantitative difference between water content that corresponds to a transition to a dilute aqueous solution obtained by Kumari et al. [266] and Sapir et al [272] could be explained by the differences in the water models used in these works.

Fetisov et al. [92] also demonstrated the microheterogeneous structure of reline DES and water mixtures using AIMD simulations. Similarly, results indicated that water preferentially solvates $\mathrm{Cl}^{-}$anions. Furthermore, it was shown that the hydrogen atoms of urea have a similar tendency to bond to the $\mathrm{Cl}^{-}$anions as well as to the oxygen of urea and water. Using MD simulations, Celebi et al. investigated the microscopic structure and thermophysical properties of aqueous reline and ethaline DESs [278]. It was shown that higher water content corresponds to more H-bond networks in reline and ethaline disappearing. Consequently, DESs were fully dissolved at $40 \mathrm{wt} \%$ of water. This corresponds 
to the results obtained for reline by Kumari et al. using the same SPC/E water model [266]. Alterations in DESs structures strongly influence their properties. With increasing water concentration, viscosity and density of reline and ethaline decreased, self-diffusion coefficients increased while the ionic conductivity increased up to $60 \mathrm{wt} \%$ of water followed by a decrease.

Recently, Celebi et al. analyzed the thermal conductivity of aqueous solutions of reline, ethaline and glyceline using non-equilibrium MD simulations [279]. Almost a doubling of the thermal conductivities was observed for all of the aforementioned DESs in the case of the addition of $25 \mathrm{wt} \%$ of water. The increase in water fraction up to $75 \mathrm{wt} \%$ leads to a three-fold increase in thermal conductivity. Bezerra et al. explored the effect of water on the electrochemical behavior of $\mathrm{Ag}+$ ions in reline by combining experiments and MD simulations [280]. Using the cyclic voltammetric technique, it was demonstrated that the addition of water catalyzes the electrochemical reduction of $\mathrm{Ag}^{+}$ions in reline DES. MD simulations revealed structural features in the investigated mixtures - upon addition of water, the number of urea molecules around the Ag+ ions slightly reduced while the water molecules adjusted to the free space in the DES. Thus, the results obtained in different studies for reline-based systems in presence of water are qualitatively consistent. The quantitative differences could be related to the differences in the particular water models used in these studies.

\subsubsection{Water's effect on the properties of DESs}

Computer simulations are widely used to analyze the effects of water on DES, which is important for practical applications [278-282]. Bezerra et al. [280] studied the effect of water content on the electrochemical properties of the $\mathrm{Cu}^{2+}$ ions in an ethaline DES. An increase in water content in ethaline led to an increase in the diffusion coefficient of the $\mathrm{Cu}^{2+}$ ions. Moreover, the addition of water electrocatalysed the electrodeposition of $\mathrm{Cu}$ on the Pt electrode. MD simulations allowed supplementing the experimental findings to understand the relationship between these properties and the structure. For instance, Bezerra et al. [280] demonstrated the complexation of $\mathrm{Cu}^{2+}$ ions with water molecules in DES. It was also shown that when the amount of water was less than $1 \%, \mathrm{Cu}^{2+}$ diffusion remained almost unaltered.

Baz et al. [282] studied thermophysical properties of glyceline DES in aqueous solutions using MD simulations. The results showed that an increase in water content reduced the viscosity of the DES, while the thermodynamic activity of water increased. It was suggested that MD simulations can be used to predict the optimal composition with low viscosity and low enough water activity to be of importance for biocatalytic applications. Lukaczynska-Anderson et al. [281] studied the complexation of $\mathrm{Ni}^{2+}$ in 1:2 ChCl:urea (reline) and 1:2 ChCl:ethylene glycol (ethaline) and demonstrated that the addition of water changes the complexation of metal cations $\left(\mathrm{Ni}^{2+}\right)$ which is reflected in electrochemical performance of DESs. Moreover, the addition of 0-10 wt \% of water to reline led to a strong decrease in viscosity and an increase in conductivity. Interestingly, ethaline appears to be less sensitive to water addition than reline.

\subsubsection{Activity and stability of enzymes in DES/water mixtures}

DESs can be also used as a non-toxic and biodegradable reaction medium for redox biocatalysis [268]. The stability and activity of enzymes in DES with different water concentrations have been addressed using MD simulations [268,271,283]. Kumari et al. [271] showed that the conformation of hen egg-white lysozyme is substantially destabilized in reline/water mixtures especially at 50/50 reline/water content. Huang et al. analyzed the activity and stability of alcohol dehydrogenase in glyceline/water mixtures [268]. At 10\% of water content, the molecular flexibility of the enzyme increased which, in turn, can 
influence the enzymatic activity. At the same time, Shehata et al. showed that slightly hydrated reline (5\%) activates thermoalkalophilic lipases while the mobility of the lid domain that controls catalytic activity increases [283].

\subsubsection{Hydrophobic DESs}

Until recently, synthesized DESs were mostly hydrophilic and showed substantial solubility in water [284]. Increased hydrophobicity of DESs extends the range of their applications. For example, hydrophobic DESs can be used for separating toxic or important products from water.

There is an increasing interest in the synthesis, analysis, and application of hydrophobic DESs, which were first synthesized by van Osch et al in 2015 [215]. Recently, Paul et al. studied the water stability of various hydrophobic DESs, tetrabutylammonium chloride-based DESs and menthol-based DESs with different organic acid-based HBDs [200]. MD simulations demonstrated the key role of $\mathrm{H}$-bond strength on water stability. H-bond strength was related to the DES structure and the length of the alkyl chain of the HBDs. It was shown that DESs based on menthol and higher fatty acid (C8-C12) are water-stable. For menthol-based DESs the order of stability was the following: dodecanoic acid $>$ decanoic acid $>$ octanoic acid $>$ hexanoic acid $>$ pyruvic acid $>$ butanoic acid $>$ levulinic acid $>$ acetic acid, for ammonium-based DESs the order corresponded to the same sequence. The same order was demonstrated for the average number of $\mathrm{H}$-bonds between HBDs and HBAs in DESs. Using MD simulations, Paul et al. investigated phase separation in a DES made of a 1:1 mixture of oleic acid and lidocaine in an aqueous solution [284]. It was found that the H-bonds and non-bonding interactions as well as the competition between them play a crucial role in the phase separation process. Phase separation at higher temperatures was defined by the increase in unfavorable interactions between the DES and water molecules. In their recent work, Salehi et al. [285] studied the interfacial properties of the following hydrophobic DESs with water at different temperatures: tetrabutylammonium chloride - decanoic acid (TBAC-dec) 1:2, thymol-decanoic acid (Thy-dec) 1:2, and DLmenthol-decanoic acid (Men-dec) 2:1. Using MD simulations, they found that the hydrophobicities of the DESs did not depend significantly on temperature. The preferential alignment of oxygen atoms of decanoic acid toward the water phase was also indicated by large peaks on the density profiles. Thy-dec and Men-dec demonstrated strong hydrophobic behaviors with no leaching of the DES constituents into water and negligible water-in-DES solubilities.

\subsubsection{Prediction of DES/water mixtures properties by ANNs}

Special attention should also be paid to the application of ANNs for the prediction of DES/water mixtures properties. For instance, Fiyadh et al. developed ANNs to predict the removal of $\mathrm{Pb}^{2+}$ from water by DES-functionalized carbon nanotubes [172]. The following experimental variables were used as input parameters: adsorbent dosage, initial concentration of metal ions, $\mathrm{pH}$, and contact time while the single output parameter was adsorption capacity. The ANN model was successfully used for prediction and the optimal topology of the neural network was found. Fiyadh et al. also studied the adsorption capacity of DES-functionalized carbon nanotubes for arsenic removal from water solution using ANNs [173].

\subsection{DES in nanotechnology}

Understanding how the molecular-level structure relates to the properties of the solvent is critical to the design and development of DESs for commercial and industrial use. Over recent years, there has been a dramatic increase in computer simulation studies of interactions of DES components with nanoparticles of different chemical structures, molecular composition, mass fraction, and other properties using detailed fully atomistic computer simulations [44,48,70,79,286-301]. Generally, these studies have been carried 
out using atomistic MD methods [286-291,293,295-302] and quantum chemistry (QC) [44,48,70,79,292,294].

To date, DESs have attracted attention for their ability to break agglomeration of carbon nanoparticles, influencing their modification processes, and creating complexes between DES components and nanoparticles. Using atomistic computer simulations, the structure of DESs have been investigated close to the surfaces of different nano-objects: single-walled carbon nanotube (SWCNT) [302], graphene [286,288,291,301], nanosurfaces [286,288,291,293,295,298,300-302], nanopores [287,289], metal nanoparticles [290,293,295298].

As discussed earlier, one of the most common DESs is reline. The orientation of components of reline near the nanoparticle surface has been investigated using MD [288,291,294,300-302] and QC [294] modeling. The results show that in DES solutions, both HBA and HBD molecules are oriented in different ways. Several studies have also shown $[291,295,296,302]$ the emergence order of DES components close to the interface. Pair distribution functions and densities between the nanofiller atoms and DES components show several peaks, characterizing the appearance of regions with different packing densities of DES components near the filler surface. In the vicinity of the nanoparticle surface, one can distinguish the appearance of one well-defined near-surface layer of DES components, which has a structure different from the one observed in the DES liquid state without contact with nanoparticle surfaces.

Lawal et al. [79] combined theoretical calculations and experimental measurements of adsorption of phenol and crystalline violet dye on carbon nanotubes modified by a DES (methyltriphenylphosphonium bromide and glycerol). At the molecular level, the interactions occurring between the surface of the SWCNT with phenol or crystalline violet dye in contact with the components of the DES were studied using QC methods. The authors concluded that the suggested DES could be used for nanofiller modification [79].

$\mathrm{Wu}$ et al. [44] studied the effect of bromine and $\mathrm{Cl}-$ anions on how solvation occurs and supercapacitors' characteristics. They showed that DES electrolytes based on tetraethylammonium bromide (TEAB) or tetraethylammonium chloride (TEAC) as the HBA and ethylene glycol (EG) as the HBD modulate how ion transport depends on temperature and electrode surface desolvation from activated carbon. In particular, their QC calculations showed that after DES formation with EG, the TEAB and TEAC LUMO energies become slightly reduced. Alternatively, HOMO energies decline more crucially in DES systems, which decreases electron loss and oxidation. The large differences between the LUMO-HOMO energies lead to the deterioration of electronic transitions and enhancement of complex stabilization.

Patidar et al. [294] characterized the amphiphilic star block ethylene oxide propylene oxide block (T1304 star) copolymers in different DES-water mixtures in solution by varying the molar water ratio. The results led to the conclusion that among the DES pool studied, glycerol with $\mathrm{ChCl}$ in DESs had the most prominent interactions with the T1304 star copolymer. The authors explained it by the fact that the large energy difference between HOMO and LUMO for a DES leads to the most stable solvent at room temperature. Using DFT, Ghenaatian and coworkers [70] studied clusters of metal particles $(\mathrm{Cu}, \mathrm{Ag}$, and $\mathrm{Au})$ with DES comprising $\mathrm{ChCl}$ and urea. Analysis of the binding energies between the metal particles and DES shows that $\mathrm{ChCl}$ :urea interacts more with $\mathrm{Au}$ and less with $\mathrm{Cu}$ and $\mathrm{Ag}$ nanoparticles. With help of DFT calculations, Shakourian-Fard et al. [292] studied different ChCl-based DESs with graphene molecules (GNF) and graphene with defective double-vacancy and Stone-Wales forms (DV-GNF and SW-GNF). The results show that graphene defects lead to DES adsorption enhancements in the following order: DV-GNF $>S W$ GNF $>$ GNF. The authors also found that the presence of aromatic fragments in DES enhances the van der Waals interactions with surfaces.

MD simulations are being extensively used to predict structural properties of DESs in the vicinity of nanoparticles. Shen et al. [287] modeled four DES systems of mixtures of choline iodide and glycerol at a molar ratio of 1:3, confined inside slotted nanopores 
whose walls are made of $\mathrm{TiO}_{2}$ or graphite. The limiting effect of the pore was found to be strongly influenced by the dominant arrangement of glycerol over DES cations and anions in the first near-surface layer close to the pore. The limiting effect of the wall considerably slows down the mobility of the DES components near the slit walls. Atilhan et al. [297] studied the solvation of various metal nanoparticles (gold, silver, etc.) in various DES solutions by all-atom MD methods. They observed the formation of two solvation layers surrounding the nanoparticles for all types of metals and DESs. In the first layer, intermolecular bulk interactions between the HBDs and metal atoms dominate, and interactions between anions and cations are almost absent. In the second layer, the concentration of their components is close to that of the DES solution. The study performed by Atilhan et al. [297] shows the promising use of different DESs for the solvation of various metal nanoparticles. They showed that due to their ability to stabilize nanoparticles and prevent their aggregation, DESs can be used as prospective solutions for the development of new nanoparticles with controlled properties.

Rozas et al. [291,302] investigated the influence of differences in the chemical structures of nanoparticles (graphene-like [291] and SWCNT-like [302]) consisting of C, BN, Si, $\mathrm{Ge}, \mathrm{MoS}_{2}$ on the structure of the solvation layer of reline. It was found that for graphenelike nanoparticles, a stable near-surface layer of DES components is formed. This layer is dominated by urea molecules due to the formation of H-bonds and there is a lack of choline and $\mathrm{Cl}^{-}$ions. A change in the radius of the SWCNT-like nanotubes did not affect the ability of the nanoparticles to undergo solvation in the DES solution. It was shown that the liquid-like structure of the DES solution is practically unchanged even near the surface of the SWCNT-like nanoparticles. Elbourne et al. [295] studied the emerging patterns of DES molecules on graphene surfaces. The orientation of molecules depending on their distance from the surface was studied. It was suggested that the formation of a near-surface DES layer implies the emergence of a separate nanostructure of the adsorbed layer from the DES components. The appearance of such a structure is apparently caused by a balance between the "surface-liquid" and "liquid-liquid" interactions, as well as the limiting effect of the solid surface at the interface.

\subsection{Biomolecules in DES}

As discussed in Introduction, DESs have a wide range of applications in pharmaceuticals as solvents, active pharmaceutical ingredients [12] and cryoprotective agents [303]. For example, it is well-known that in water solution, urea forms H-bonds with proteins breaking intramolecular protein contacts and causing denaturation [304-306]. A surprising and counterintuitive fact is the observed stabilization of protein structure in the DES based on urea and $\mathrm{ChCl}$ reported by Gorke et al. [307]. To explain this, Monhemi et al. compared the results of an MD simulation of Candida antarctica lipase B in reline and in urea solution [308]. It was shown that $\mathrm{ChCl}$ limits the diffusion of urea molecules to the protein core. Moreover, reline components form H-bonds with residues of the enzyme leading to greater enzyme stability, instead of its denaturation. This problem was further investigated by Chakrabarti's group [309,310]. In their first work, they analyzed the effect of the ammonium salt on stabilization of DESs based on urea [309]. Comparison of peptide structures in DESs based on two different ammonium salts ( $\mathrm{ChCl}$ and triethylammonium acetate chlorides) in different compositions (relative proportions of 1:2 molar ratio and 1:5 molar ratio) showed that reducing the concentration of ammonium salt leads to a destabilization of the protein structure. However, in case of $\mathrm{ChCl}$, the protein remains more stable than in case of triethylammonium acetate. In their next work [310], Chakrabarti et al. revealed the molecular mechanisms of protein stabilization in a series of simulations of the HP-36 peptide, fully confirming the results of Monhemi et al. [308]. In addition, Pal et al. demonstrated the stabilization effect of glyceline on the protein [311]. MD simulations in this case revealed stabilizing H-bonds between the glycerol and protein residues. These H-bonds make the protein more rigid and structurally stable at high temperatures. 
The same group recently studied the effect of reline on the structure of nucleic acids (Thrombin-Binding G-quadruplex Aptamer (TBA)) [312,313]. In their first work, Pal et al. demonstrated that an increase of reline concentration in water solution decreases the flexibility of TBA [312] suggesting that reline is a good choice for nucleic acid storage. In another publication, Pal et al. explored the temperature-mediated conformational dynamics of c-kit oncogene promoter G-quadruplex DNA in reline [311]. The authors demonstrated increased thermal stability of the DNA structure similar to what was observed for proteins [311] and revealed the molecular interactions responsible for these phenomena.

A series of publications from Aparicio's group [133-135,314] deserves special attention. In their work on lidocaine solubility, they predicted that the solubility of lidocaine in two different DESs ( $\mathrm{ChCl}+$ lactic acid, $\beta$-alanine + lactic acid) is several orders of magnitude larger than in water and revealed the interactions responsible for the solvation [38]. In the follow-up work, they studied the solubility of lidocaine in three newly designed DESs based on arginine and three different organic acids (glutamic acid, oxalic acid, tartaric acid) [134]. They showed that long-lived H-bonds between lidocaine and both arginine and organic acids are the main reason for the high solubility of lidocaine and demonstrated how the solubility of medicinal compounds in a DES can be controlled by the selection of suitable HBDs and HBAs. In their most recent work [135], Aparicio's group investigated the behavior of two $\beta$-lactam antibiotics (piperacillin and ampicillin) in the same arginine DESs [134] and determined its structure and the main interactions between DESs and the antibiotics.

Another important work of Aparicio's group focused on the investigation of cytotoxicity of different DESs by the simulation of lipid biomembranes in eleven DESs based on $\mathrm{ChCl}$ and different HBDs [314]. Atilhan et al. showed that the free HBDs of the DESs are inserted in the bilayer [314]. The authors showed that the insertion of HBDs initiates bilayer disruption. These results predict high cytotoxicity of the concentrated solutions of DESs. However, the number of HBDs inserted in the bilayer is strictly dependent on the hydrophobicity of the HBD. Thus, this work demonstrates the ability to regulate cytotoxicity by varying the HBD type in the DES [314].

It can be concluded that DESs are prospective solvents for pharmaceutical applications. QC and MD techniques have demonstrated their ability to resolve the intermolecular interactions and how DESs can stabilize the structures of biomolecules such as DNA and proteins. DESs' ability to dissolve antibiotics, together with their low toxicity, makes them promising solvents in pharmacology.

\subsection{Biomass pretreatment by DES}

Owing to their low cost and toxicity, biodegradability, high thermal and chemical stability, DESs have emerged as promising solvents for the pretreatment of biomass, i.e., by-products from plants, animals, and microorganisms [315]. DESs could be used for the dissolution and separation of biomass, the exaction of useful chemicals from biomass, as well as for biomass conversion [315]. It is highly important for the optimization of biomass pretreatment to understand the molecular mechanisms responsible for the process. In this regard, computational methods have proved to be irreplaceable. Below we give typical examples of such studies.

Mohan et al. [316] studied the dissolution of glucose in DESs based on tetrabutylammonium bromide using DFT calculations and MD simulations. These techniques allowed the analysis of the glucose-DES interactions. It was shown that the anion of the hydrogen bond acceptor and the HBD molecules form hydrogen bonds with glucose and thus govern the dissolution of glucose. Similar conclusion was made by Smirnov et al. [108] in their simulation of nanocrystalline cellulose in reline. In particular, it was revealed that the formation of $\mathrm{H}$-bonds between the cellulose hydroxyl groups, the urea CO group and the $\mathrm{Cl}^{-}$ions are the key for dissolution, see Figure 5. The importance of $\mathrm{H}$-bonds for cellulose dissolution was also demonstrated in the case of 1,8-diazabicyclo[5.4.0]undec-7enium based DES [317]. In their study [317], Fu et al. utilized DFT calculations to describe 
interactions in systems consisting of cellobiose and DES molecules. It was established that both the HBA and HBD in the DES interact with cellulose via H-bonds. It was also proposed that this interaction could destroy the H-bond network of cellulose chains, thereby promoting the dissolution process. ILs dissolve cellulose in a similar fashion [318] with anions playing a major role in cellulose dissolution.

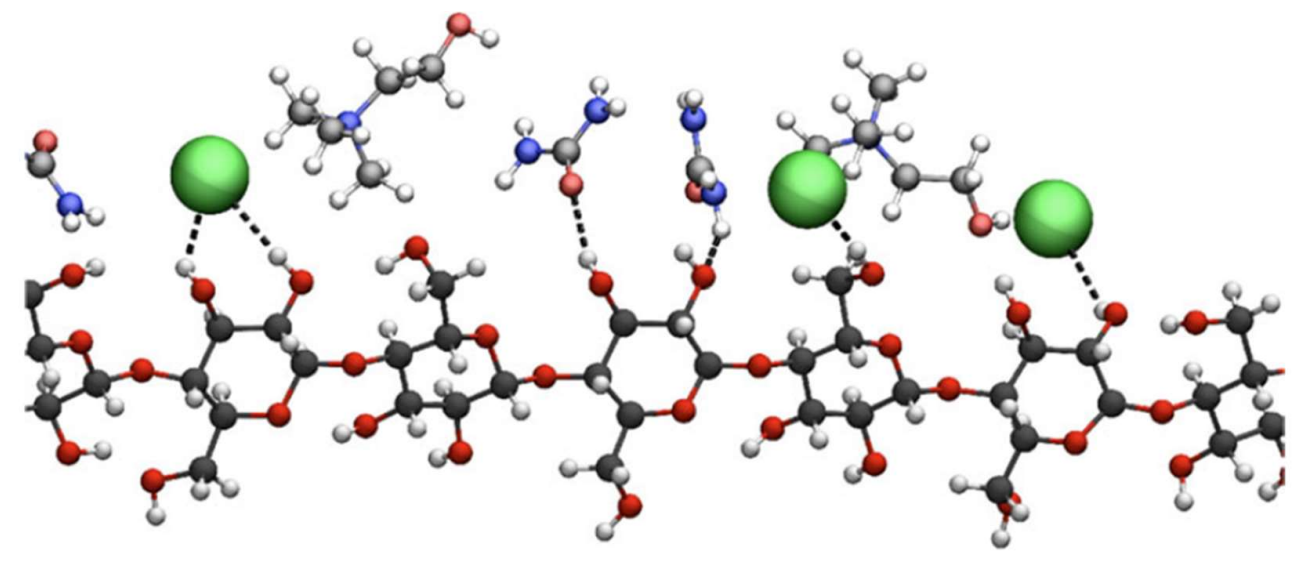

Figure 5. Snapshot illustrating the typical interactions of cellulose with $\mathrm{Cl}^{-}$ions and urea molecules. Gray dotted lines show H-bonds. Red balls represent oxygen atoms, blue balls - nitrogen atoms, white balls - hydrogen atoms, grey balls - carbon atoms and green balls $-\mathrm{Cl}^{-}$ions. Reprinted by permission from: Springer Nature, Cellulose, [108], COPYRIGHT 2020.

It is worth mentioning that the cellulose-based products obtained from biomass could be used to develop novel DES-containing materials. For example, Smith et al. [110] reported experimental and simulation results on bacterial cellulose gels containing DES glyceline. Both X-ray diffraction analyses and MD simulations confirmed that the DESs has almost no effect on the crystalline structure of cellulose. Moreover, MD simulations allowed the authors to explain the increased diffusion rates for DES components in gels, which was verified by nuclear magnetic resonance; it was suggested that faster diffusion stems from the migration of chloride from the bulk to the cellulose surface.

Some studies [181,319] have focused on the dissolution of lignin from biomass. Muley et al. [319] investigated lignin tetramers immersed in a DES consisting of oxalic acid and $\mathrm{ChCl}$ under external electric fields using MD simulations. They showed that an electric field could lengthen certain lignin bonds and therefore increase their probability of breaking, thus contributing to biomass deconstruction. Xu et al. [181] performed DFT calculations together with principal component analyses to evaluate factors influencing lignin removal when using ChCl-based DESs. It was established that the hydrophilic ability, polarity, acidity and ability to form $\mathrm{H}$-bonds have a significant effect on the pretreatment process.

Recently, an effective procedure has been developed for $\beta$-carotene extraction from pumpkins using DESs based on fatty acids [179]. To this end, the RSM and ANN approaches were used to optimize the extraction process. Namely, they allowed selecting the temperature, ultrasound power, and solvent to solid ratio to reach the highest yield of $\beta$-carotene from pumpkin.

\section{Future Directions}

The field of computational research of DES systems is rapidly evolving. During the past five years, a number of fundamental questions about the relation between DESs' structure and properties have been answered with the aid of computer simulations. It is now well understood that the nature of the eutectic phenomena of DESs is directly related to the H-bond network and its subtleties. Understanding the role of each of components 
in classic DESs (such as reline, ethaline or glyceline), and the interactions between them, allows for obtaining the desired structural and transport properties. For example, increasing the number of donor sites of an HBD not only should change the eutectic composition but also increase the stability of the H-bond network, and as a result raise viscosity. An increase of the hydrophobic part of the cation should lead to the appearance of structural heterogeneities. However, the development of new DESs with improved properties sets new tasks for computational chemistry. For example, the development of ternary DESs has great potential to enhance their properties. At the same time, increasing the number of DES components significantly complicates the prediction of the properties and emphasizes the role of computational research as an indispensable step in DES development.

The development of DESs with application-specific optimal properties is a large and active field in computational research. Most of the applications are related to the interactions of DESs with various compounds and mediums. However, in some research areas, such as solubility studies with biomolecules and molecular mechanisms of the interactions between DESs and nanoparticles, there are currently only a few investigations. While these provide much needed information about studied systems, the low number of these publications does not allow obtaining comprehensive fundamental knowledge about the molecular processes. Moreover, the appearance of new DES applications requires knowledge from computational chemistry. For example, the recent developments of polarizable DESs for 3D printing open questions about how to control DESs' viscosity and the complex mixtures based on them [11]. These questions can be answered using computer simulation techniques. It is important to note that DES models and approaches are currently imperfect and, in some cases, cannot provide quantitatively correct information. As can be seen from this review, work is underway to develop new approaches.

The vast growth of experimental and computational works devoted to DES publications provides a significant increase in the amount of new data. This creates a fertile field for ML techniques that should kickstart a new stage of the DES evolution.

In this review, it has been discussed in depth how particle simulations at atomistic and quantum levels provide excellent means for detailed studies of complex systems. However, these systems can only be simulated on up-to nanoscale spatial lengths and nanosecond time scales. To study DESs on a larger scale, which would be desirable for industrial applications for instance, simulation techniques that can model systems on the meso- (intermediate) or macroscale might be better suited. In particular, it would be desirable to capture the microstructure evolution of a DES, for example, near its eutectic point. Furthermore, meso- and macroscale modeling can also provide information about the behaviour of parameters such as chemical potential, surface tension and viscosity, necessary for advancing our understanding of DESs [30].

At a high level of coarse-graining [148], phase-field modeling (PFM) is a very powerful mathematical and computational framework for microstructure simulations [320]. In PFM, instead of particles, a system is represented using one or more continuous variables called order parameters and a corresponding set of partial differential equations can be determined from a free energy potential or even derived phenomenologically. The order parameters are typically based on the symmetries of the system around a phase transition, e.g. the eutectic point, and represent the phase as a field of values (hence the name phase-field) at a mesoscopic scale. The appeal of PFM comes from its ability to capture large-scale behaviour. Additionally and very importantly, the interfaces between the bulk regions and the complex dynamics emerge naturally from the construction of a PFM [321]. The PFM approach has been successful in a wide variety of application such as directional solidification and dendritric growth [322-324], formation of polycrystalline structures [325,326] cardiac electric signals [327,328], and [325,329] and electrochemical effects [330]. On the computational side, PFM is highly amenable to large-scale parallelizable simulations and there are a number of software packages available to simulate various phasefield models based on both finite element and finite difference methods that usually employ some level of parallelization [331-336]. 
While currently there are no direct applications of PFM to DESs, it is a potential new approach and has been used in modeling the formation and behavior of eutectic materials. The application of PFM to eutectics initially began with describing isothermal phase transitions in binary alloys [337]. This work was extended to include eutectic growth by Elder et al. [338] and separately by Karma [339]. The disadvantage of the initial attempts of formulating a model was that the pure substances had an infinitely high melting temperature. There were further extensions to mitigate this issue as well as to include non-isothermal eutectic systems [340,341]. Recent work on PFM of eutectics includes studies of directional solidification of ternary eutectics by Hötzer et al., who base their PFM on multicomponent alloy solidification [342-345] and simulate a ternary eutectic at the three phase invariant point to study microstructure formation. Additionally, phase-field simulations were performed for the ternary eutectic Al-Ag-Cu by Steinmetz et al., who found good agreement of directional solidification patterns with experimental results [346].

One step to applying PFM to DESs is understanding the phase behavior of such systems. Some work has been done on this topic; a study by Kollau et al. showed that one of the difficulties in adequately describing the phase behavior arises because typical DES components typically have different sizes and shapes, thus, an ideal entropy of mixing does not appropriately represent DESs. They found that significant differences in the phase behavior of DES comes from choice of entropy expression and molar volumes [347].

It is important to note that despite all of our efforts, not all publications devoted to DES simulations were included in the review due to their high number. To help the reader and to put the studies that we may have missed and new studies that become published, in a perspective, we present systemized information about the publications in Tables 2-4 in Appendix with brief information about every publication.

Funding: This work was supported by the Ministry of Education and Science of the Russian Federation (agreement № 075-15-2021-954 dated 23.09.21). R.M.d.S. and M.C.C.R. thank FAPESP (The São Paulo Research Foundation) grants Process 2020/06766-9 and 2016/21070-5.

Acknowledgments: The authors are grateful to Artem Aleksandrov for creating the graphic abstract for this article.

Conflicts of Interest: The authors declare no conflict of interest

\section{Appendix}

Table 2. Atomistic simulation simulations of DES consisting systems, force field used, and the topic of the publication. It should be noted that the partial charges could vary greatly in the publications with the same force field due to variations of approaches for their calculations. We refer to current publications for the details.

\begin{tabular}{|c|c|c|c|c|}
\hline No & DES & FF / Corrections & Topic of the publication & $\begin{array}{c}\text { Ref- } \\
\text { er- } \\
\text { ence }\end{array}$ \\
\hline 1 & $\begin{array}{l}\text { 1-ethyl-3-methylimidazolium chloride:Urea } \\
\text { Different molar ratios }\end{array}$ & $\begin{array}{c}\text { CL\&P } \\
\text { OPLS-AA }\end{array}$ & $\begin{array}{l}\text { Investigation of DES struc- } \\
\text { ture }\end{array}$ & [212] \\
\hline 2 & $\begin{array}{c}\text { 1-octyl-3-methylimidazolium : Tetrafluorob- } \\
\text { orate 1-ethyl-3-methylimidazolium : Tetra- } \\
\text { fluoroborate } \\
\text { Different molar ratios }\end{array}$ & CL\&P & $\begin{array}{l}\text { Investigation of DES struc- } \\
\text { ture }\end{array}$ & [348] \\
\hline 3 & Acetamide : $\operatorname{LiBr}(3.5: 1)$ & $\begin{array}{c}\text { CHARMM } 27 \\
\text { only / no corrections }\end{array}$ & Support to experiment & [232] \\
\hline 4 & Acetamide : $\mathrm{LiClO}_{4}(3.5: 1)$ & $\begin{array}{l}\text { CHARMM } 27 \text { + separate } \\
\text { parameters for ions }\end{array}$ & $\begin{array}{l}\text { Mechanisms of DES com- } \\
\text { ponents motion }\end{array}$ & [230] \\
\hline 5 & Acetamide $: \mathrm{LiClO}_{4}(3.5: 1)$ & $\begin{array}{l}\text { CHARMM } 27+\text { separate } \\
\text { parameters for ions }\end{array}$ & $\begin{array}{l}\text { Mechanism of acetamide in } \\
\text { DESs }\end{array}$ & [231] \\
\hline
\end{tabular}




\begin{tabular}{|c|c|c|c|c|}
\hline 6 & $\begin{array}{l}\text { Acetamide }: \mathrm{LiClO}_{4}(3.5: 1) \\
\text { Acetamide }: \mathrm{LiNO}_{3}(3.5: 1) \\
\text { Acetamide }: \mathrm{LiBr}(3.5: 1)\end{array}$ & $\begin{array}{l}\text { CHARMM } 27+\text { separate } \\
\text { parameters for ions }\end{array}$ & $\begin{array}{l}\text { Orientation jumps of acet- } \\
\text { amide molecules }\end{array}$ & [234] \\
\hline 7 & $\begin{array}{c}\text { Acetamide }: \mathrm{LiClO}_{4}(4.1: 1) \\
\text { Acetamide }: \mathrm{LiNO}_{3}(3.5: 1) \\
\text { Acetamide }: \mathrm{LiBr}(3.5: 1)\end{array}$ & $\begin{array}{l}\text { CHARMM } 27+\text { separate } \\
\text { parameters for ions }\end{array}$ & Support to experiment & [233] \\
\hline 8 & Acetamide : LiNO3 (3.5:1) & $\begin{array}{l}\text { CHARMM } 27+\text { separate } \\
\text { parameters for ions }\end{array}$ & $\begin{array}{l}\text { Mechanisms of DES com- } \\
\text { ponents motion }\end{array}$ & [229] \\
\hline 9 & $\begin{array}{l}\text { Acetamide : Urea (1.5:1) } \\
\text { Acetamide : Urea (2.3:1) }\end{array}$ & $\begin{array}{l}\text { CHARMM + GROMOS96 } \\
\text { / no corrections }\end{array}$ & $\begin{array}{l}\text { Temperature dependent } \\
\text { relaxation dynamics, parti- } \\
\text { cle motion characteristics, } \\
\text { and heterogeneity aspects } \\
\text { of deep eutectic solvents }\end{array}$ & [235] \\
\hline 10 & Acetamide : Urea (2.3:1) & $\begin{array}{l}\text { CHARMM + GROMOS96 } \\
\text { / no corrections }\end{array}$ & $\begin{array}{l}\text { Structural H-bond relaxa- } \\
\text { tion }\end{array}$ & [236] \\
\hline 11 & Acetamide : Urea (2.3:1) & $\begin{array}{c}\text { OPLS-DES / no correc- } \\
\text { tions }\end{array}$ & $\begin{array}{l}\text { Heterogeneity of reorienta- } \\
\text { tional relaxation and trans- } \\
\text { lational dynamics }\end{array}$ & [237] \\
\hline 12 & $\begin{array}{l}\text { Arginine : Glutamic acid }(1: 1) \\
\text { Arginine : Oxalic acid }(1: 1) \\
\text { Arginine : Tartaric acid }(1: 1)\end{array}$ & $\begin{array}{l}\text { No name of FF. Parame- } \\
\text { ters are given }\end{array}$ & Lidocaine in DES & [134] \\
\hline 13 & $\begin{array}{l}\text { Arginine : Glutamic acid }(1: 1) \\
\text { Arginine : Oxalic acid (1:1) } \\
\text { Arginine : Tartaric acid }(1: 1)\end{array}$ & $\begin{array}{l}\text { No name of FF. Parame- } \\
\text { ters are given }\end{array}$ & Antibiotics in DES & [135] \\
\hline 14 & $\begin{array}{l}\text { Benzene-1,4-diol : Urea } \\
\text { Different molar ratios }\end{array}$ & AMBER99 & $\begin{array}{l}\text { Investigation of DES struc- } \\
\text { ture and dynamics and wa- } \\
\text { ter effect on it }\end{array}$ & [349] \\
\hline 15 & Betaine : Lactic acid (1:1) & $\begin{array}{c}\text { No name of FF. Parame- } \\
\text { ters are given }\end{array}$ & $\begin{array}{l}\text { Investigation of DES struc- } \\
\text { ture }\end{array}$ & {$[137]$} \\
\hline 16 & $\begin{array}{l}\text { Betaine Monohydrate : Glycerol } \\
\text { Different molar ratios }\end{array}$ & GAFF / no corrections & $\begin{array}{c}\text { Extraction of palmitic acid } \\
\text { by DES }\end{array}$ & {$[350]$} \\
\hline 17 & Betaine Monohydrate : Glycerol (1:2) & GAFF / no corrections & $\begin{array}{c}\text { Investigation of DES struc- } \\
\text { ture }\end{array}$ & {$[351]$} \\
\hline 18 & $\begin{array}{l}\text { Bis(trifluoromethanesulfonyl)imide : Me- } \\
\text { thanesulfonamide Bis(trifluoromethanesul- } \\
\text { fonyl)imide : Dimethylmethanesulfonamide } \\
\text { Different molar ratios }\end{array}$ & OPLS-AA / no corrections & $\begin{array}{l}\text { Characterization of the } \\
\text { transport properties of bi- } \\
\text { nary DESs }\end{array}$ & [352] \\
\hline 19 & $\begin{array}{c}\text { Caprolactam : Tetrabutylammonium bro- } \\
\text { mide }(1: 1) \\
\text { Caprolactam : Tetrabutylammonium bro- } \\
\text { mide }(1: 1) \\
\mathrm{ChCl}: \text { Urea }(1: 2) \\
\text { Methyltriphenylphosphonium bromide : } \\
\text { Monoethanolamine (1:6) }\end{array}$ & $\begin{array}{l}\text { Gromos54a7, } \\
\text { the optimized forcefield } \\
\text { parameters were obtained } \\
\text { from the Automated To- } \\
\text { pology Builder (ATB) da- } \\
\text { tabase }\end{array}$ & $\begin{array}{l}\text { Natural Gas Desulfuriza- } \\
\text { tion using DES }\end{array}$ & [353] \\
\hline 20 & $\begin{array}{c}\text { Ceineole : Succinic acid (1:1) Ceineole : Malic } \\
\text { acid (1:1) } \\
\text { Ceineole }: \text { Lactic acid (1:1) }\end{array}$ & $\begin{array}{l}\text { No name of FF. Parame- } \\
\text { ters are given }\end{array}$ & $\begin{array}{c}\text { Investigation of DES struc- } \\
\text { ture }\end{array}$ & [138] \\
\hline 21 & $\mathrm{ChCl}$ : Ethylene glycol (1:4) & OPLS-AA / no corrections & DES for gas separation & {$[257]$} \\
\hline
\end{tabular}




\begin{tabular}{|c|c|c|c|c|}
\hline 22 & $\begin{array}{c}\mathrm{ChCl}: \text { 1,2-ethanediol (1:2) } \\
\mathrm{ChCl}: \text { 1,3-propanediol (1:3) } \\
\mathrm{ChCl}: 1,4 \text {-butanediol (1:3) }\end{array}$ & $\begin{array}{l}\text { OPLS and GAFF / no cor- } \\
\text { rections }\end{array}$ & $\begin{array}{c}\text { Dependence of Solvation } \\
\text { Dynamics in Alcohol- } \\
\text { Based DES }\end{array}$ & [354] \\
\hline 23 & $\begin{array}{c}\mathrm{ChCl}: \text { 1,2-ethanediol, } \\
\mathrm{ChCl}: \text { 1,3-propanediol } \\
\mathrm{ChCl}: 1,4 \text {-butanediol } \\
\mathrm{ChCl}: 1,5 \text { - pentanediol }\end{array}$ & $\begin{array}{c}\text { Combination of OPLS-AA } \\
\text { and Amber parameters }\end{array}$ & $\begin{array}{c}\text { Investigation of DES struc- } \\
\text { ture }\end{array}$ & [355] \\
\hline 24 & $\mathrm{ChCl}$ : Acetyl salicylic acid $(1: 1)$ & GAFF / no corrections & $\begin{array}{c}\text { Investigation of DES struc- } \\
\text { ture }\end{array}$ & [203] \\
\hline 25 & $\begin{array}{c}\mathrm{ChCl}: \text { Citric acid }(1: 1) \\
\mathrm{ChCl}: \text { Fructose }(1: 1) \\
\mathrm{ChCl}: \text { Malic acid }(1: 1) \\
\mathrm{ChCl}: \text { Lactic acid }(1: 1)\end{array}$ & $\begin{array}{c}\text { No name of FF. } \\
\text { Parameters are given }\end{array}$ & $\begin{array}{c}\text { Gas Solubility and Rheo- } \\
\text { logical Behavior of Natural } \\
\text { DES }\end{array}$ & {$[37]$} \\
\hline 26 & $\begin{array}{l}\mathrm{ChCl} \text { : Ethylene glycol } \\
\text { Different molar ratios }\end{array}$ & OPLS-AA / no corrections & DES for $\mathrm{CO}_{2}$ separation & [255] \\
\hline 27 & $\begin{array}{l}\mathrm{ChCl} \text { : Ethylene glycol (1:1) } \\
\mathrm{ChCl} \text { : Ethylene glycol (1:2) }\end{array}$ & $\begin{array}{l}\text { OPLS-AA CL\&P / charges } \\
\text { scaling for ions is } 0.8\end{array}$ & $\begin{array}{c}\text { Water effect on DES struc- } \\
\text { ture }\end{array}$ & [274] \\
\hline 38 & ChCl : Ethylene glycol (1:2) & GAFF $/ \pm 0.9 \mathrm{e}$ for the ions & $\begin{array}{c}\mathrm{CO}_{2} \text { uptake by a DES in slit } \\
\text { nanopores }\end{array}$ & {$[289]$} \\
\hline 29 & $\mathrm{ChCl}$ : Ethylene glycol (1:2) & OPLS / no corrections & DES at a solid electrode & {$[293]$} \\
\hline 30 & ChCl : Ethylene glycol (1:2) & INTERFACE and CGenFF & DES at solid interfaces & [295] \\
\hline 31 & ChCl : Ethylene glycol (1:2) & $\begin{array}{l}\text { GAFF / charges scaling } \\
\text { for ions is } \pm 0.9\end{array}$ & $\begin{array}{c}\text { Investigation of DES struc- } \\
\text { ture }\end{array}$ & {$[145]$} \\
\hline 32 & $\mathrm{ChCl}$ : Ethylene glycol (1:2) & $\begin{array}{l}\text { CHARMM General Force } \\
\text { Field / no corrections }\end{array}$ & $\begin{array}{c}\text { Investigation of DES struc- } \\
\text { ture }\end{array}$ & {$[195]$} \\
\hline 33 & ChCl : Ethylene glycol (1:2) & $\begin{array}{l}\text { FF developed by authors } \\
(0.8 \text { FFM3) based on OPLS }\end{array}$ & $\begin{array}{c}\text { Investigation of DES struc- } \\
\text { ture }\end{array}$ & {$[196]$} \\
\hline 34 & $\mathrm{ChCl}$ : Ethylene glycol (1:2) & CL\&Pol & Force field validation & [121] \\
\hline 35 & ChCl : Ethylene glycol (1:2) & $\begin{array}{l}\text { CL\&Pol } \\
\text { CL\&P }\end{array}$ & Force field validation & [123] \\
\hline 36 & $\mathrm{ChCl}$ : Ethylene glycol (1:2) & OPLS-AA / no corrections & $\begin{array}{l}\text { Water effect on DES physi- } \\
\text { cochemical properties }\end{array}$ & {$[280]$} \\
\hline 37 & $\mathrm{ChCl}$ : Ethylene glycol (1:2) & GAFF / no corrections & $\begin{array}{l}\text { Solvatochromic parame- } \\
\text { ters, and preferential solva- } \\
\text { tion in aqueous solutions } \\
\text { of DES and its components }\end{array}$ & {$[273]$} \\
\hline 38 & $\mathrm{ChCl}$ : Ethylene glycol (1:2) & OPLS / no corrections & $\mathrm{CO}_{2}$ absorption in DES & {$[142]$} \\
\hline 39 & $\begin{array}{c}\mathrm{ChCl} \text { : Ethylene glycol (1:2) } \\
\mathrm{ChCl} \text { : Glycerol }(1: 2) \\
\mathrm{ChCl} \text { : Malonic acid }(1: 2)\end{array}$ & $\begin{array}{c}\text { GAFF / charge scaling for } \\
\text { ions is } 0.9\end{array}$ & $\begin{array}{c}\text { Investigation of DES struc- } \\
\text { ture }\end{array}$ & [107] \\
\hline 40 & $\begin{array}{c}\text { ChCl : Ethylene glycol (1:2) } \\
\text { ChCl : Glycerol }(1: 2) \\
\mathrm{ChCl}: \text { Urea }(1: 2)\end{array}$ & GAFF / no corrections & $\begin{array}{l}\text { Solvation dynamics of an } \\
\text { ionic probe in DES }\end{array}$ & [356] \\
\hline 41 & $\begin{array}{l}\mathrm{ChCl} \text { : Ethylene glycol }(1: 2) \\
\mathrm{ChCl}: \text { Levulinic acid }(1: 2)\end{array}$ & $\begin{array}{c}\text { GAFF / charge scaling for } \\
\text { ions is } 0.9 \text { for systems } \\
\text { with ethylene glycol }\end{array}$ & $\begin{array}{l}\text { Fluorinated refrigerants in } \\
\text { DESs }\end{array}$ & {$[103]$} \\
\hline
\end{tabular}


0.8 - for systems with levulinic acid

$\mathrm{ChCl}$ and Ethylene glycol - GAFF

$\mathrm{ChCl}$ : Ethylene glycol (1:2)

$\mathrm{ChCl}$ : Levulinic acid (1:2)

$\mathrm{ChCl}$ : Ethylene glycol (1:2)

43

$\mathrm{ChCl}$ : Propylene glycol (1:2)

$\mathrm{ChCl}$ : 1,3-propanediol (1:2)

$\mathrm{ChCl}$ : Glycerol (1:2)

44

$\mathrm{ChCl}$ : Ethylene glycol (1:3)

$\mathrm{ChCl}$ : Glycerol (1:3)

$\mathrm{ChCl}$ : Ethylene urea (1:2)

$\mathrm{ChCl}$ : Thiourea (1:2)

45

$\mathrm{ChCl}$ : Ethylene glycol (1:2)

$\mathrm{ChCl}$ : Glycerol (1:2)

$\mathrm{ChCl}$ : Glucose (1:3, 1:1, 3:1)

\section{ChCl : Glycerol}

ChCl : Glycerol : Resorcinol (1:5:3)

ChCl : Glycerol (1 : 2)

ChCl : Glycerol (1:1)

$\mathrm{ChCl}$ : Glycerol (1:2, 1:3)

$\mathrm{ChCl}$ : Glycerol (1:2)

$\mathrm{ChCl}$ : Glycerol (1:2)

$\mathrm{ChCl}$ : Glycerol (1:2)

$\mathrm{ChCl}$ : Ethylene glycol (1:2)

$\mathrm{ChCl}$ : Glycerol (1:2)

$\mathrm{ChCl}:$ Lactic acid (1:1)

$\beta$-alanine : Lactic acid (1:1)

$\mathrm{ChCl}:$ Lactic acid (1:9)

$\mathrm{ChCl}$ : Levulinic acid (1:2)

ChCl : Levulinic acid (1:2)

$\mathrm{ChCl}$ : Malonic acid

$\mathrm{ChCl}$ : Oxalic acid
Levulinic acid - HF/6-

$31 G^{*}+$ AMBER or DFT

for optimized clusters

FF developed by authors

(0.74FFM16) based on + OPLS

\section{COMPASS}

"UNIVERSAL" force field Forcite and Blends Module Materials studio package

CHARMM 36 / no corrections

OPLS-AA / no corrections

Parameters are given

CHARMM36 / no corrections

Gromos54a7 / no corrections

GAFF / no corrections

GAFF / charge scaling is 0.9

GAFF / no corrections

GAFF

CGenFF

no corrections

GAFF / charge scaling for ions is 0.9

No name of FF. Parameters are given

GAFF / no corrections

No name of FF. Parameters are given No name of FF.

Parameters are given

GAFF / no corrections
AMBER

OPLS-DES
DES for gas separation

Investigation of DES structure

Silica nanoparticles in DES

Desulfurization mechanism by the DES solvents

Investigation of DES structure

Gels based on DES and cellulose

Investigation of DES structure

Water effect on DES structure

Effects of a cholinium based DES on function and structure of versatile peroxidase

[359]

Investigation of DES structure

[197]

Protein in DES

solvation of enzyme in DES

[360]

Validation of force field for mixtures of DES and water and interaction DES with enzyme

Effect of water on thermophysical properties DES

Lidocaine in DES

Lignin dissolution behaviors of DES

DES on the metal surface

DES for $\mathrm{CO}_{2}$ capture Investigation of DES structure 


\section{$\mathrm{ChCl}:$ Succinic acid \\ $\mathrm{ChCl}$ : Fumaric acid \\ Different molar ratios}

\begin{tabular}{|c|c|}
\hline 61 & $\mathrm{ChCl}:$ Malonic acid $(1: 1,1: 2)$ \\
\hline 62 & $\mathrm{ChCl}$ : Oxalic acid (1:1) \\
\hline 63 & $\mathrm{ChCl}$ : Phenyl propionic acid (1:2) \\
\hline 64 & $\begin{array}{l}\mathrm{ChCl} \text { : Phenyl propionic acid. Different mo- } \\
\qquad \text { lar ratios }\end{array}$ \\
\hline 65 & $\mathrm{ChCl}$ : Phenylacetic acid (1:2) \\
\hline 66 & $\begin{array}{l}\mathrm{ChCl} \text { : Propylene glycol (1:2) } \\
\mathrm{ChCl} \text { : Ethylene glycol (1:2) }\end{array}$ \\
\hline 67 & $\mathrm{ChCl}$ : Sesamol (1:3) \\
\hline 68 & $\begin{array}{l}\mathrm{ChCl}: \text { Urea } \\
\text { Different molar ratios }\end{array}$ \\
\hline 69 & $\begin{array}{c}\mathrm{ChCl}: \text { Urea } \\
\text { Different molar ratios }\end{array}$ \\
\hline 70 & $\mathrm{ChCl}$ : Urea (1:2) \\
\hline 71 & $\mathrm{ChCl}$ : Urea (1:2) \\
\hline 72 & $\mathrm{ChCl}$ : Urea (1:2) \\
\hline 73 & $\mathrm{ChCl}:$ Urea $(1: 2)$ \\
\hline 74 & $\mathrm{ChCl}$ : Urea (1:2) \\
\hline 75 & $\mathrm{ChCl}$ : Urea (1:2) \\
\hline 76 & $\mathrm{ChCl}$ : Urea (1:2) \\
\hline 77 & $\mathrm{ChCl}$ : Urea (1:2) \\
\hline 78 & $\mathrm{ChCl}:$ Urea (1:2) \\
\hline 79 & $\mathrm{ChCl}$ : Urea (1:2) \\
\hline 80 & $\mathrm{ChCl}:$ Urea (1:2) \\
\hline 81 & $\mathrm{ChCl}$ : Urea (1:2) \\
\hline 82 & $\mathrm{ChCl}$ : Urea (1:2) \\
\hline
\end{tabular}

GAFF / no corrections

CHARMM36 / no corrections

CHARMM 36 / charges scaling is 0.8 .

CHARMM 36 / no corrections

No name of FF.

Parameters are given

FF developed by authors

(0.74FFM16) based on OPLS

OPLS-AA / no corrections

CL\&P / charge scaling for ions is 0.9 .

GAFF / charge scaling for ions is 0.8

GROMOS 96 / no corrections

GAFF / charge scaling is 0.8

OPLS-AA / no corrections

GAFF / charge scaling is 0.8

CHARMM22 / no corrections

No name of FF. Parameters are given

No name of FF. Parameters are given

Combine force field based on CGenFF and CHARMM 36

$\mathrm{GAFF} / \pm 0.9 \mathrm{e}$ for the ions

OPLS-AA / no corrections q4-MD force field / no corrections

Monte Carlo / Empirical potential structure refinement (EPSR)

OPLS-AA / no corrections
Separation of nitrogen-containing aromatics by DES

Biomass separation

Investigation of DES structure

Investigation of DES structure

[363]

$\mathrm{CO}_{2}$ absorption with DES

Investigation of DES structure

Water effect on DES structure

Investigation of DES structure

Investigation of DES structure

Protein in DES

DNA in DES

Protein in DES

DNA in DES

DES near graphene

DES at 2D nanomaterial interfaces

DES with different nanotubes

DES nanodroplet at carbon material

DES droplets on ionic substrates

Dissolution of cellulose in DES

Molecular encapsulation

Investigation of DES structure

Separation of uranyl Ions 


\begin{tabular}{|c|c|c|c|c|}
\hline 83 & $\mathrm{ChCl}:$ Urea (1:2) & Various force-fields & Force fields comparison & [209] \\
\hline 84 & $\mathrm{ChCl}$ : Urea (1:2) & OPLS-AA / no corrections & $\begin{array}{l}\text { Flow resistance of DES } \\
\text { confined in ionic model } \\
\text { nanoslits }\end{array}$ & [367] \\
\hline 85 & $\mathrm{ChCl}$ : Urea (1:2) & $\begin{array}{c}\text { CHARMM36 / no correc- } \\
\text { tions }\end{array}$ & $\begin{array}{l}\text { Conformation and Stability } \\
\text { of Lysozyme in DES/water } \\
\text { mixtures }\end{array}$ & [271] \\
\hline 86 & ChCl : Urea (1:2) & $\begin{array}{c}\text { CHARMM36 / no correc- } \\
\text { tions }\end{array}$ & $\begin{array}{c}\text { Stability and activity of li- } \\
\text { pase in DES/water mix- } \\
\text { tures }\end{array}$ & [283] \\
\hline 87 & $\mathrm{ChCl}:$ Urea (1:2) & OPLS-AA / no corrections & $\begin{array}{l}\text { Water effect on DES struc- } \\
\text { ture }\end{array}$ & {$[275]$} \\
\hline 88 & $\mathrm{ChCl}$ : Urea (1:2) & $\begin{array}{c}\text { CHARMM36 / no correc- } \\
\text { tions }\end{array}$ & $\begin{array}{c}\text { Water effect on DES struc- } \\
\text { ture }\end{array}$ & [266] \\
\hline 89 & $\mathrm{ChCl}$ : Urea (1:2) & $\begin{array}{c}\text { CHARMM36/ charge scal- } \\
\text { ing is } 0.89\end{array}$ & $\begin{array}{c}\text { Water effect on DES struc- } \\
\text { ture }\end{array}$ & {$[272]$} \\
\hline 90 & ChCl : Urea (1:2) & OPLS-AA / no corrections & $\begin{array}{c}\text { Effect of DES on the water } \\
\text { structure }\end{array}$ & [368] \\
\hline 91 & $\mathrm{ChCl}:$ Urea $(1: 2)$ & $\begin{array}{l}\text { Merck Molecular Force } \\
\text { Field (MMFF) }\end{array}$ & $\begin{array}{l}\text { Water effect on DES } \\
\text { thermo-physical properties }\end{array}$ & [29] \\
\hline 92 & $\mathrm{ChCl}:$ Urea $(1: 2)$ & $\begin{array}{c}\text { Gromos54a7 / no correc- } \\
\text { tions }\end{array}$ & $\begin{array}{l}\text { Intermolecular interactions } \\
\text { between DES and dime- } \\
\text { thylsulfoxide }\end{array}$ & [369] \\
\hline 93 & $\begin{array}{l}\qquad \mathrm{ChCl} \text { : Urea }(1: 2) \\
\text { Butiyltrimetylammonium chloride : Urea } \\
\qquad(1: 2)\end{array}$ & $\begin{array}{l}\text { Lopes-Padua and OPLS- } \\
\text { AA / no corrections }\end{array}$ & $\begin{array}{c}\text { Investigation of DES struc- } \\
\text { ture }\end{array}$ & [193] \\
\hline 94 & $\begin{array}{c}\mathrm{ChCl} \text { : Urea }(1: 2) \\
\mathrm{ChCl}: \text { Ethylene glycol }(1: 2)\end{array}$ & $\begin{array}{l}\text { GAFF based FF / charge } \\
\text { scaling for ions is } 0.9 \text { for } \\
\text { systems with urea } \\
0.8 \text { - for systems with eth- } \\
\text { ylene glycol }\end{array}$ & $\begin{array}{c}\text { Water effect on DES prop- } \\
\text { erties }\end{array}$ & {$[278]$} \\
\hline 95 & $\begin{array}{c}\mathrm{ChCl}: \text { Urea }(1: 2) \\
\mathrm{ChCl}: \text { Ethylene glycol }(1: 2)\end{array}$ & $\begin{array}{l}\text { Merck Molecular Force } \\
\text { Field (MMFF) }\end{array}$ & $\begin{array}{c}\text { Water effect on DES prop- } \\
\text { erties }\end{array}$ & [281] \\
\hline 96 & $\begin{array}{c}\text { ChCl : Urea }(1: 2) \\
\mathrm{ChCl}: \text { Ethylene Glycol }(1: 2)\end{array}$ & $\begin{array}{c}\text { No name of FF. } \\
\text { Aspen plus simulator } \\
\text { GAFF based FF / charge }\end{array}$ & $\begin{array}{c}\mathrm{CO}_{2} \text { removal } \\
\text { from shale gas by DESs }\end{array}$ & {$[254]$} \\
\hline 97 & $\begin{array}{c}\mathrm{ChCl} \text { : Urea }(1: 2) \\
\mathrm{ChCl}: \text { Ethylene glycol }(1: 2) \\
\mathrm{ChCl}: \text { Glycerol }(1: 2)\end{array}$ & $\begin{array}{l}\text { scaling for ions is } 0.9 \text { for } \\
\text { systems with urea } \\
0.8 \text { - for systems with eth- } \\
\text { ylene glycol or glycerol }\end{array}$ & $\begin{array}{c}\text { DES for absorption refrig- } \\
\text { eration systems }\end{array}$ & {$[370]$} \\
\hline 98 & $\begin{array}{c}\mathrm{ChCl} \text { : Urea }(1: 2) \\
\mathrm{ChCl}: \text { Ethylene glycol }(1: 2) \\
\mathrm{ChCl}: \text { Glycerol }(1: 2)\end{array}$ & $\begin{array}{l}\text { GAFF based FF / charge } \\
\text { scaling for ions is } 0.9 \text { for } \\
\text { systems with urea } \\
0.8 \text { - for systems with eth- } \\
\text { ylene glycol or glycerol }\end{array}$ & $\begin{array}{l}\text { Water effect on DES ther- } \\
\text { mal conductivity }\end{array}$ & {$[279]$} \\
\hline 99 & $\begin{array}{c}\mathrm{ChCl} \text { : Urea }(1: 2) \\
\mathrm{ChCl}: \text { Ethylene glycol }(1: 2) \\
\mathrm{ChCl}: \text { Glycerol }(1: 2) \\
\end{array}$ & $\begin{array}{l}\text { Gromos54a7 / no correc- } \\
\text { tions }\end{array}$ & $\begin{array}{c}\text { Water effect on DES struc- } \\
\text { ture }\end{array}$ & {$[371]$} \\
\hline
\end{tabular}




\begin{tabular}{|c|c|c|c|c|}
\hline 100 & $\begin{array}{c}\mathrm{ChCl} \text { : Urea (1:2) } \\
\mathrm{ChCl} \text { : Ethylene glycol (1:2) } \\
\mathrm{ChCl} \text { : Glycerol (1:2) }\end{array}$ & GAFF / no corrections & $\begin{array}{l}\text { Solvatochromic properties } \\
\text { and ion solvation structure } \\
\text { in DESs }\end{array}$ & [372] \\
\hline 101 & $\begin{array}{c}\mathrm{ChCl} \text { : Urea }(1: 2) \\
\mathrm{ChCl}: \text { Ethylene glycol }(1: 2) \\
\mathrm{ChCl}: \text { Glycerol }(1: 2) \\
\mathrm{ChCl}: \text { Urea }(1: 2)\end{array}$ & GAFF / no corrections & $\begin{array}{l}\text { Solvatochromic behavior of } \\
\text { dimethyl sulfoxide with } \\
\text { DESs }\end{array}$ & [373] \\
\hline 102 & $\begin{array}{c}\mathrm{ChCl} \text { : ethylene glycol }(1: 2) \\
\mathrm{ChCl} \text { : Glycerol }(1: 2) \\
\text { and their mixtures }\end{array}$ & $\begin{array}{l}\text { No name of FF. Parame- } \\
\text { ters are given }\end{array}$ & DESs on 2D materials & [299] \\
\hline 103 & $\begin{array}{c}\mathrm{ChCl} \text { : Urea (1:2) } \\
\mathrm{ChCl}: \text { Ethylene glycol }(1: 2) \\
\mathrm{ChCl}: \text { Glycerol }(1: 2) \\
\mathrm{ChCl}: \text { Malonic acid }(1: 1) \\
\mathrm{ChCl}: \text { Oxalic acid }(1: 1)\end{array}$ & $\begin{array}{c}\text { OPLS, GAFF } \\
\text { / scaling of } 1-4 \text { intramo- } \\
\text { lecular interaction ener- } \\
\text { gies }\end{array}$ & $\begin{array}{l}\text { Hildebrand and Hansen } \\
\text { solubility parameters of } \\
\text { DESs }\end{array}$ & {$[374]$} \\
\hline 104 & $\begin{array}{c}\mathrm{ChCl}: \text { Urea }(1: 2) \\
\mathrm{ChCl}: \text { Ethylene glycol }(1: 2) \\
\mathrm{ChCl} \text { : Glycerol }(1: 2) \\
\mathrm{ChCl} \text { : Oxalic acid }(1: 1) \\
\mathrm{ChCl} \text { : Malonic acid }(1: 1) \\
\mathrm{ChCl}: \text { Glutaric acid }(1: 1) \\
\mathrm{ChCl} \text { : Malic acid }(1: 1) \\
\mathrm{ChCl} \text { : Citric acid }(1: 1) \\
\mathrm{ChCl} \text { : Levulinic acid }(1: 2) \\
\mathrm{ChCl}: \text { Phenyl acetic acid }(1: 2) \\
\mathrm{ChCl} \text { : Acetamide }(1: 2)\end{array}$ & $\begin{array}{l}\text { Combine force field based } \\
\text { on CGenFF and } \\
\text { CHARMM } 36\end{array}$ & Lipid membrane in DES & [314] \\
\hline 105 & $\begin{array}{c}\mathrm{ChCl} \text { : Urea (1:2) } \\
\mathrm{ChCl}: \text { Ethylene glycol (1:2) } \\
\mathrm{ChCl} \text { : Glycerol (1:2) } \\
\mathrm{ChCl}: \text { Propylene glycol (1:2) }\end{array}$ & GAFF / no corrections & $\begin{array}{l}\text { Extraction mechanism of 1- } \\
\text { butanol separation } \\
\text { from alkanol azeotropic } \\
\text { system using choline-based } \\
\text { DES }\end{array}$ & [265] \\
\hline 106 & $\begin{array}{c}\mathrm{ChCl}: \text { Urea }(1: 2) \\
\mathrm{ChCl}: \text { Ethylene glycol }(1: 2) \\
\mathrm{ChCl}: \text { Levulinic acid }(1: 2) \\
\text { Betaine : Levulinic acid (1:2) }\end{array}$ & $\begin{array}{l}\text { Modified AMBER force } \\
\text { field }\end{array}$ & $\begin{array}{l}\text { Mercury Capture from Pe- } \\
\text { troleum using DES }\end{array}$ & [143] \\
\hline & $\begin{array}{c}\mathrm{ChCl}: \text { Urea }(1: 2) \\
\mathrm{ChCl}: \text { Ethylene Glycole }(1: 2) \\
\mathrm{ChCl}: \text { Glycerol }(1: 2)\end{array}$ & & & \\
\hline 107 & $\begin{array}{l}\text { ChCl : 2-aminoethan-1-ol (1:6) } \\
\text { Allyltriphenyl phosphonium bromid : Eth- } \\
\text { ylene glycol (1:4) } \\
\text { Allyltriphenyl phosphonium bromid : Tri- } \\
\text { ethylene Glycol (1:4) }\end{array}$ & $\begin{array}{l}\text { No name of FF. } \\
\text { Forcite module, from Ma- } \\
\text { terials Studio software }\end{array}$ & $\begin{array}{l}\text { Molecular interaction be- } \\
\text { tween the different DESs } \\
\text { and } \mathrm{CO}_{2}\end{array}$ & [258] \\
\hline & $\begin{array}{l}\text { Allyltriphenyl phosphonium bromid : Le- } \\
\text { vulinic acid (1:4) }\end{array}$ & & & \\
\hline 108 & $\begin{array}{c}\mathrm{ChCl}: \text { Urea }(1: 2) \\
\mathrm{ChCl}: \text { Glycerol }(1: 2) \\
\mathrm{ChCl}: \text { Levulinic acid (1:2) } \\
\mathrm{ChCl}: \text { Malonic acid }(1: 1) \\
\mathrm{ChCl}: \text { Phenylacetic acid }(1: 2)\end{array}$ & $\begin{array}{l}\text { No name of FF. Parame- } \\
\text { ters are given } \\
\text { Charges are calculated for } \\
\text { clusters. }\end{array}$ & $\begin{array}{l}\text { Investigation of DES struc- } \\
\text { ture }\end{array}$ & [375] \\
\hline
\end{tabular}




\begin{tabular}{|c|c|c|c|c|}
\hline 109 & $\begin{array}{c}\mathrm{ChCl}: \text { Urea }(1: 2) \\
\mathrm{ChCl}: \text { Glycerol }(1: 2) \\
\mathrm{ChCl}: \text { Malonic acid }(1: 1)\end{array}$ & $\begin{array}{l}\text { No name of FF. MDy- } \\
\text { naMix v.5.2 molecular } \\
\text { modeling software }\end{array}$ & $\begin{array}{l}\text { Mechanisms of acid gases } \\
\text { capture in DES }\end{array}$ & [249] \\
\hline 110 & $\begin{array}{c}\mathrm{ChCl}: \text { Urea (1:2) } \\
\mathrm{ChCl}: \text { Glycolic acid (1:1) }\end{array}$ & $\begin{array}{c}\text { OPLS / charge scaling is } \\
0.8\end{array}$ & $\begin{array}{l}\text { Stability and activity of al- } \\
\text { cohol dehydrogenase in } \\
\text { DES/water mixtures }\end{array}$ & [268] \\
\hline 111 & $\begin{array}{c}\mathrm{ChCl} \text { : Urea }(1: 2) \\
\mathrm{ChCl} \text { : Thiourea }(1: 2) \\
\mathrm{ChCl} \text { : Methyl urea }(1: 2) \\
\mathrm{ChCl} \text { : Dimethyl urea }(1: 2) \\
\mathrm{ChCl}: 1,1 \text {-dimethylurea }(1: 2) \\
\mathrm{ChCl}: \mathrm{N}, \mathrm{N}^{\prime} \text { - ethylene urea }(1: 2)\end{array}$ & $\begin{array}{l}\text { GAFF/charges scaling is } \\
0.9 \text { for } \\
\text { urea and } 0.8 \text { for } \mathrm{ChCl}\end{array}$ & $\begin{array}{c}\text { Investigation of DES struc- } \\
\text { ture }\end{array}$ & [102] \\
\hline 112 & $\begin{array}{c}\mathrm{ChCl}: \text { Urea }(1: 2) \\
\mathrm{ChF}: \text { Urea }(1: 2) \\
\text { ChNO3 }: \text { Urea }(1: 2) \\
\text { Ch acetate }: \text { Urea }(1: 2)\end{array}$ & CL\&P & $\begin{array}{l}\text { Investigation of DES struc- } \\
\text { ture }\end{array}$ & [211] \\
\hline 113 & $\mathrm{ChCl}$ : Water & $\begin{array}{c}\text { ChCl: LJ parameters (AM- } \\
\text { BER) + partial charges } \\
\text { (DFT) } \\
\text { Water: TIP3P }\end{array}$ & Water structuring in DES & [376] \\
\hline 114 & $\mathrm{ChCl}:$ Water (1:3.3) & OPLS-AA / no corrections & $\begin{array}{c}\text { Investigation of DES struc- } \\
\text { ture }\end{array}$ & [377] \\
\hline 115 & $\begin{array}{c}\mathrm{ChCl} \text { derivatives consisted of a series of } \\
\text { elongated alkyl side chains and elongated } \\
\text { alcohol side chains } \\
{[\mathrm{Ch}]+,[\mathrm{C} 4 \mathrm{Ch}]+,[\mathrm{C} 6 \mathrm{Ch}]+,[\mathrm{C} 8 \mathrm{Ch}]+,} \\
{[(\mathrm{C} 4) 3 \mathrm{Ch}]+,[\mathrm{ChC} 4 \mathrm{OH}]+,[\mathrm{ChC} 6 \mathrm{OH}]+,} \\
[\mathrm{ChC} 8 \mathrm{OH}]+,[\mathrm{ChC} 10 \mathrm{OH}]+,[\mathrm{ChC} 12 \mathrm{OH}]+)\end{array}$ & CL\&P & $\begin{array}{c}\text { Investigation of DES struc- } \\
\text { ture }\end{array}$ & [220] \\
\hline & $\begin{array}{c}\text { HBD: Ethylene glycol } \\
\text { Molar ratio 1:4 }\end{array}$ & & & \\
\hline 116 & $\begin{array}{l}\text { Choline chloride : Trifluoroacetamide (1:2.5) } \\
\text { Chlorocholine chloride : Trifluoroacetamide } \\
\text { (1:2.5) } \\
\text { Tetrametilammonium chloride : Trifluoroa- } \\
\text { cetamide (1:2.5) } \\
\text { Tetraethylammonium chloride : Trifluoroa- } \\
\text { cetamide (1:2.5) } \\
\text { Benziltriethylammoniun chloride : Trifluoro- } \\
\text { acetamide (1:2.5) }\end{array}$ & GAFF / no corrections & $\begin{array}{l}\text { Investigation of DES struc- } \\
\text { ture }\end{array}$ & [221] \\
\hline 117 & Choline iodide: Glycerol (1:3) & GAFF $/ \pm 0.9 \mathrm{e}$ for the ions & DES in nanopores & [287] \\
\hline 118 & $\begin{array}{c}\text { Decanoic acid : Menthol }(1: 1,1: 2) \\
\text { Decanoic acid : Lidocain }(2: 1) \\
\text { Menthol : Lidocain }(2: 1) \\
\text { Thymol : Lidocaine }(1: 1,2: 1) \\
\text { Thymol : Menthol }(1: 1,2: 1)\end{array}$ & $\begin{array}{c}\text { OPLS-AA/M } \\
\text { Parameters are given }\end{array}$ & $\begin{array}{l}\text { Investigation of DES struc- } \\
\text { ture }\end{array}$ & [219] \\
\hline 119 & $\begin{array}{l}\text { DL-menthol : Hexanoic acid (1:1) } \\
\text { DL-menthol : Octanoic acid (1:1) } \\
\text { DL-menthol : Decanoic acid (1:1) }\end{array}$ & $\begin{array}{l}\text { CHARMM36 / no correc- } \\
\text { tions }\end{array}$ & $\begin{array}{l}\text { Dynamics of hydrogen- } \\
\text { bonding and translational }\end{array}$ & [378] \\
\hline
\end{tabular}


DL-menthol based DESs

HBDs: Acetic acid, Butanoic acid, Hexanoic acid, Octanoic acid, Decanoic acid, Dodecanoic acid, Pyruvic acid, Levulinic acid

Tetrabutylammonium chloride based DESs HBDs: Acetic acid, Octanoic acid Ethylene glycol (1:4)

Methyltriphenylphosphonium bromide :

Ferric chloride : Tetrabutylphosphonium bromide Different molar ratios L-Arginine : Glutamic acid (1:1) L-Arginine : Oxalic acid (1:1) L-Arginine : Tartaric acid (1:1)

$$
\text { L-Menthol : Acetic acid (1:1) }
$$

LiBr : Acetamide (4.5:1)

$\mathrm{LiNO}_{3}$ : Acetamide (4.5:1)

$\mathrm{LiClO}_{4}$ : Acetamide (4.5:1)

$\mathrm{LiBr}$ : Acetamide (4.5:1)

$\mathrm{LiNO}_{3}$ : Acetamide (4.5:1)

$\mathrm{LiClO}_{4}$ : Acetamide (4.5:1)

$\mathrm{LiCl}$ and LiTFSI based DESs

HBDs: Urea, Acetamide, :N,N0 dimethylpropyleneurea, 2-imidazolidinone, Tetramethylurea Molar ratio 1:5

$\mathrm{LiClO}_{4}$ : Acetamide (1:3.5)

$\mathrm{LiClO}_{4}$ : Acetamide (1:5.2)

$\mathrm{LiClO}_{4}$ : Propion amid (1:5.2)

Different molar ratios

Different molar ratios

Methyltriphenylphosphonium bromide : Ethylene glycol (1:4) Ethyleneglycol (1:4)
Litium bis-(trifluoromethanesulfonyl)- imide

Litium bis-(trifluoromethanesulfonyl)- imide

GAFF / no corrections

GAFF / no corrections

Methyltriphenylphosphonium bromide :

Gromos54A7

No name of FF.

Parameters are given

AMBER 14

OPLS-UA

CHARMM 22 for nucleic acids

COMPASS II

CHARMM27 / no corrections tions

GAFF / no corrections
CHARMM 22 / no correc-

OPLS-AA / no corrections

OPLS-AA / no corrections Glycerol (1:4)
GAFF / no corrections

Water Stability of Hydrophobic DES

dynamics and their dependence on acid tail length

Investigation of DES structure

Nitric oxide solubility in DES

Structure Elucidation of DES

Investigation of DES structure ture

Investigation of DES structure

Water effect on DES properties

Investigation of DES structure

Investigation of DES structure

Investigation of DES structure

Extraction of benzene from hydrocarbon mixture using a phosphonium based DES

Extraction of a polyaromatic hydrocarbon from fuel oils using DES
Investigation of DES struc- 
Tetrabutylammonium bromide : Ethyleneglycol (1:4)

Tetrabutylammonium bromide : Glycerol

134

Methyltriphenylphosphonium bromide :

Monoethanolamine

Different molar ratios

Monoethanolamine (MEA) and Methyltriphenylphosphonium bromide (MTPPBr) based DESs.

Different molar ratios

Monoethanolamine hydrochloride : Methyldiethanolamine

Diethanolamine hydrochloride : Methyldi-

$\mathrm{N}$-methyl diethanolamine hydrochloride : Methyldiethanolamine Different molar ratios

Morpholine and Morpholine based DESs.

HBDs: Urea, Diethylene glycol, Carboxylic acid, Thiourea, Methanol

\section{Molar ratio 1:4}

Oleic acid : Lidocaine (1:1)

Proline : Glycolic acid Proline :Malic acid

Different molar ratios

Tetraalkylammonium chloride : Decanoic acid (1:2)

Cation alkylchain lengths-4, 7, 8)

Tetrabutilamonium chloride : Ethylene gly-

$$
\operatorname{col}(1: 3)
$$

Tetrabutilamonium chloride : Glycerol (1:5)

Tetrabutylammonium bromide : Formic acid

Tetrabutylammonium bromide : Imidazole

Tetrabutylammonium bromide : Ethylene

$$
\text { glycol (1:4) }
$$

Tetrabutylammonium bromide : Glycerol

$$
(1: 4)
$$

Tetrabutylammonium bromide : Sulfolane

$$
\text { Different molar ratios }
$$

Tetrabutylammonium chloride : Decanoic

$$
\text { acid (1:2) }
$$

Thymol : Decanoic acid (1:2)

DL-menthol : Decanoic acid (2:1)
No name of FF. Parameters are given

Gromos54a7, Ions: MTPP+ (AMBER), MEA and $\mathrm{CO}_{2}$ : ATB database

GAFF / no corrections

OPLS-AA / no corrections

GAFF / no corrections

Amber-Cornell force field

GAFF/charges scaling is 0.6-1.0

LJ well-depth scaling factors

OPLS-AA/ partial charges scaling for ions is 0.8

No name of FF. Parameters are given

GAFF / no corrections

OPLS-AA and CL\&P

\section{GAFF / charge scaling for} ions is 0.833

Gromos54a7 / no corrections
Investigation of DES structure

$\mathrm{CO}_{2}$ absorption in DES

$\mathrm{CO}_{2}$ capture performance by DES

Investigation of DES structure

Phase separation property of a hydrophobic DES

Investigation of DES structure

Investigation of DES structure

Investigation of DES structure

Oil desulfurization by DES

Dissolution of carbohydrates in DES

Quantification of the total vapor pressures of DESs

Interfacial Properties of Hydrophobic DES

Investigation of DES structure 


\begin{tabular}{|c|c|c|c|c|}
\hline 147 & $\begin{array}{l}\text { Tetrabutylammonium chloride : Polyeth- } \\
\text { ylene glycol : Ferric chloride (4:1:0.05) }\end{array}$ & $\begin{array}{l}\text { Gromos54a7 / no correc- } \\
\text { tions }\end{array}$ & $\begin{array}{l}\text { Mechanism of desulfuriza- } \\
\text { tion by the DES }\end{array}$ & [262] \\
\hline 148 & $\begin{array}{l}\text { Tetrabutylphosphonium } \\
\text { bromide: Phenol (1:4) } \\
\text { Tetrabutylphosphonium } \\
\text { bromide: Diethylene glycol (1:4) } \\
\text { Allyltriphenylphosphonium } \\
\text { bromide: Phenol (1:4) } \\
\text { Allyltriphenylphosphonium } \\
\text { bromide: Phenol (1:6) }\end{array}$ & AMBER / no corrections & $\mathrm{CO}_{2}$ solubility in DESs & [259] \\
\hline 149 & Triethylammonium acetate: Urea (1:2) & OPLS-AA / no corrections & Protein in DES & [309] \\
\hline
\end{tabular}

Table 3. QM calculations of DES consisting systems, method and basis, and the topic of the publication. Corrections of method and basis are not indicated. We refer to current publications for the details.

\begin{tabular}{|c|c|c|c|c|}
\hline No & DES & Method / Basis & Topic of the publication & $\begin{array}{r}\text { Ref- } \\
\text { er- } \\
\text { ence }\end{array}$ \\
\hline 1 & $\begin{array}{l}\text { 1-ethyl-3-methylimidazolium chloride : Imid- } \\
\text { azole } \\
\text { Different molar ratios }\end{array}$ & $\begin{array}{c}\text { AIMD } \\
\text { The BLYP functional } \\
\text { with triple- } \zeta \text { valence po- } \\
\text { larization basis set and } \\
\text { GTH pseudopotentials. } \\
\text { CP2K/QUICKSTEP code }\end{array}$ & $\begin{array}{l}\text { DES as physical solvents } \\
\text { for remarkable separation } \\
\text { of } \mathrm{H}_{2} \mathrm{~S} \text { from } \mathrm{CO}_{2}\end{array}$ & {$[388]$} \\
\hline & & $\begin{array}{c}\text { DFT } \\
\text { B3LYP/6-311G } \\
+G(2 d, 2 p)\end{array}$ & & \\
\hline 2 & $\begin{array}{c}\text { 1,8-diazabicyclo[5.4.0]undec-7-enium : me- } \\
\text { thylthiourea }(4: 1)\end{array}$ & $\begin{array}{c}\text { DFT } \\
\text { M06e2X/6-311++G(d,p) } \\
\text { DFT }\end{array}$ & $\begin{array}{l}\text { Dissolution of cellulose in } \\
\text { DES }\end{array}$ & {$[317]$} \\
\hline 3 & $\begin{array}{l}24 \text { choline chloride-based DES with molar ra- } \\
\text { tio from 1:4 to } 15: 1\end{array}$ & $\begin{array}{c}\text { B3LYP/6-311G }(\mathrm{d}, \mathrm{p}) \\
\text { B3LYP/def2-SVP def2- } \\
\text { SVP/J } \\
\text { B3LYP/6- } \\
\text { 311G(d,p)/def2-TZVP } \\
\text { def2- TZVP/J }\end{array}$ & Biomass separation & {$[181]$} \\
\hline 4 & $\begin{array}{c}\text { Alanine : Lactic Acid (1:1) } \\
\text { Alanine : Malic Acid }(1: 1) \\
\text { Betaine : Lactic Acid }(1: 1) \\
\mathrm{ChCl}: \text { Malic Acid }(1: 1) \\
\mathrm{ChCl}: \text { Lactic Acid }(1: 1) \\
\mathrm{ChCl}: \text { Fructose }(1: 1)\end{array}$ & $\begin{array}{c}\text { DFT } \\
\text { B3LYP / 6-311++G(d,p) }\end{array}$ & $\mathrm{CO}_{2}$ absorption by DES & {$[62]$} \\
\hline 5 & $\begin{array}{c}\text { Alanine : Lactic acid (1:1) } \\
\text { Betaine : Lactic acid (1:1) } \\
\mathrm{ChCl}: \text { Lactic acid }(1: 1) \\
\mathrm{ChCl}: \text { Malic acid }(1: 1) \\
\mathrm{ChCl}: \text { Phenylacetic acid }(1: 2)\end{array}$ & $\begin{array}{c}\text { DFT } \\
\text { B3LYP/6- 311++G(d,p) }\end{array}$ & $\begin{array}{l}\text { High Pressure Methane } \\
\text { Solubility in Natural DES }\end{array}$ & [389] \\
\hline
\end{tabular}


6

8

9

10

11

12

13

14

15

16

17

18

19
AlCl3 : Urea (1:1, 1.5 :1)

Arginine : Glutamic acid (1:1)

Arginine : Oxalic acid (1:1)

Arginine : Tartaric acid (1:1)

Arginine : Glutamic acid (1:1)

Arginine : Oxalic acid (1:1)

Arginine : Tartaric acid (1:1)

Betain : Glycerol (1:2)

Betain : dl-lactic acid (1:2)

Betain : Levulinic acid (1:2)

Betaine : Lactic acid (1:1)

Camphor : 1-decanol

Camphor : Decanoic acid

Camphor : 3,4-xylenol

Caprolactam : Tetrabutylammonium bromide $(1: 1)$

Caprolactam : Tetrabutylammonium bromide (1:1)

$\mathrm{ChCl}$ : Urea (1:2)

Methyltriphenylphosphonium bromide : Monoethanolamine $(1: 6)$

Ceineole : Succinic acid (1:1) Ceineole : Malic acid $(1: 1)$

Ceineole : Lactic acid (1:1)

$\mathrm{ChCl}:$ 1, 2-butanediol (1:4)

$\mathrm{ChCl}:$ 1, 3-butanediol (1:4)

$\mathrm{ChCl}: 1$, 4-butanediol (1:4)

$\mathrm{ChCl}$ : 4-chlorophenol

$\mathrm{ChCl}$ : 4-ethylphenol

$\mathrm{ChCl}$ : Phenol

$\mathrm{ChCl}:$ 2-methylphenol

$\mathrm{ChCl}:$ 3-methylphenol

$\mathrm{ChCl}$ : 4-methylphenol

$\mathrm{ChCl}$ : 2,6-dimethylphenol

Different molar ratios

$\mathrm{ChCl}$ : Acetyl salicylic acid (1:1)

ChCl : Acrylic acid (1:2)

$\mathrm{ChCl}$ : Carboxylic acid (1:2)

$\mathrm{ChCl}$ : Formic acid (1:2)

$\mathrm{ChCl}$ : Citric acid

$\mathrm{ChCl}$ : Ethylene glycol

$\mathrm{ChCl}$ : Fructose

\section{AIMD}

DFT/PAW

DFT

B3LYP / 6-311++G(d,p)

DFT

B3LYP / 6-311++G(d,p)

DFT

GGA/VMN-BP function

in DNP 4.4 basis set

DFT

B3LIP/

6-311++G(d,p)

DFT

B3LYP/6-311++G(d,p)

DFT
B3LYP/6-311++G(d,p)

Natural Gas Desulfurization using DES

$$
\begin{gathered}
\text { DFT } \\
\text { B3LIP/ } \\
6-311++\mathrm{G}(\mathrm{d}, \mathrm{p}) \\
\text { DFT }
\end{gathered}
$$

DMol3 module with the generalized gradient approximation (GGA)based Perdew-Wan

(PW91) functional
The structure of DES and supercapacitor performance
[144]

$$
\begin{aligned}
& \text { Extractive desulfurization } \\
& \text { of fuels by DES }
\end{aligned}
$$

Investigation of DES structure Investigation of DES structure

B3LYP/DNP

DFT Interactions Between Deep B3LYP/ 6-311++G(d,p) Eutectic Solvents and $\mathrm{SO}_{2}$ 


\begin{tabular}{|c|c|c|c|c|}
\hline & $\begin{array}{c}\mathrm{ChCl}: \text { Glycerol } \\
\mathrm{ChCl}: \text { Lactic acid } \\
\mathrm{ChCl}: \text { Levulinic acid } \\
\mathrm{ChCl}: \text { Malic acid } \\
\mathrm{ChCl}: \text { Phenylacetic acid } \\
\text { amide } \\
\text { 1-Butyl-3-methylimidazolium chloride : Acet- } \\
\text { amide } \\
\text { 1-Ethyl-3-methylimidazolium chloride : Acet- } \\
\text { 1-Ethyl-3-methylimidazolium chloride : Eth- } \\
\text { ylene glycol }\end{array}$ & & & \\
\hline 20 & $\begin{array}{c}\mathrm{ChCl}: \mathrm{D}-(-) \text {-ribose } \\
\mathrm{ChCl}: \mathrm{D}-(-) \text {-fructose } \\
\text { Different molar ratios }\end{array}$ & $\begin{array}{c}\text { DFT } \\
\text { B3LYP / 6-311++G(d,p) }\end{array}$ & $\begin{array}{c}\text { DES as absorbents for } \mathrm{NH}_{3} \\
\text { capture }\end{array}$ & [77] \\
\hline 21 & $\mathrm{ChCl}$ : Ethylene glycol (1:2) & $\begin{array}{c}\text { AIMD } \\
\text { GPW/PBE/ } \\
\text { MOLOPT-TZVP-GTH } \\
\text { basis set }\end{array}$ & $\begin{array}{l}\text { Investigation of DES struc- } \\
\text { ture }\end{array}$ & [145] \\
\hline 22 & $\mathrm{ChCl}$ : Ethylene glycol (1:2) & $\begin{array}{c}\text { AIMD } \\
\text { BLIP/DZVP }\end{array}$ & $\begin{array}{l}\text { Investigation of DES struc- } \\
\text { ture }\end{array}$ & [196] \\
\hline 23 & $\mathrm{ChCl}$ : Ethylene glycol (1:2) & DFT/PAW & $\begin{array}{l}\text { Eutectic-mediated selective } \\
\text { synthesis of nanocrystals }\end{array}$ & [277] \\
\hline 24 & $\mathrm{ChCl}$ : Ethylene glycol (1:2) & $\begin{array}{c}\text { DFT } \\
\text { B3LYP / 6- 31G(d) } \\
\text { TD-DFT } \\
\text { CAM-B3LYP/ TZVP }\end{array}$ & $\begin{array}{l}\text { Solvatochromic parameters, } \\
\text { and preferential solvation } \\
\text { in aqueous solutions of } \\
\text { DES and its components }\end{array}$ & [273] \\
\hline 25 & $\mathrm{ChCl}$ : Ethylene glycol (1:2) & $\begin{array}{c}\text { DFT } \\
\text { B3LYP/6-311++G (d,p) } \\
\text { AIMD }\end{array}$ & $\begin{array}{l}\text { Dissolution of dimethylfor- } \\
\text { mamide in DES }\end{array}$ & [390] \\
\hline 26 & $\mathrm{ChCl}$ : Ethylene glycol (1:2) & $\begin{array}{c}\text { MOLOPT-DZVP-SR- } \\
\text { GTH } \\
\text { with GGA } \\
\text { BLYP with GTH pseu- } \\
\text { dopotentials to repre- } \\
\text { sent the core electrons. }\end{array}$ & $\mathrm{CO}_{2}$ absorption in DES & [142] \\
\hline 27 & $\begin{array}{c}\mathrm{ChCl} \text { : Ethylene glycol (1:2) } \\
\mathrm{ChCl} \text { : Glycerol (1:2) } \\
\mathrm{ChCl}: \text { Urea (1:2) } \\
\mathrm{ChCl} \text { : Ethylene glycol (1:2) }\end{array}$ & $\begin{array}{c}\text { DFT } \\
\text { B3LYP/6-311++G(d,p) }\end{array}$ & $\begin{array}{l}\text { Solvation dynamics of an } \\
\text { ionic probe in DES }\end{array}$ & [356] \\
\hline 28 & $\begin{array}{c}\mathrm{ChCl}: \text { Malic acid }(1: 2) \\
\mathrm{ChCl}: \text { Tartaric acid (2:1) } \\
\mathrm{ChCl}: \text { Oxalic acid }(1: 2) \\
\mathrm{ChCl}: \text { Glycerol }(1: 2)\end{array}$ & $\begin{array}{l}\text { HF, M06, B3LYP, CAM- } \\
\text { B3LYP or PBEPBE/ } \\
\text { 6-31G(d,p) }\end{array}$ & $\begin{array}{l}\text { Investigation of DES struc- } \\
\text { ture }\end{array}$ & [50] \\
\hline 29 & $\mathrm{ChCl}$ : Glycerol (1:1) & $\begin{array}{c}\text { DFT } \\
\text { BLYP/MOLOPT-DZVP- } \\
\text { SR-GTH }\end{array}$ & $\mathrm{SO}_{2}$ solvation in DES & [85] \\
\hline
\end{tabular}




\begin{tabular}{|c|c|c|c|c|}
\hline 30 & ChCl : Glycerol (1:2) & $\begin{array}{c}\text { DFT } \\
\text { M062x/ } \\
6-31++g(d, p)\end{array}$ & $\begin{array}{c}\text { Investigation of DES struc- } \\
\text { ture }\end{array}$ & {$[65]$} \\
\hline 31 & $\begin{array}{c}\mathrm{ChCl}: \text { Glycerol (1:2) } \\
\mathrm{ChCl}: \text { Glycerol (1:3) } \\
\mathrm{ChCl}: \text { Malonic acid (1:1) }\end{array}$ & $\begin{array}{c}\text { DFT } \\
\text { B3LYP/6-31+G(d,p) }\end{array}$ & Mitigation of $\mathrm{CO}_{2}$ in DES & [55] \\
\hline \multirow[t]{2}{*}{32} & $\begin{array}{l}\mathrm{ChCl}: \text { Imidazole : Ethylene glycol (3:7:14) } \\
\mathrm{ChCl}: \text { Triazole : Ethylene glycol }(3: 7: 14) \\
\mathrm{ChCl}: \text { Tetrazole : Ethylene glycol }(3: 7: 14)\end{array}$ & $\begin{array}{c}\text { AIMD } \\
\text { BLYP } \\
\text { triple- } \zeta \text { valence polari- } \\
\text { zation basis set and } \\
\text { GTH pseudopotentials }\end{array}$ & $\begin{array}{c}\text { DES for Highly Efficient } \\
\text { and Reversible Capture of } \\
\text { Ammonia }\end{array}$ & [391] \\
\hline & & $\begin{array}{c}\text { DFT } \\
6-31++G(d, p)\end{array}$ & & \\
\hline 33 & $\begin{array}{c}\mathrm{ChCl}: \text { Lactic acid : Ethanol }(1: 2: 1) \\
\mathrm{ChCl}: \text { Lactic acid : Ethylene glycol } \\
\qquad(1: 2: 1)\end{array}$ & $\begin{array}{l}\text { Semiempirical method } \\
\text { with the PM6 level }\end{array}$ & $\begin{array}{c}\text { Investigation of DES struc- } \\
\text { ture }\end{array}$ & {$[43]$} \\
\hline 34 & $\begin{array}{c}\text { ChCl : Lactic acid }(1: 1) \\
\beta \text {-alanine : Lactic acid }(1: 1)\end{array}$ & $\begin{array}{c}\text { DFT } \\
\text { B3LYP / 6-311++G(d,p) } \\
\text { DFT }\end{array}$ & Lidocaine in DES & [38] \\
\hline 35 & $\mathrm{ChCl}:$ Lactic acid (1:9) & $\begin{array}{l}\text { M06-2X functional with } \\
\text { the standard 6- } \\
311+G(d, p) / / 6-311 G(d, p) \\
\text { basis set. }\end{array}$ & $\begin{array}{l}\text { Lignin dissolution behav- } \\
\text { iors of DES }\end{array}$ & {$[362]$} \\
\hline 36 & $\mathrm{ChCl}$ : Levulinic acid (1:2) & $\begin{array}{c}\text { DFT } \\
\text { B3LYP/6-31+G(d,p) } \\
\text { DFT }\end{array}$ & DES for $\mathrm{CO}_{2}$ capture & [35] \\
\hline 37 & $\mathrm{ChCl}$ : Malonic acid : 1, 4-butanediol (1:1:1) & $\begin{array}{l}\text { B3LYP/3-21G } \\
\text { semiempirical method } \\
\text { with the PM6 level }\end{array}$ & $\begin{array}{c}\text { Investigation of DES struc- } \\
\text { ture }\end{array}$ & {$[228]$} \\
\hline 38 & $\begin{array}{c}\mathrm{ChCl}: \text { Malonic acid : n-butanol (1:1:1) } \\
\mathrm{ChCl}: \text { Malonic acid : Iso-butanol (1:1:1) } \\
\mathrm{ChCl}: \text { Malonic acid : Butandiol (1:1:1) }\end{array}$ & $\begin{array}{l}\text { Semiempirical method } \\
\text { with the PM6 level }\end{array}$ & $\begin{array}{c}\text { Investigation of DES struc- } \\
\text { ture }\end{array}$ & {$[42]$} \\
\hline 39 & $\begin{array}{c}\mathrm{ChCl}: \text { Oxalic acid } \\
\mathrm{ChCl}: \text { Citric acid } \\
\mathrm{ChCl}: \text { Glycerol } \\
\mathrm{ChCl}: \text { Ethylene glycol } \\
\text { Different molar ratios }\end{array}$ & 3-21 G basis set & $\begin{array}{l}\text { Toxicity assessment and en- } \\
\text { hanced drug solubility pro- } \\
\text { file of green DES deriva- } \\
\text { tives }\end{array}$ & [392] \\
\hline $\begin{array}{c}404 \\
1\end{array}$ & $\begin{array}{c}\mathrm{ChCl}: \text { Phenol }(1: 2) \\
\mathrm{ChCl}: \text { Glycol ethylene }(1: 2) \\
\mathrm{ChCl}: \text { Levulinic acid }(1: 2)\end{array}$ & $\begin{array}{c}\text { DFT } \\
\text { B3LYP/6-311++G(d,p) }\end{array}$ & Desulfurization using DES & [54] \\
\hline 42 & $\mathrm{ChCl}$ : Phenylacetic acid (1:2) & $\begin{array}{c}\text { DFT } \\
\text { B3LYP/6-31+G(d,p) }\end{array}$ & $\mathrm{CO}_{2}$ absorption with DES & [36] \\
\hline 43 & $\begin{array}{l}\mathrm{ChCl} \text { : R-3-hydroxyl acids } \\
\text { Different molar ratios }\end{array}$ & $\begin{array}{c}\text { DFT } \\
\text { B3LYP/6-31G+(2d,2p) } \\
\text { B3LYP-D3/6- } \\
\text { 311G++(2d,2p) }\end{array}$ & $\begin{array}{l}\text { Investigation of DES struc- } \\
\text { ture }\end{array}$ & {$[60]$} \\
\hline 44 & $\begin{array}{c}\mathrm{ChCl}: \text { Urea }(1: 1) \\
\mathrm{ChCl}: \text { Ethylene glycol }(1: 1)\end{array}$ & $\begin{array}{l}\text { AIMD } \\
\text { BLYP/triple- } \zeta \text { double- } \\
\text { polarization basis set }\end{array}$ & $\begin{array}{l}\text { Solvation structure around } \\
\qquad \mathrm{CO}_{2} \text { and } \mathrm{SO}_{2} \text { in DESs }\end{array}$ & [73] \\
\hline
\end{tabular}




\begin{tabular}{|c|c|c|c|c|}
\hline & & $\begin{array}{l}\text { and Goedecker-Teter- } \\
\text { Hutter pseudopotentials }\end{array}$ & & \\
\hline 45 & $\mathrm{ChCl}$ : Urea $(1: 2)$ & $\begin{array}{c}\text { DFT } \\
\text { M06e2X/6-311++G(d,p) }\end{array}$ & $\begin{array}{c}\text { Interaction of } \mathrm{Cu}, \mathrm{Ag} \text { and } \\
\mathrm{Au} \text { nanoparticles with DES }\end{array}$ & [393] \\
\hline 46 & $\mathrm{ChCl}$ : Urea (1:2) & $\begin{array}{c}\text { DFT } \\
\text { B3LYP/6-311++G(d,p) }\end{array}$ & $\begin{array}{c}\text { Investigation of DES struc- } \\
\text { ture }\end{array}$ & [59] \\
\hline 47 & $\mathrm{ChCl}$ : Urea (1:2) & $\begin{array}{c}\text { DFT } \\
\text { B3LYP/6-311++G(2d,p) }\end{array}$ & $\begin{array}{c}\text { Investigation of DES struc- } \\
\text { ture }\end{array}$ & [47] \\
\hline 48 & ChCl : Urea (1:2) & $\begin{array}{c}\text { periodic DFT } \\
\text { B3LYP/6-31+G(d,p) }\end{array}$ & $\begin{array}{c}\text { Investigation of DES struc- } \\
\text { ture }\end{array}$ & [53] \\
\hline 49 & $\mathrm{ChCl}$ : Urea (1:2) & $\begin{array}{c}\text { AIMD } \\
\text { DFT } \\
\text { B3LYP/TZ2P }\end{array}$ & $\begin{array}{l}\text { Water effect on DES struc- } \\
\text { ture }\end{array}$ & [92] \\
\hline 50 & $\begin{array}{c}\mathrm{ChCl} \text { : Urea (1:2) } \\
\mathrm{ChCl}: \text { Acetylsalicylic acid (1:2) } \\
\mathrm{ChCl}: \text { Sesamol }(1: 2) \\
\mathrm{ChCl}: \text { Pyrogallol }(1: 1)\end{array}$ & $\begin{array}{c}\text { DFT } \\
\text { B3LYP/ } \\
\text { ug-cc-pVTZ }\end{array}$ & $\begin{array}{l}\text { Solubilization properties } \\
\text { and structural characteriza- } \\
\text { tion in DES }\end{array}$ & [76] \\
\hline 51 & $\begin{array}{c}\text { ChCl : Urea (1:2) } \\
\mathrm{ChCl}: \text { Ethylene glycol }(1: 2)\end{array}$ & $\begin{array}{c}\text { DFT } \\
\text { M06-2X/6-31++G(d,p) }\end{array}$ & $\begin{array}{l}\text { Extractive Desulfurization } \\
\text { of Fuel with DES }\end{array}$ & [68] \\
\hline 52 & $\begin{array}{c}\mathrm{ChCl}: \text { Urea }(1: 2) \\
\mathrm{ChCl}: \text { Ethylene glycol }(1: 2) \\
\mathrm{ChCl}: \text { Glycerol }(1: 2)\end{array}$ & $\begin{array}{l}\text { AIMD } \\
\text { DFTB3 }\end{array}$ & $\begin{array}{c}\text { Investigation of DES struc- } \\
\text { ture }\end{array}$ & [192] \\
\hline 53 & $\begin{array}{c}\mathrm{ChCl} \text { : Urea (1:2) } \\
\mathrm{ChCl}: \text { Ethylene glycol (1:2) } \\
\mathrm{ChCl}: \text { Glycerol }(1: 2)\end{array}$ & $\begin{array}{c}\text { DFT } \\
\text { B3LYP/cc-pVDZ }\end{array}$ & $\begin{array}{l}\text { Solvatochromic behavior of } \\
\text { dimethyl sulfoxide with } \\
\text { DESs }\end{array}$ & [373] \\
\hline 54 & $\begin{array}{c}\mathrm{ChCl}: \text { Urea }(1: 2) \\
\mathrm{ChCl}: \text { Ethylene glycol }(1: 2) \\
\mathrm{ChCl}: \text { Glycerol }(1: 2) \\
\mathrm{ChCl}: \text { Propylene glycol }(1: 2)\end{array}$ & $\begin{array}{c}\text { DFT } \\
\text { B3LYP/ 6-311G(d) }\end{array}$ & $\begin{array}{l}\text { Extraction mechanism of 1- } \\
\text { butanol separation from al- } \\
\text { kanol azeotropic system us- } \\
\text { ing choline-based DES }\end{array}$ & [265] \\
\hline 55 & $\begin{array}{c}\mathrm{ChCl} \text { : Urea }(1: 2) \\
\mathrm{ChCl}: \text { Ethylene glycol }(1: 2) \\
\mathrm{ChCl} \text { : Levulinic acid }(1: 2) \\
\text { Betaine : Levulinic acid }(1: 2)\end{array}$ & $\begin{array}{l}\text { AIMD } \\
\text { BLYP with a triple- } \zeta, \\
\text { double polarization ba- } \\
\text { sis set for nonmetal at- } \\
\text { oms, and GTH pseudo- } \\
\text { potentials }\end{array}$ & $\begin{array}{l}\text { Mercury Capture from Pe- } \\
\text { troleum Using DES }\end{array}$ & [143] \\
\hline 56 & $\begin{array}{c}\text { ChCl : Urea }(1: 2) \\
\mathrm{ChCl} \text { : Ethylene glycol }(1: 2) \\
\text { Choline iodide: Glycerol }(1: 1) \\
\mathrm{ChCl} \text { : Benzoic acid }(1: 2)\end{array}$ & $\begin{array}{c}\text { DFT } \\
\text { M06-2X/cc-pVDZ level }\end{array}$ & $\begin{array}{l}\text { Adsorption of DESs onto } \\
\text { graphene and defective } \\
\text { graphene nanoflake }\end{array}$ & [292] \\
\hline 57 & $\begin{array}{c}\mathrm{ChCl} \text { : Urea (1:2) } \\
\mathrm{ChCl}: \text { Glycerol }(1: 2) \\
\mathrm{ChCl}: \text { Malonic acid }(1: 1)\end{array}$ & $\begin{array}{c}\text { DFT } \\
\text { B3LYP/6-311+G(d) }\end{array}$ & $\begin{array}{l}\text { Mechanisms of acid gases } \\
\text { capture at relevant inter- } \\
\text { faces and at atomistic level } \\
\text { in DES }\end{array}$ & [249] \\
\hline 58 & $\begin{array}{c}\mathrm{ChCl} \text { : Urea }(1: 2) \\
\mathrm{ChCl} \text { : Thio urea }(1: 2) \\
\mathrm{ChCl}: \text { Ehylene glycol }(1: 2) \\
\mathrm{ChCl}: \text { Glycerol }(1: 2) \\
\mathrm{ChCl}: \text { Urea }(1: 2)\end{array}$ & $\begin{array}{c}\text { DFT } \\
\text { B3LYP/6-31G }\end{array}$ & $\begin{array}{l}\text { Ammonium-based DES for } \\
\text { secondary water flooding }\end{array}$ & [394] \\
\hline 59 & $\begin{array}{c}\mathrm{ChCl} \text { : Thio urea }(1: 2) \\
\mathrm{ChCl} \text { : Methyl urea }(1: 2) \\
\mathrm{ChCl} \text { : Dimethyl urea }(1: 2)\end{array}$ & $\begin{array}{c}\text { AIMD } \\
\text { BLYP-D3(BJ) }\end{array}$ & $\begin{array}{c}\text { Investigation of DES struc- } \\
\text { ture }\end{array}$ & [102] \\
\hline
\end{tabular}




\begin{tabular}{|c|c|c|c|c|}
\hline & $\begin{array}{c}\mathrm{ChCl}: \text { 1,1-dimethylurea }(1: 2) \\
\mathrm{ChCl}: \mathrm{N}, \mathrm{N}^{\prime} \text { - ethylene urea }(1: 2)\end{array}$ & & & \\
\hline 60 & $\begin{array}{l}\text { ChCl based DESs } \\
\text { HBDs: straight-chain monobasic acids }\end{array}$ & $\begin{array}{c}\text { DFT } \\
\text { B3LYP/6-31G(d) }\end{array}$ & Sulfur removal by DES & [56] \\
\hline 61 & ChCl:Urea (1:2) & $\begin{array}{l}\text { BLYP-D2/ } \\
\text { DZVP-MOLOPT-SR- } \\
\text { GTH }\end{array}$ & $\begin{array}{l}\text { Investigation of DES struc- } \\
\text { ture }\end{array}$ & [191] \\
\hline 62 & $\begin{array}{l}\text { DESs based on } \mathrm{LiCl} \text { and LiTFSI } \\
\text { HBD: Urea, Acetamide, N,N0 dimethylpro- } \\
\text { pyleneurea, 2-imidazolidinone, Tetra- } \\
\text { methylurea } \\
\text { Molar ratio 1:5 }\end{array}$ & $\begin{array}{c}\text { DFT } \\
\text { B3LIP/ } \\
6-311++G(d, p)\end{array}$ & $\begin{array}{l}\text { Investigation of DES struc- } \\
\text { ture }\end{array}$ & [226] \\
\hline 63 & $\begin{array}{c}\text { L-Arginine : Glutamic acid }(1: 1) \\
\text { L-Arginine : Oxalic acid }(1: 1) \\
\text { L-Arginine : Tartaric acid }(1: 1)\end{array}$ & $\begin{array}{c}\text { DFT } \\
\text { B3LYP/6-31++G(d,p) }\end{array}$ & $\begin{array}{c}\text { Nitric oxide solubility in } \\
\text { DES }\end{array}$ & [136] \\
\hline 64 & L-Menthol : Acetic acid (1:1) & $\omega \mathrm{B} 97 \mathrm{XD} / 6-311 \mathrm{G}(\mathrm{d}, \mathrm{p})$ & $\begin{array}{c}\text { Structure Elucidation of } \\
\text { DES }\end{array}$ & [139] \\
\hline 65 & $\begin{array}{l}\text { Lactic acid : Alanine }(7: 1) \\
\text { Lactic acid : Glycine }(7: 1) \\
\text { Lactic acid : Histidine }(9: 1)\end{array}$ & $\begin{array}{l}\text { DFT } \\
\text { B3LYP / } \\
6-311 G(d, p)\end{array}$ & $\begin{array}{l}\text { Vapor-liquid equilibria, va- } \\
\text { por pressure and water ac- } \\
\text { tivity for the aqueous solu- } \\
\text { tions of natural deep eutec- } \\
\quad \text { tic solvents (NDESs) }\end{array}$ & [49] \\
\hline 66 & $\begin{array}{l}\text { Litium bis-(trifluoromethanesulfonyl)- imide } \\
\text { : Urea } \\
\text { Different molar ratios }\end{array}$ & $\begin{array}{c}\text { B3LYP/ } \\
\text { def2-TZVPP }\end{array}$ & $\begin{array}{l}\text { Investigation of DES struc- } \\
\text { ture }\end{array}$ & {$[382]$} \\
\hline 67 & $\begin{array}{l}\text { Methyltriphenylphosphonium bromide : Eth- } \\
\text { ylene glycol (1:4) }\end{array}$ & $\begin{array}{c}\text { DFT } \\
\text { B3LYP/6-31G(d) }\end{array}$ & $\begin{array}{l}\text { Extraction of a polyaro- } \\
\text { matic hydrocarbon from } \\
\text { fuel oils using DES }\end{array}$ & {$[264]$} \\
\hline 68 & $\begin{array}{l}\text { Methyltriphenylphosphonium bromide : } \\
\text { Glycerol (1:2) }\end{array}$ & $\mathrm{HF} / 6-31 \mathrm{G}(\mathrm{d})$ & $\begin{array}{l}\text { Adsorption of phenol and } \\
\text { crystal violet dye on carbon } \\
\text { nanotube functionalized } \\
\text { with deep eutectic solvent }\end{array}$ & [79] \\
\hline 69 & $\begin{array}{l}\text { Monoethanolamine hydrochloride : Methyl- } \\
\text { diethanolamine } \\
\text { Diethanolamine hydrochloride : Methyldi- } \\
\text { ethanolamine } \\
\text { N-methyl diethanolamine hydrochloride : } \\
\text { Methyldiethanolamine } \\
\text { Different molar ratios }\end{array}$ & $\begin{array}{c}\text { DFT } \\
\text { B3LYP/6-31G(d,p) }\end{array}$ & $\begin{array}{c}\mathrm{CO}_{2} \text { capture performance } \\
\text { by DES }\end{array}$ & [383] \\
\hline 70 & $\begin{array}{l}\text { Tetrabutylammonium bromide : Formic acid } \\
\qquad(1: 1) \\
\text { Tetrabutylammonium bromide : Imidazole } \\
(1: 2)\end{array}$ & $\begin{array}{c}\text { DFT } \\
\text { B3LYP/6-311++G(d,p) }\end{array}$ & Oil desulfuration by DES & [133] \\
\hline 71 & $\begin{array}{l}\text { Tetrabutylammonium bromide : Ethylene } \\
\text { glycol (1:4) } \\
\text { Tetrabutylammonium bromide : Glycerol } \\
(1: 4)\end{array}$ & $\begin{array}{c}\text { DFT } \\
\text { B3LYP/6-311+G(d) }\end{array}$ & $\begin{array}{l}\text { Dissolution of carbohy- } \\
\text { drates in DES }\end{array}$ & [316] \\
\hline 72 & $\begin{array}{l}\text { Tetrabutylphosphonium } \\
\text { bromide: Phenol (1:4) } \\
\text { Tetrabutylphosphonium } \\
\text { bromide: Diethylene glycol (1:4) }\end{array}$ & $\begin{array}{c}\text { DFT } \\
\text { B3LYP/6-31++G(d,p) }\end{array}$ & $\mathrm{CO}_{2}$ solubility in DESs & [259] \\
\hline
\end{tabular}




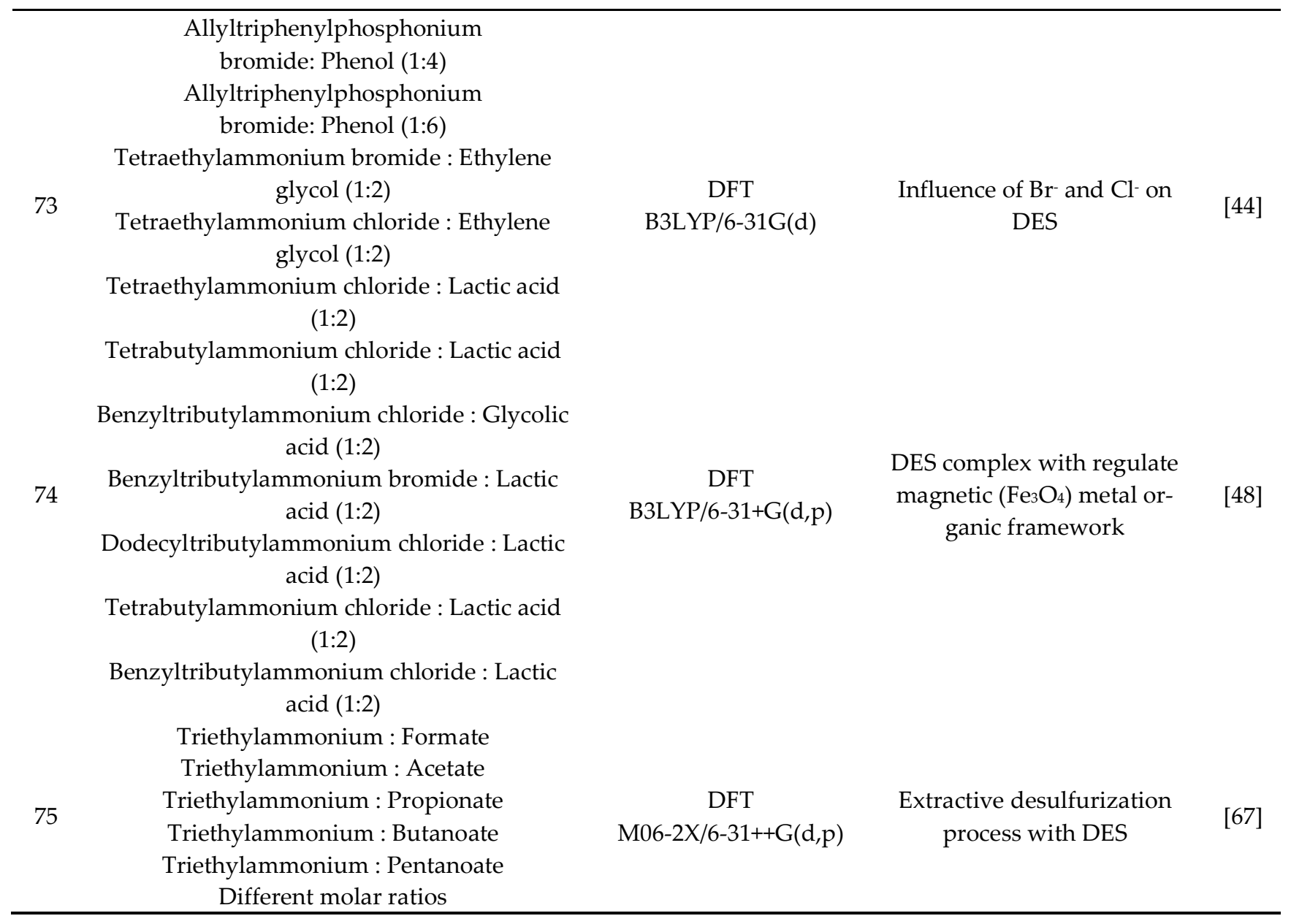

Table 4. Machine Learning calculations of DES consisting systems, used method and model, and the topic of the publication.

\begin{tabular}{|c|c|c|c|c|}
\hline No & DES & Models and Methods & Topic of the publication & $\begin{array}{l}\text { Ref- } \\
\text { er- } \\
\text { ence }\end{array}$ \\
\hline 1 & $\begin{array}{c}\text { DESs based on ammonium } \\
\text { salt and on phosphonium } \\
\text { salt }\end{array}$ & $\begin{array}{l}\text { Artificial neural network model. } \\
\text { A feed forward back propagation neural } \\
\text { network with } 9 \text { hidden neurons. } \\
\text { The group contribution method applied } \\
\text { the modified Lydersen-Joback-Reid, } \\
\text { Lee-Kesler and the modified Rackett } \\
\text { equations. }\end{array}$ & Prediction of DES densities & [168] \\
\hline 2 & $\begin{array}{l}\text { DESs based on ammonium } \\
\text { salt and on phosphonium } \\
\text { salt }\end{array}$ & $\begin{array}{l}\text { Artificial neural network model 8-4-1. } \\
\text { A feed-forward neural network with } 4 \\
\text { hidden neurons } \\
\text { Levenberg-Marquardt optimization } \\
\text { method. }\end{array}$ & $\begin{array}{l}\text { Prediction of glycerol re- } \\
\text { moval from palm-oil based } \\
\text { biodiesel using DESs. } \\
\text { Total glycerol content }\end{array}$ & [169] \\
\hline
\end{tabular}


3

DESs based on amine with different HDSs.

4

5

6

7

8
Benzyltriphenylphosphonium chloride : Glycerol

$(16: 1)$

\begin{abstract}
Allyl triphenyl phosphonium bromide : Glycerol
\end{abstract}

A combination of multilinear regression and artificial neural networks methods

The stepwise regression algorithm was used for the regression analysis of the experimental viscosity data expressed by sprofile and temperature multilinear regression model descriptors.

Response surface methodology and Artificial neural networking.

Artificial neural network model. A total of two types of neural network to analyse the feed-forward back-propagation and the layer recurrent.

The non-linear autoregressive network with exogenous inputs neural network strategy.

The back-propagation training algorithm was selected to update the bias and weight vector values corresponding to the momentum, and the tangent sigmoid transfer function (tansig) was selected as the neuron transfer function for the network.

The nonlinear autoregressive network with exogenous inputs (NARX) neural network strategy.

Three kinetic models were used to identify the adsorption rate and mechanism, and the pseudo-second order best described the adsorption kinetics.

Anrtificial neural network The nonlinear autoregressive exogenous model network

Feedforward neural network and layer recurrent neural network.
Prediction of the viscosity of DESs

Study of the efficacy of 10 NDES (natural DES), including 3 new NDES, to extract procyanidins and anthocyanins from cranberry pomace

Prediction of lead removal from water using DES functionalized CNTs

Prediction of arsenic removal from water solution using DES functionalized CNTs

Prediction of arsenic removal from water solution using DES functionalized CNTs

Prediction of mercury removal from water solution using DES functionalized

\section{CNTs}


9

DESs based on acid $\mathrm{ChCl}$ and Levulinic acid as HBAs

DESs based on $\mathrm{ChCl}, \mathrm{N}, \mathrm{N}-$ diethyl ethanol ammonium chloride, and methyl triphenyl phosphonium bromide salts

Choline chloride : citric acid

11 $1: 1$

Choline chloride : monohydrate 1:1
Artificial neural network model. Feed-forward back propagation neural network with 8 hidden neurons

Artificial neural network model.

Artificial neural network and genetic algorithm approach.

The feed-forward backpropagation neural network algorithm with 4 input layer neurons and 2 output layer neurons for 4 independent and 2 dependent variables. The optimum number of hidden layer neurons was 11 .

DESs based on allyltriphenylphosphonium bromide : Triethylene glycol with molar ratios of 1:4, 1:10 and 1:16.

DESs based on

$13 \mathrm{ChCl}$ : Glycerol $\mathrm{ChCl}: \mathrm{P}$-coumaric acid.

DESs based on tetraalkylammonium bro-
Linear and quadratic regression models.

Principal component analysis Partial least squares

Furthermore, based on molecular simulation, the detailed relationships between key variables were further analyzed.

Principal component analysis. Regression analysis. mide.

Modeling of $\mathrm{CO}_{2}$ solubility in various DESs.

Prediction of the electrical conductivity DESs at different temperatures and compositions

[177].

Experiment design for microwave-assisted extraction of phytochemical compounds from black jamun pulp

Estimation of carbon dioxide solubility in DESs

Revealing the biomass pretreatment mechanism by evaluating the inner relationships among $42 \mathrm{key}$ process factors

Prediction of DES eutectic temperatures 


\section{References}

1. Hansen, B.B.; Spittle, S.; Chen, B.; Poe, D.; Zhang, Y.; Klein, J.M.; Horton, A.; Adhikari, L.; Zelovich, T.; Doherty, B.W.; et al. Deep Eutectic Solvents: A Review of Fundamentals and Applications. Chem. Rev. 2021, 121, 1232-1285.

2. Smith, E.L.; Abbott, A.P.; Ryder, K.S. Deep Eutectic Solvents (DESs) and Their Applications. Chem. Rev. 2014, 114, 11060-11082.

3. Abbott, A.P.; Capper, G.; Davies, D.L.; Munro, H.L.; Rasheed, R.K.; Tambyrajah, V. Preparation of Novel, Moisture-Stable, Lewis-Acidic Ionic Liquids Containing Quaternary Ammonium Salts with Functional Side chainsElectronic Supplementary Information (ESI) Available: Plot of Conductivity vs. Temperature for the Ionic Liquid Formed from Zinc Chloride and Choline Chloride (2: 1). See Http://www. Rsc. org/suppdata/cc/b1/b106357j. Chem. Commun. 2001, 2010-2011.

4. Meng, X.; Ballerat-Busserolles, K.; Husson, P.; Andanson, J.-M. Impact of Water on the Melting Temperature of Urea + Choline Chloride Deep Eutectic Solvent. New J. Chem. 2016, 40, 4492-4499.

5. Amde, M.; Liu, J.-F.; Pang, L. Environmental Application, Fate, Effects, and Concerns of Ionic Liquids: A Review. Environ. Sci. Technol. 2015, 49, 12611-12627.

6. Abo-Hamad, A.; Hayyan, M.; AlSaadi, M.A.; Hashim, M.A. Potential Applications of Deep Eutectic Solvents in Nanotechnology. Chem. Eng. J. 2015, 273, 551-567.

7. Nkuku, C.A.; LeSuer, R.J. Electrochemistry in Deep Eutectic Solvents. J. Phys. Chem. B 2007, 111, 13271-13277.

8. Cunha, S.C.; Fernandes, J.O. Extraction Techniques with Deep Eutectic Solvents. Trends Analyt. Chem. 2018, 105, 225-239.

9. Alam, M.A.; Muhammad, G.; Khan, M.N.; Mofijur, M.; Lv, Y.; Xiong, W.; Xu, J. Choline Chloride-Based Deep Eutectic Solvents as Green Extractants for the Isolation of Phenolic Compounds from Biomass. J. Clean. Prod. 2021, 309, 127445.

10. Crump, M.R.; Bidinger, S.L.; Pavinatto, F.J.; Gong, A.T.; Sweet, R.M.; MacKenzie, J.D. Sensorized Tissue Analogues Enabled by a 3D-Printed Conductive Organogel. npj Flexible Electronics 2021, 5, 1-8.

11. Smirnov, M.A.; Fedotova, V.S.; Sokolova, M.P.; Nikolaeva, A.L.; Elokhovsky, V.Y.; Karttunen, M. Polymerizable Choline- and Imidazolium-Based Ionic Liquids Reinforced with Bacterial Cellulose for 3D-Printing. Polymers 2021, 13, doi:10.3390/polym13183044.

12. Pedro, S.N.; Freire, C.S.R.; Silvestre, A.J.D.; Freire, M.G. Deep Eutectic Solvents and Pharmaceuticals. Encyclopedia 2021, 1, 942963.

13. Emami, S.; Shayanfar, A. Deep Eutectic Solvents for Pharmaceutical Formulation and Drug Delivery Applications. Pharmaceutical development and 2020.

14. Svigelj, R.; Dossi, N.; Grazioli, C.; Toniolo, R. Deep Eutectic Solvents (DESs) and Their Application in Biosensor Development. Sensors 2021, 21, doi:10.3390/s21134263.

15. Liu, Y.; Dai, Z.; Zhang, Z.; Zeng, S.; Li, F.; Zhang, X.; Nie, Y.; Zhang, L.; Zhang, S.; Ji, X. Ionic Liquids/deep Eutectic Solvents for CO2 Capture: Reviewing and Evaluating. Green Energy E Environment 2021, 6, 314-328.

16. Pelaquim, F.P.; Barbosa Neto, A.M.; Dalmolin, I.A.L.; Costa, M.C. da Gas Solubility Using Deep Eutectic Solvents: Review and Analysis. Ind. Eng. Chem. Res. 2021, 60, 8607-8620.

17. Choi, Y.H.; van Spronsen, J.; Dai, Y.; Verberne, M.; Hollmann, F.; Arends, I.W.C.E.; Witkamp, G.-J.; Verpoorte, R. Are Natural Deep Eutectic Solvents the Missing Link in Understanding Cellular Metabolism and Physiology? Plant Physiol. 2011, 156, 17011705.

18. Smirnov, M.A.; Tolmachev, D.A.; Glova, A.D.; Sokolova, M.P.; Geydt, P.V.; Lukasheva, N.V.; Lyulin, S.V. Combined Use of Atomic Force Microscopy and Molecular Dynamics in the Study of Biopolymer Systems., doi:10.1134/S1811238221020089.

19. Shao, S.; Do, T.N.; Razi, A.; Chitgupi, U.; Geng, J.; Alsop, R.J.; Dzikovski, B.G.; Rheinstädter, M.C.; Ortega, J.; Karttunen, M.; et al. Design of Hydrated Porphyrin-Phospholipid Bilayers with Enhanced Magnetic Resonance Contrast. Small 2017, 13, 1602505.

20. Lee, E.H.; Hsin, J.; Sotomayor, M.; Comellas, G.; Schulten, K. Discovery through the Computational Microscope. Structure 2009, 17, 1295-1306. 
21. Dror, R.O.; Dirks, R.M.; Grossman, J.P.; Xu, H.; Shaw, D.E. Biomolecular Simulation: A Computational Microscope for Molecular Biology. Annu. Rev. Biophys. 2012, 41, 429-452.

22. Wu, J.; Liang, Q.; Yu, X.; Lü, Q.-F.; Ma, L.; Qin, X.; Chen, G.; Li, B. Deep Eutectic Solvents for Boosting Electrochemical Energy Storage and Conversion: A Review and Perspective. Adv. Funct. Mater. 2021, 31, 2011102.

23. Lee, M.S.; Lee, K.; Nam, M.W.; Jeong, K.M.; Lee, J.E.; Kim, N.W.; Yin, Y.; Lim, S.Y.; Yoo, D.E.; Lee, J.; et al. Natural Deep Eutectic Solvents as a Storage Medium for Human Interferon- $\alpha 2$ : A Green and Improved Strategy for Room-Temperature Biologics. J. Ind. Eng. Chem. 2018, 65, 343-348.

24. Lu, C.; Cao, J.; Wang, N.; Su, E. Significantly Improving the Solubility of Non-Steroidal Anti-Inflammatory Drugs in Deep Eutectic Solvents for Potential Non-Aqueous Liquid Administration. Med. Chem. Commun. 2016, 7, $955-959$.

25. Abbott, A.P.; Ahmed, E.I.; Prasad, K.; Qader, I.B.; Ryder, K.S. Liquid Pharmaceuticals Formulation by Eutectic Formation. Fluid Phase Equilib. 2017, 448, 2-8.

26. Chakraborty, S.; Chormale, J.H.; Bansal, A.K. Deep Eutectic Systems: An Overview of Fundamental Aspects, Current Understanding and Drug Delivery Applications. Int. J. Pharm. 2021, 610, 121203.

27. Di Pietro, M.E.; Hammond, O.; van den Bruinhorst, A.; Mannu, A.; Padua, A.; Mele, A.; Costa Gomes, M. Connecting Chloride Solvation with Hydration in Deep Eutectic Systems. Phys. Chem. Chem. Phys. 2021, 23, 107-111.

28. Ma, C.; Laaksonen, A.; Liu, C.; Lu, X.; Ji, X. The Peculiar Effect of Water on Ionic Liquids and Deep Eutectic Solvents. Chem. Soc. Rev. 2018, 47, 8685-8720.

29. Shah, D.; Mjalli, F.S. Effect of Water on the Thermo-Physical Properties of Reline: An Experimental and Molecular Simulation Based Approach. Phys. Chem. Chem. Phys. 2014, 16, 23900-23907.

30. Kovács, A.; Neyts, E.C.; Cornet, I.; Wijnants, M.; Billen, P. Modeling the Physicochemical Properties of Natural Deep Eutectic Solvents. ChemSusChem 2020, doi:10.1002/cssc.202000286.

31. Alkhatib, I.I.I.; Bahamon, D.; Llovell, F.; Abu-Zahra, M.R.M.; Vega, L.F. Perspectives and Guidelines on Thermodynamic Modelling of Deep Eutectic Solvents. J. Mol. Liq. 2020, 298, 112183.

32. Kaur, S.; Kumari, M.; Kashyap, H.K. Microstructure of Deep Eutectic Solvents: Current Understanding and Challenges. J. Phys. Chem. B 2020, 124, 10601-10616.

33. Shama, V.M.; Swami, A.R.; Aniruddha, R.; Sreedhar, I.; Reddy, B.M. Process and Engineering Aspects of Carbon Capture by Ionic Liquids. Journal of CO2 Utilization 2021, 48, 101507.

34. González de Castilla, A.; Bittner, J.P.; Müller, S.; Jakobtorweihen, S.; Smirnova, I. Thermodynamic and Transport Properties Modeling of Deep Eutectic Solvents: A Review on gE-Models, Equations of State, and Molecular Dynamics. J. Chem. Eng. Data 2020, 65, 943-967.

35. Ullah, R.; Atilhan, M.; Anaya, B.; Khraisheh, M.; García, G.; ElKhattat, A.; Tariq, M.; Aparicio, S. A Detailed Study of Cholinium Chloride and Levulinic Acid Deep Eutectic Solvent System for CO2 Capture via Experimental and Molecular Simulation Approaches. Phys. Chem. Chem. Phys. 2015, 17, 20941-20960.

36. Altamash, T.; Atilhan, M.; Aliyan, A.; Ullah, R.; García, G.; Aparicio, S. Insights into Choline Chloride-phenylacetic Acid Deep Eutectic Solvent for CO2 Absorption. RSC Adv. 2016, 6, 109201-109210.

37. Altamash, T.; Nasser, M.S.; Elhamarnah, Y.; Magzoub, M.; Ullah, R.; Anaya, B.; Aparicio, S.; Atilhan, M. Gas Solubility and Rheological Behavior of Natural Deep Eutectic Solvents (NADES) via Combined Experimental and Molecular Simulation Techniques. ChemistrySelect 2017, 2, 7278-7295.

38. Gutiérrez, A.; Atilhan, M.; Aparicio, S. A Theoretical Study on Lidocaine Solubility in Deep Eutectic Solvents. Phys. Chem. Chem. Phys. 2018, 20, 27464-27473.

39. Tomasi, J.; Mennucci, B.; Cammi, R. Quantum Mechanical Continuum Solvation Models. Chem. Rev. 2005, 105, $2999-3093$. 
40. Bernales, V.S.; Marenich, A.V.; Contreras, R.; Cramer, C.J.; Truhlar, D.G. Quantum Mechanical Continuum Solvation Models for Ionic Liquids. J. Phys. Chem. B 2012, 116, 9122-9129.

41. Marenich, A.V.; Cramer, C.J.; Truhlar, D.G. Performance of SM6, SM8, and SMD on the SAMPL1 Test Set for the Prediction of Small-Molecule Solvation Free Energies. J. Phys. Chem. B 2009, 113, 4538-4543.

42. Jangir, A.K.; Patel, D.; More, R.; Parmar, A.; Kuperkar, K. New Insight into Experimental and Computational Studies of Choline Chloride-Based “green” Ternary Deep Eutectic Solvent (TDES). J. Mol. Struct. 2019, 1181, 295-299.

43. Jangir, A.K.; Mandviwala, H.; Patel, P.; Sharma, S.; Kuperkar, K. Acumen into the Effect of Alcohols on Choline Chloride: LLactic Acid-Based Natural Deep Eutectic Solvent (NADES): A Spectral Investigation Unified with Theoretical and Thermophysical Characterization. J. Mol. Liq. 2020, 317, 113923.

44. Wu, D.; Xu, L.H.; Feng, H.J.; Zhu, Y.W.; Chen, X.Y.; Cui, P. Design and Theoretical Study of Novel Deep Eutectic Solvents: The Effects of Bromine and Chloride Anions on Solvation Structure and Supercapacitor Performance. J. Power Sources 2021, 492, 229634.

45. Bader, R.F.W. Atoms in Molecules in External Fields. J. Chem. Phys. 1989, 91, 6989-7001.

46. Sowlati-Hashjin, S.; Karttunen, M.; Matta, C.F. Manipulation of Diatomic Molecules with Oriented External Electric Fields: Linear Correlations in Atomic Properties Lead to Nonlinear Molecular Responses. J. Phys. Chem. A 2020, 124, 4720-4731.

47. Zhu, S.; Li, H.; Zhu, W.; Jiang, W.; Wang, C.; Wu, P.; Zhang, Q.; Li, H. Vibrational Analysis and Formation Mechanism of Typical Deep Eutectic Solvents: An Experimental and Theoretical Study. J. Mol. Graph. Model. 2016, 68, 158-175.

48. Wei, X.; Wang, Y.; Chen, J.; Xu, F.; Liu, Z.; He, X.; Li, H.; Zhou, Y. Adsorption of Pharmaceuticals and Personal Care Products by Deep Eutectic Solvents-Regulated Magnetic Metal-Organic Framework Adsorbents: Performance and Mechanism. Chem. Eng. J. 2020, 392, 124808.

49. Faraji, S.; Mokhtarpour, M.; Behboudi, E.; Sadrmousavi, A.; Shekaari, H.; Zafarani-Moattar, M.T. Vapor-Liquid Equilibria and Computational Study for Aqueous Solutions of Novel Deep Eutectic Solvents (Amino Acid/Lactic Acid) at 298.15 K. J. Chem. Eng. Data 2020, 65, 3262-3269.

50. Naseem, Z.; Shehzad, R.A.; Ihsan, A.; Iqbal, J.; Zahid, M.; Pervaiz, A.; Sarwari, G. Theoretical Investigation of Supramolecular Hydrogen-Bonded Choline Chloride-Based Deep Eutectic Solvents Using Density Functional Theory. Chem. Phys. Lett. 2021, $769,138427$.

51. Gautam, R.; Kumar, N.; Lynam, J.G. Theoretical and Experimental Study of Choline Chloride-Carboxylic Acid Deep Eutectic Solvents and Their Hydrogen Bonds. J. Mol. Struct. 2020, 1222, 128849.

52. Zhang, C.; Jia, Y.; Jing, Y.; Wang, H.; Hong, K. Main Chemical Species and Molecular Structure of Deep Eutectic Solvent Studied by Experiments with DFT Calculation: A Case of Choline Chloride and Magnesium Chloride Hexahydrate. J. Mol. Model. 2014, 20,2374 .

53. Araujo, C.F.; Coutinho, J.A.P.; Nolasco, M.M.; Parker, S.F.; Ribeiro-Claro, P.J.A.; Rudić, S.; Soares, B.I.G.; Vaz, P.D. Inelastic Neutron Scattering Study of Reline: Shedding Light on the Hydrogen Bonding Network of Deep Eutectic Solvents. Phys. Chem. Chem. Phys. 2017, 19, 17998-18009.

54. Słupek, E.; Makoś, P. Absorptive Desulfurization of Model Biogas Stream Using Choline Chloride-Based Deep Eutectic Solvents. Sustain. Sci. Pract. Policy 2020, 12, 1619.

55. García, G.; Atilhan, M.; Aparicio, S. A Theoretical Study on Mitigation of CO2 through Advanced Deep Eutectic Solvents. Int. J. Greenhouse Gas Control 2015, 39, 62-73.

56. Zhu, W.; Wang, C.; Li, H.; Wu, P.; Xun, S.; Jiang, W.; Chen, Z.; Zhao, Z.; Li, H. One-Pot Extraction Combined with Metal-Free Photochemical Aerobic Oxidative Desulfurization in Deep Eutectic Solvent. Green Chem. 2015, 17, $2464-2472$.

57. Makoś, P.; Słupek, E.; Gębicki, J. Extractive Detoxification of Feedstocks for the Production of Biofuels Using New Hydrophobic Deep Eutectic Solvents - Experimental and Theoretical Studies. J. Mol. Liq. 2020, 308, 113101. 
58. Sinclair, N.S.; Poe, D.; Savinell, R.F.; Maginn, E.J.; Wainright, J.S. A Nitroxide Containing Organic Molecule in a Deep Eutectic Solvent for Flow Battery Applications. J. Electrochem. Soc. 2021, 168, 020527.

59. Ashworth, C.R.; Matthews, R.P.; Welton, T.; Hunt, P.A. Doubly Ionic Hydrogen Bond Interactions within the Choline ChlorideUrea Deep Eutectic Solvent. Phys. Chem. Chem. Phys. 2016, 18, 18145-18160.

60. Archer, L.; Jachimska, B.; Krzan, M.; Szaleniec, M.; Hebda, E.; Radzik, P.; Pielichowski, K.; Guzik, M. Physical Properties of Biomass-Derived Novel Natural Deep Eutectic Solvents Based on Choline Chloride and (R)-3-Hydroxyacids. J. Mol. Liq. 2020, 315, 113680.

61. Atilhan, M.; Altamash, T.; Aparicio, S. Quantum Chemistry Insight into the Interactions Between Deep Eutectic Solvents and SO2. Molecules 2019, 24, doi:10.3390/molecules24162963.

62. Altamash, T.; Amhamed, A.; Aparicio, S.; Atilhan, M. Effect of Hydrogen Bond Donors and Acceptors on CO2 Absorption by Deep Eutectic Solvents. Processes 2020, 8, 1533.

63. Miguel, Á.; Fornari, R.P.; García, N.; Bhowmik, A.; Carrasco-Busturia, D.; García-Lastra, J.M.; Tiemblo, P. Understanding the Molecular Structure of the Elastic and Thermoreversible AlCl3 : Urea/Polyethylene Oxide Gel Electrolyte. ChemSusChem 2020, $13,5523-5530$.

64. da Costa Lopes, A.M.; Gomes, J.R.B.; Coutinho, J.A.P.; Silvestre, A.J.D. Novel Insights into Biomass Delignification with Acidic Deep Eutectic Solvents: A Mechanistic Study of $\beta-\mathrm{O}-4$ Ether Bond Cleavage and the Role of the Halide Counterion in the Catalytic Performance. Green Chem. 2020, 22, 2474-2487.

65. Wagle, D.V.; Baker, G.A.; Mamontov, E. Differential Microscopic Mobility of Components within a Deep Eutectic Solvent. J. Phys. Chem. Lett. 2015, 6, 2924-2928.

66. Pisano, P.L.; Espino, M.; Fernández, M. de L.Á.; Silva, M.F.; Olivieri, A.C. Structural Analysis of Natural Deep Eutectic Solvents. Theoretical and Experimental Study. Microchem. J. 2018, 143, 252-258.

67. Wang, X.; Jiang, W.; Zhu, W.; Li, H.; Yin, S.; Chang, Y.; Li, H. A Simple and Cost-Effective Extractive Desulfurization Process with Novel Deep Eutectic Solvents. RSC Adv. 2016, 6, 30345-30352.

68. Wagle, D.V.; Zhao, H.; Deakyne, C.A.; Baker, G.A. Quantum Chemical Evaluation of Deep Eutectic Solvents for the Extractive Desulfurization of Fuel. ACS Sustainable Chem. Eng. 2018, 6, 7525-7531.

69. Makoś, P.; Boczkaj, G. Deep Eutectic Solvents Based Highly Efficient Extractive Desulfurization of Fuels - Eco-Friendly Approach. J. Mol. Liq. 2019, 296, 111916.

70. Ghenaatian, H.R.; Shakourian-Fard, M.; Kamath, G. Interaction of Cun, Agn and Aun (n=1-4) Nanoparticles with ChCl:Urea Deep Eutectic Solvent. Journal of Molecular Graphics and Modelling 2021, 105, 107866.

71. Xu, L.H.; Wu, D.; Zhong, M.; Wang, G.B.; Chen, X.Y.; Zhang, Z.J. The Construction of a New Deep Eutectic Solvents System Based on Choline Chloride and Butanediol: The Influence of the Hydroxyl Position of Butanediol on the Structure of Deep Eutectic Solvent and Supercapacitor Performance. J. Power Sources 2021, 490, 229365.

72. Li, C.; Lu, D.; Wu, C. A Theoretical Study on Screening Ionic Liquids for SO2 Capture under Low SO2 Partial Pressure and High Temperature. J. Ind. Eng. Chem. 2021, 98, 161-167.

73. Malik, A.; Dhattarwal, H.S.; Kashyap, H.K. Distinct Solvation Structures of CO2 and SO2 in Reline and Ethaline Deep Eutectic Solvents Revealed by AIMD Simulations. J. Phys. Chem. B 2021, 125, 1852-1860.

74. McGaughy, K.; Reza, M.T. Systems Analysis of SO2-CO2 Co-Capture from a Post-Combustion Coal-Fired Power Plant in Deep Eutectic Solvents. Energies 2020, 13, 438.

75. Sanjari, R.; Kazemipour, M.; Zeidabadinejad, L.; Ansari, M. Computational Modeling, Fabrication, and Characterization of the Deep Eutectic Solvent-Based Green Molecular Cage for Selective Metronidazole Extraction from Plasma Followed by UHPLC with Diode Array Detector Determination. J. Sep. Sci. 2021, doi:10.1002/jssc.202100251. 
76. Migliorati, V.; Fazio, G.; Pollastri, S.; Gentili, A.; Tomai, P.; Tavani, F.; D'Angelo, P. Solubilization Properties and Structural Characterization of Dissociated $\mathrm{HgO}$ and $\mathrm{HgCl} 2$ in Deep Eutectic Solvents. J. Mol. Liq. 2021, 329, 115505.

77. Li, Z.-L.; Zhong, F.-Y.; Huang, J.-Y.; Peng, H.-L.; Huang, K. Sugar-Based Natural Deep Eutectic Solvents as Potential Absorbents for NH3 Capture at Elevated Temperatures and Reduced Pressures. J. Mol. Liq. 2020, 317, 113992.

78. Li, G.; Xie, Q.; Liu, Q.; Liu, J.; Wan, C.; Liang, D.; Zhang, H. Separation of Phenolic Compounds from Oil Mixtures by Betainebased Deep Eutectic Solvents. Asia-Pac. J. Chem. Eng. 2020, 15, doi:10.1002/apj.2515.

79. Lawal, I.A.; Lawal, M.M.; Azeez, M.A.; Ndungu, P. Theoretical and Experimental Adsorption Studies of Phenol and Crystal Violet Dye on Carbon Nanotube Functionalized with Deep Eutectic Solvent. J. Mol. Liq. 2019, 288, 110895.

80. Lopes, M.M.; Barrulas, R.V.; Paiva, T.G.; Ferreira, A.S.D.; Zanatta, M.; Corvo, M.C. Molecular Interactions in Ionic Liquids: The NMR Contribution towards Tailored Solvents. In Nuclear Magnetic Resonance; IntechOpen, 2019.

81. Barich, D.H.; Nicholas, J.B.; Haw, J.F. Gauge-Including Atomic Orbital Proton Chemical Shifts of Strong Hydrogen Bonds: The Importance of Electron Correlation. J. Phys. Chem. A 2001, 105, 4708-4715.

82. Refson, K.; Tulip, P.R.; Clark, S.J. Variational Density-Functional Perturbation Theory for Dielectrics and Lattice Dynamics. Phys. Rev. B Condens. Matter 2006, 73, 155114.

83. Milman, V.; Perlov, A.; Refson, K.; Clark, S.J.; Gavartin, J.; Winkler, B. Structural, Electronic and Vibrational Properties of Tetragonal Zirconia under Pressure: A Density Functional Theory Study. J. Phys. Condens. Matter 2009, $21,485404$.

84. Ratcliff, L.E.; Mohr, S.; Huhs, G.; Deutsch, T.; Masella, M.; Genovese, L. Challenges in Large Scale Quantum Mechanical Calculations. Wiley Interdiscip. Rev. Comput. Mol. Sci. 2017, 7, e1290.

85. Korotkevich, A.; Firaha, D.S.; Padua, A.A.H.; Kirchner, B. Ab Initio Molecular Dynamics Simulations of SO 2 Solvation in Choline Chloride/glycerol Deep Eutectic Solvent. Fluid Phase Equilib. 2017, 448, 59-68.

86. VandeVondele, J.; Hutter, J. Gaussian Basis Sets for Accurate Calculations on Molecular Systems in Gas and Condensed Phases. J. Chem. Phys. 2007, 127, 114105.

87. Becke, A.D. Density-Functional Exchange-Energy Approximation with Correct Asymptotic Behavior. Phys. Rev. A 1988, 38, 3098-3100.

88. Lee, C.; Yang, W.; Parr, R.G. Development of the Colle-Salvetti Correlation-Energy Formula into a Functional of the Electron Density. Phys. Rev. B Condens. Matter 1988, 37, 785-789.

89. Goedecker, S.; Teter, M.; Hutter, J. Separable Dual-Space Gaussian Pseudopotentials. Phys. Rev. B Condens. Matter 1996, 54, 17031710.

90. Grimme, S.; Antony, J.; Ehrlich, S.; Krieg, H. A Consistent and Accurate Ab Initio Parametrization of Density Functional Dispersion Correction (DFT-D) for the 94 Elements H-Pu. J. Chem. Phys. 2010, 132, 154104.

91. Grimme, S.; Ehrlich, S.; Goerigk, L. Effect of the Damping Function in Dispersion Corrected Density Functional Theory. J. Comput. Chem. 2011, 32, 1456-1465.

92. Fetisov, E.O.; Harwood, D.B.; Kuo, I.-F.W.; Warrag, S.E.E.; Kroon, M.C.; Peters, C.J.; Siepmann, J.I. First-Principles Molecular Dynamics Study of a Deep Eutectic Solvent: Choline Chloride/Urea and Its Mixture with Water. J. Phys. Chem. B 2018, 122, 12451254.

93. Zahn, S.; Kirchner, B.; Mollenhauer, D. Charge Spreading in Deep Eutectic Solvents. Chemphyschem 2016, 17, 3354-3358.

94. Hospital, A.; Goñi, J.R.; Orozco, M.; Gelpí, J.L. Molecular Dynamics Simulations: Advances and Applications. Adv. Appl. Bioinform. Chem. 2015, 8, 37-47.

95. Wong-ekkabut, J.; Karttunen, M. The Good, the Bad and the User in Soft Matter Simulations. Biochimica et Biophysica Acta (BBA) - Biomembranes 2016, 1858, 2529-2538.

96. Hub, J.S.; de Groot, B.L.; Grubmüller, H.; Groenhof, G. Quantifying Artifacts in Ewald Simulations of Inhomogeneous Systems with a Net Charge. J. Chem. Theory Comput. 2014, 10, 381-390. 
97. Manna, M.; Kulig, W.; Javanainen, M.; Tynkkynen, J.; Hensen, U.; Müller, D.J.; Rog, T.; Vattulainen, I. How To Minimize Artifacts in Atomistic Simulations of Membrane Proteins, Whose Crystal Structure Is Heavily Engineered: $\beta_{2}$-Adrenergic Receptor in the Spotlight. J. Chem. Theory Comput. 2015, 11, 3432-3445.

98. Bedrov, D.; Piquemal, J.-P.; Borodin, O.; MacKerell, A.D.; Roux, B.; Schröder, C. Molecular Dynamics Simulations of Ionic Liquids and Electrolytes Using Polarizable Force Fields. Chem. Rev. 2019, 119, 7940-7995.

99. Doherty, B.; Acevedo, O. OPLS Force Field for Choline Chloride-Based Deep Eutectic Solvents. J. Phys. Chem. B 2018, 122, 99829993.

100. Avula, N.V.S.; Karmakar, A.; Kumar, R.; Balasubramanian, S. Efficient Parametrization of Force Field for the Quantitative Prediction of the Physical Properties of Ionic Liquid Electrolytes. J. Chem. Theory Comput. 2021, 17, 4274-4290.

101. García, G.; Atilhan, M.; Aparicio, S. The Impact of Charges in Force Field Parameterization for Molecular Dynamics Simulations of Deep Eutectic Solvents. J. Mol. Liq. 2015, 211, 506-514.

102. Shayestehpour, O.; Zahn, S. Molecular Features of Reline and Homologous Deep Eutectic Solvents Contributing to Nonideal Mixing Behavior. J. Phys. Chem. B 2020, 124, 7586-7597.

103. Abedin, R.; Shen, Y.; Flake, J.C.; Hung, F.R. Deep Eutectic Solvents Mixed with Fluorinated Refrigerants for Absorption Refrigeration: A Molecular Simulation Study. J. Phys. Chem. B 2020, 124, 4536-4550.

104. Reddy, T.D.N.; Mallik, B.S. Reciprocity between Ion-Dipole and Hydrogen Bond Interactions in the Binary Mixtures of N,NDimethylformamide with Ionic Liquids. J. Mol. Liq. 2020, 301, 112487.

105. Tolmachev, D.A.; Boyko, O.S.; Lukasheva, N.V.; Martinez-Seara, H.; Karttunen, M. Overbinding and Qualitative and Quantitative Changes Caused by Simple Na+ and K+ Ions in Polyelectrolyte Simulations: Comparison of Force Fields with and without NBFIX and ECC Corrections. J. Chem. Theory Comput. 2020, 16, 677-687.

106. Celebi, A.T.; Dawass, N.; Moultos, O.A.; Vlugt, T.J.H. How Sensitive Are Physical Properties of Choline Chloride-Urea Mixtures to Composition Changes: Molecular Dynamics Simulations and Kirkwood-Buff Theory. J. Chem. Phys. 2021, 154, 184502.

107. Perkins, S.L.; Painter, P.; Colina, C.M. Experimental and Computational Studies of Choline Chloride-Based Deep Eutectic Solvents. J. Chem. Eng. Data 2014, 59, 3652-3662.

108. Smirnov, M.A.; Sokolova, M.P.; Tolmachev, D.A.; Vorobiov, V.K.; Kasatkin, I.A.; Smirnov, N.N.; Klaving, A.V.; Bobrova, N.V.; Lukasheva, N.V.; Yakimansky, A.V. Green Method for Preparation of Cellulose Nanocrystals Using Deep Eutectic Solvent. Cellulose 2020, 27, 4305-4317.

109. McDaniel, J.G.; Yethiraj, A. Influence of Electronic Polarization on the Structure of Ionic Liquids. J. Phys. Chem. Lett. 2018, 9, 4765-4770.

110. Smith, C.J., 2nd; Wagle, D.V.; Bhawawet, N.; Gehrke, S.; Hollóczki, O.; Pingali, S.V.; O’Neill, H.; Baker, G.A. Combined SmallAngle Neutron Scattering, Diffusion NMR, and Molecular Dynamics Study of a Eutectogel: Illuminating the Dynamical Behavior of Glyceline Confined in Bacterial Cellulose Gels. J. Phys. Chem. B 2020, 124, 7647-7658.

111. McDaniel, J.G.; Yethiraj, A. Understanding the Properties of Ionic Liquids: Electrostatics, Structure Factors, and Their Sum Rules. J. Phys. Chem. B 2019, 123, 3499-3512.

112. Son, C.Y.; McDaniel, J.G.; Schmidt, J.R.; Cui, Q.; Yethiraj, A. First-Principles United Atom Force Field for the Ionic Liquid BMIM(+)BF4(-): An Alternative to Charge Scaling. J. Phys. Chem. B 2016, 120, 3560-3568.

113. Chaumont, A.; Engler, E.; Schurhammer, R. Is Charge Scaling Really Mandatory When Developing Fixed-Charge Atomistic Force Fields for Deep Eutectic Solvents? J. Phys. Chem. B 2020, 124, 7239-7250.

114. Rick, S.W.; Stuart, S.J. Potentials and Algorithms for Incorporating Polarizability in Computer Simulations. Rev. Comput. Chem. 2002, 18, 89-146. 
115. Patel, S.; Mackerell, A.D., Jr; Brooks, C.L., 3rd CHARMM Fluctuating Charge Force Field for Proteins: II Protein/solvent Properties from Molecular Dynamics Simulations Using a Nonadditive Electrostatic Model. J. Comput. Chem. 2004, 25, 15041514.

116. Borodin, O. Polarizable Force Field Development and Molecular Dynamics Simulations of Ionic Liquids. J. Phys. Chem. B 2009, 113, 11463-11478.

117. Lemkul, J.A.; Huang, J.; Roux, B.; MacKerell, A.D., Jr An Empirical Polarizable Force Field Based on the Classical Drude Oscillator Model: Development History and Recent Applications. Chem. Rev. 2016, 116, 4983-5013.

118. Yu, H.; van Gunsteren, W.F. Accounting for Polarization in Molecular Simulation. Comput. Phys. Commun. 2005, 172, 69-85.

119. Olano, L.R.; Rick, S.W. Fluctuating Charge Normal Modes: An Algorithm for Implementing Molecular Dynamics Simulations with Polarizable Potentials. J. Comput. Chem. 2005, 26, 699-707.

120. Schmollngruber, M.; Lesch, V.; Schröder, C.; Heuer, A.; Steinhauser, O. Comparing Induced Point-Dipoles and Drude Oscillators. Phys. Chem. Chem. Phys. 2015, 17, 14297-14306.

121. Goloviznina, K.; Gong, Z.; Costa Gomes, M.F.; Pádua, A.A.H. Extension of the CL\&Pol Polarizable Force Field to Electrolytes, Protic Ionic Liquids, and Deep Eutectic Solvents. J. Chem. Theory Comput. 2021, 17, 1606-1617.

122. Goloviznina, K.; Gong, Z.; Padua, A.A.H. The CL \&Pol Polarizable Force Field for the Simulation of Ionic Liquids and Eutectic Solvents. Wiley Interdiscip. Rev. Comput. Mol. Sci. 2021, doi:10.1002/wcms.1572.

123. de Souza, R.M.; Karttunen, M.; Ribeiro, M.C.C. Fine-Tuning the Polarizable CL\&Pol Force Field for the Deep Eutectic Solvent Ethaline. arXiv [cond-mat.soft] 2021.

124. Jeong, K.-J.; McDaniel, J.G.; Yethiraj, A. Deep Eutectic Solvents: Molecular Simulations with a First-Principles Polarizable Force Field. J. Phys. Chem. B 2021, 125, 7177-7186.

125. Canongia Lopes, J.N.; Pádua, A.A.H. CL\&P: A Generic and Systematic Force Field for Ionic Liquids Modeling. Theor. Chem. Acc. 2012, 131, doi:10.1007/s00214-012-1129-7.

126. Goloviznina, K.; Canongia Lopes, J.N.; Costa Gomes, M.; Pádua, A.A.H. Transferable, Polarizable Force Field for Ionic Liquids. J. Chem. Theory Comput. 2019, 15, 5858-5871.

127. Szalewicz, K. Symmetry-Adapted Perturbation Theory of Intermolecular Forces. Wiley Interdiscip. Rev. Comput. Mol. Sci. 2012, $2,254-272$.

128. Tang, K.T.; Toennies, J.P. An Improved Simple Model for the van Der Waals Potential Based on Universal Damping Functions for the Dispersion Coefficients. J. Chem. Phys. 1984, 80, 3726-3741.

129. Thole, B.T. Molecular Polarizabilities Calculated with a Modified Dipole Interaction. Chem. Phys. 1981, 59, 341-350.

130. Maglia de Souza, R.; Karttunen, M.; Ribeiro, M.C.C. Fine-Tuning the Polarizable CL\&Pol Force Field for the Deep Eutectic Solvent Ethaline. J. Chem. Inf. Model. 2021, doi:10.1021/acs.jcim.1c01181.

131. Szabadi, A.; Elfgen, R.; Macchieraldo, R.; Kearns, F.L.; Lee Woodcock, H.; Kirchner, B.; Schröder, C. Comparison between Ab Initio and Polarizable Molecular Dynamics Simulations of 1-Butyl-3-Methylimidazolium Tetrafluoroborate and Chloride in Water. J. Mol. Liq. 2021, 337, 116521.

132. McDaniel, J.G.; Schmidt, J.R. Physically-Motivated Force Fields from Symmetry-Adapted Perturbation Theory. J. Phys. Chem. A 2013, 117, 2053-2066.

133. Gutiérrez, A.; Atilhan, M.; Aparicio, S. Theoretical Study of Oil Desulfuration by Ammonium-Based Deep Eutectic Solvents. Energy Fuels 2018, 32, 7497-7507.

134. Gutiérrez, A.; Aparicio, S.; Atilhan, M. Design of Arginine-Based Therapeutic Deep Eutectic Solvents as Drug Solubilization Vehicles for Active Pharmaceutical Ingredients. Phys. Chem. Chem. Phys. 2019, 21, 10621-10634.

135. Gutiérrez, A.; Atilhan, M.; Aparicio, S. Behavior of Antibiotics in Natural Deep Eutectic Solvents. J. Chem. Eng. Data 2020, 65, 4669-4683. 
136. Atilhan, M.; Aparicio, S. A Nanoscopic Explanation of Nitric Oxide Solubility in Natural Deep Eutectic Solvents. J. Mol. Liq. 2021, 324, 114673.

137. Gutiérrez, A.; Alcalde, R.; Atilhan, M.; Aparicio, S. Insights on Betaine + Lactic Acid Deep Eutectic Solvent. Ind. Eng. Chem. Res. 2020, 59, 11880-11892.

138. Rozas, S.; Alomari, N.; Atilhan, M.; Aparicio, S. Theoretical Insights into the Cineole-Based Deep Eutectic Solvents. J. Chem. Phys. 2021, 154, 184504.

139. Ali, M.A.; Rahman, M.S.; Roy, R.; Gambill, P.; Raynie, D.E.; Halim, M.A. Structure Elucidation of Menthol-Based Deep Eutectic Solvent Using Experimental and Computational Techniques. J. Phys. Chem. A 2021, 125, 2402-2412.

140. Cui, Y.; Fulfer, K.D.; Ma, J.; Weldeghiorghis, T.K.; Kuroda, D.G. Solvation Dynamics of an Ionic Probe in Choline ChlorideBased Deep Eutectic Solvents. Phys. Chem. Chem. Phys. 2016, 18, 31471-31479.

141. Ahmadi, R.; Hemmateenejad, B.; Safavi, A.; Shojaeifard, Z.; Shahsavar, A.; Mohajeri, A.; Heydari Dokoohaki, M.; Zolghadr, A.R. Deep Eutectic-water Binary Solvent Associations Investigated by Vibrational Spectroscopy and Chemometrics. Phys. Chem. Chem. Phys. 2018, 20, 18463-18473.

142. Alizadeh, V.; Esser, L.; Kirchner, B. How Is CO2 Absorbed into a Deep Eutectic Solvent? J. Chem. Phys. 2021, 154, 094503.

143. Warrag, S.E.E.; Fetisov, E.O.; van Osch, D.J.G.P.; Harwood, D.B.; Kroon, M.C.; Siepmann, J.I.; Peters, C.J. Mercury Capture from Petroleum Using Deep Eutectic Solvents. Ind. Eng. Chem. Res. 2018, 57, 9222-9230.

144. Carrasco-Busturia, D.; Lysgaard, S.; Jankowski, P.; Vegge, T.; Bhowmik, A.; García-Lastra, J.M. Ab Initio Molecular Dynamics Investigations of the Speciation and Reactivity of Deep Eutectic Electrolytes in Aluminum Batteries. ChemSusChem 2021, 14, 2034-2041.

145. Zhang, Y.; Poe, D.; Heroux, L.; Squire, H.; Doherty, B.W.; Long, Z.; Dadmun, M.; Gurkan, B.; Tuckerman, M.E.; Maginn, E.J. Liquid Structure and Transport Properties of the Deep Eutectic Solvent Ethaline. J. Phys. Chem. B 2020, 124, 5251-5264.

146. Joshi, S.Y.; Deshmukh, S.A. A Review of Advancements in Coarse-Grained Molecular Dynamics Simulations. Mol. Simul. 2021.

147. Sanbonmatsu, K.Y.; Tung, C.-S. High Performance Computing in Biology: Multimillion Atom Simulations of Nanoscale Systems. J. Struct. Biol. 2007, 157, 470-480.

148. Murtola, T.; Bunker, A.; Vattulainen, I.; Deserno, M.; Karttunen, M. Multiscale Modeling of Emergent Materials: Biological and Soft Matter. Phys. Chem. Chem. Phys. 2009, 11, 1869-1892.

149. Faller, R.; Schmitz, H.; Biermann, O.; Müller-Plathe, F. Automatic Parameterization of Force Fields for Liquids by Simplex Optimization. J. Comput. Chem. 1999, 20, 1009-1017.

150. Lyubartsev, A.P.; Laaksonen, A. Calculation of Effective Interaction Potentials from Radial Distribution Functions: A Reverse Monte Carlo Approach. Phys. Rev. E Stat. Phys. Plasmas Fluids Relat. Interdiscip. Topics 1995, 52, 3730-3737.

151. Marrink, S.J.; Tieleman, D.P. Perspective on the Martini Model. Chem. Soc. Rev. 2013, 42, 6801-6822.

152. Kitjanon, J.; Khuntawee, W.; Phongphanphanee, S.; Sutthibutpong, T.; Chattham, N.; Karttunen, M.; Wong-ekkabut, J. Nanocomposite of Fullerenes and Natural Rubbers: MARTINI Force Field Molecular Dynamics Simulations. Polymers 2021, 13, 4044.

153. Liwo, A.; Czaplewski, C.; Sieradzan, A.K.; Lipska, A.G.; Samsonov, S.A.; Murarka, R.K. Theory and Practice of Coarse-Grained Molecular Dynamics of Biologically Important Systems. Biomolecules 2021, 11, doi:10.3390/biom11091347.

154. Singh, N.; Li, W. Recent Advances in Coarse-Grained Models for Biomolecules and Their Applications. Int. J. Mol. Sci. 2019, 20, doi:10.3390/ijms20153774.

155. Dhamankar, S.; Webb, M.A. Chemically Specific Coarse-graining of Polymers: Methods and Prospects. Journal of Polymer Science 2021.

156. de Souza, R.M.; Ratochinski, R.H.; Karttunen, M.; Dias, L.G. Self-Assembly of Phosphocholine Derivatives Using the ELBA Coarse-Grained Model: Micelles, Bicelles, and Reverse Micelles. J. Chem. Inf. Model. 2020, 60, 522-536. 
157. Krishna, V.; Noid, W.G.; Voth, G.A. The Multiscale Coarse-Graining Method. IV. Transferring Coarse-Grained Potentials between Temperatures. J. Chem. Phys. 2009, 131, 024103.

158. de Souza, R.M.; Lourenço, T.C.; Amaral de Siqueira, L.J.; Karttunen, M.; Da Silva, J.L.F.; Dias, L.G. Development of CoarseGrained Force Field to Investigate Sodium-Ion Transport Mechanisms in Cyanoborate-Based Ionic Liquid. J. Mol. Liq. 2021, 338, 116648 .

159. Español, P.; Warren, P. Statistical Mechanics of Dissipative Particle Dynamics. EPL 1995, 30, 191.

160. Groot, R.D.; Warren, P.B. Dissipative Particle Dynamics: Bridging the Gap between Atomistic and Mesoscopic Simulation. J. Chem. Phys. 1997, 107, 4423-4435.

161. Hu, L.; Yan, Z.; Zhang, J.; Peng, X.; Mo, X.; Wang, A.; Chen, L. Surfactant Aggregates within Deep Eutectic Solvent-Assisted Synthesis of Hierarchical ZIF-8 with Tunable Porosity and Enhanced Catalytic Activity. J. Mater. Sci. 2019, 54, 11009-11023.

162. Fan, T.; Chen, L.; Qiu, S.; Yang, C.; Hu, L.; Peng, X.; Zhang, J.; Yan, Z. Synthesis of Hierarchical Porous ZIF-8/3DCNTs Composite Sensor for Ultrasensitive Detection of DA and DFT Studies. J. Electroanal. Chem. 2020, 878, 114541.

163. Fan, T.; Chen, L.; Xia, X.; Wu, Y.; Zhang, J.; Yin, K.; Liu, F.; Yan, Z. Dissipative Particle Dynamics Quantitative Simulation of the Formation Mechanism and Emulsification Driving Force of Deep Eutectic Solvent-Based Surfactant-Free and Water-Free Microemulsion. Ind. Eng. Chem. Res. 2021, 60, 3249-3258.

164. Kubat, M. An Introduction to Machine Learning; Springer, Cham, 2017; ISBN 9783319639123.

165. Bishop, C.M. Pattern Recognition and Machine Learning by Christopher M. Bishop; Springer Science+Business Media, LLC, 2006;.

166. Koutsoukos, S.; Philippi, F.; Malaret, F.; Welton, T. A Review on Machine Learning Algorithms for the Ionic Liquid Chemical Space. Chem. Sci. 2021, 12, 6820-6843.

167. Todeschini, R.; Consonni, V. Molecular Descriptors for Chemoinformatics: Volume I: Alphabetical Listing / Volume II: Appendices, References; John Wiley \& Sons, 2009; ISBN 9783527628773.

168. Shahbaz, K.; Baroutian, S.; Mjalli, F.S.; Hashim, M.A.; AlNashef, I.M. Densities of Ammonium and Phosphonium Based Deep Eutectic Solvents: Prediction Using Artificial Intelligence and Group Contribution Techniques. Thermochim. Acta 2012, 527, 5966.

169. Shahbaz, K.; Baroutian, S.; Mjalli, F.S.; Hashim, M.A.; AlNashef, I.M. Prediction of Glycerol Removal from Biodiesel Using Ammonium and Phosphunium Based Deep Eutectic Solvents Using Artificial Intelligence Techniques. Chemometrics Intellig. Lab. Syst. 2012, 118, 193-199.

170. Benguerba, Y.; Alnashef, I.M.; Erto, A.; Balsamo, M.; Ernst, B. A Quantitative Prediction of the Viscosity of Amine Based DESs Using So-Profile Molecular Descriptors. J. Mol. Struct. 2019, 1184, 357-363.

171. Alrugaibah, M.; Yagiz, Y.; Gu, L. Use Natural Deep Eutectic Solvents as Efficient Green Reagents to Extract Procyanidins and Anthocyanins from Cranberry Pomace and Predictive Modeling by RSM and Artificial Neural Networking. Sep. Purif. Technol. 2021, 255, 117720.

172. Fiyadh, S.S.; AlSaadi, M.A.; AlOmar, M.K.; Fayaed, S.S.; Hama, A.R.; Bee, S.; El-Shafie, A. The Modelling of Lead Removal from Water by Deep Eutectic Solvents Functionalized CNTs: Artificial Neural Network (ANN) Approach. Water Sci. Technol. 2017, $76,2413-2426$.

173. Fiyadh, S.S.; AlSaadi, M.A.; AlOmar, M.K.; Fayaed, S.S.; El-Shafie, A. Arsenic Removal from Water Using N,NDiethylethanolammonium Chloride Based DES-Functionalized CNTs: (NARX) Neural Network Approach. Journal of Water Supply: Research and Technology-Aqua 2018, 67, 531-542.

174. Fiyadh Seef Saadi; AlSaadi Mohammed Abdulhakim; AlOmar Mohamed Khalid; Fayaed Sabah Saadi; Mjalli Farouq S.; ElShafie Ahmed BTPC-Based DES-Functionalized CNTs for As3+ Removal from Water: NARX Neural Network Approach. J. Environ. Eng. 2018, 144, 04018070. 
175. Fiyadh, S.S.; AlOmar, M.K.; Binti Jaafar, W.Z.; AlSaadi, M.A.; Fayaed, S.S.; Binti Koting, S.; Lai, S.H.; Chow, M.F.; Ahmed, A.N.; El-Shafie, A. Artificial Neural Network Approach for Modelling of Mercury Ions Removal from Water Using Functionalized CNTs with Deep Eutectic Solvent. Int. J. Mol. Sci. 2019, 20, doi:10.3390/ijms20174206.

176. Dashti, A.; Raji, M.; Amani, P.; Baghban, A.; Mohammadi, A.H. Insight into the Estimation of Equilibrium CO2 Absorption by Deep Eutectic Solvents Using Computational Approaches. Sep. Sci. Technol. 2021, 56, 2351-2368.

177. Bagh, F.S.G.; Shahbaz, K.; Mjalli, F.S.; AlNashef, I.M.; Hashim, M.A. Electrical Conductivity of Ammonium and Phosphonium Based Deep Eutectic Solvents: Measurements and Artificial Intelligence-Based Prediction. Fluid Phase Equilib. 2013, $356,30-37$.

178. Sharma, M.; Dash, K.K. Deep Eutectic Solvent-based Microwave-assisted Extraction of Phytochemical Compounds from Black Jamun Pulp. J. Food Process Eng. 2021, 44, doi:10.1111/jfpe.13750.

179. Stupar, A.; Šeregelj, V.; Ribeiro, B.D.; Pezo, L.; Cvetanović, A.; Mišan, A.; Marrucho, I. Recovery of $\beta$-Carotene from Pumpkin Using Switchable Natural Deep Eutectic Solvents. Ultrason. Sonochem. 2021, 76, 105638.

180. Ghaedi, H.; Ayoub, M.; Sufian, S.; Murshid, G.; Farrukh, S.; Shariff, A.M. Investigation of Various Process Parameters on the Solubility of Carbon Dioxide in Phosphonium-Based Deep Eutectic Solvents and Their Aqueous Mixtures: Experimental and Modeling. Int. J. Greenhouse Gas Control 2017, 66, 147-158.

181. Xu, H.; Kong, Y.; Peng, J.; Song, X.; Liu, Y.; Su, Z.; Li, B.; Gao, C.; Tian, W. Comprehensive Analysis of Important Parameters of Choline Chloride-Based Deep Eutectic Solvent Pretreatment of Lignocellulosic Biomass. Bioresour. Technol. 2021, $319,124209$.

182. Kollau, L.J.B.M.; Tuinier, R.; Verhaak, J.; den Doelder, J.; Filot, I.A.W.; Vis, M. Design of Nonideal Eutectic Mixtures Based on Correlations with Molecular Properties. J. Phys. Chem. B 2020, 124, 5209-5219.

183. Huan, T.D.; Batra, R.; Chapman, J.; Krishnan, S.; Chen, L.; Ramprasad, R. A Universal Strategy for the Creation of Machine Learning-Based Atomistic Force Fields. npj Computational Materials 2017, 3.

184. Botu, V.; Ramprasad, R. Adaptive Machine Learning Framework to Accelerate Ab Initio Molecular Dynamics. Int. J. Quantum Chem. 2015, 115, 1074-1083.

185. Häse, F.; Fdez Galván, I.; Aspuru-Guzik, A.; Lindh, R.; Vacher, M. How Machine Learning Can Assist the Interpretation of Ab Initio Molecular Dynamics Simulations and Conceptual Understanding of Chemistry. Chem. Sci. 2019, 10, $2298-2307$.

186. Korolev, V.; Mitrofanov, A.; Korotcov, A.; Tkachenko, V. Graph Convolutional Neural Networks as "General-Purpose" Property Predictors: The Universality and Limits of Applicability. J. Chem. Inf. Model. 2020, 60, 22-28.

187. Jha, D.; Choudhary, K.; Tavazza, F.; Liao, W.-K.; Choudhary, A.; Campbell, C.; Agrawal, A. Enhancing Materials Property Prediction by Leveraging Computational and Experimental Data Using Deep Transfer Learning. Nat. Commun. 2019, $10,5316$.

188. Ramakrishnan, R.; Dral, P.O.; Rupp, M.; von Lilienfeld, O.A. Quantum Chemistry Structures and Properties of 134 Kilo Molecules. Sci Data 2014, 1, 140022.

189. Kirklin, S.; Saal, J.E.; Meredig, B.; Thompson, A.; Doak, J.W.; Aykol, M.; Rühl, S.; Wolverton, C. The Open Quantum Materials Database (OQMD): Assessing the Accuracy of DFT Formation Energies. npj Computational Materials 2015, 1, 1-15.

190. Rimsza, J.M.; Corrales, L.R. Adsorption Complexes of Copper and Copper Oxide in the Deep Eutectic Solvent 2:1 Urea-choline Chloride. Computational and Theoretical Chemistry 2012, 987, 57-61.

191. Zahn, S. Deep Eutectic Solvents: Similia Similibus Solvuntur? Phys. Chem. Chem. Phys. 2017, 19, 4041-4047.

192. Stefanovic, R.; Ludwig, M.; Webber, G.B.; Atkin, R.; Page, A.J. Nanostructure, Hydrogen Bonding and Rheology in Choline Chloride Deep Eutectic Solvents as a Function of the Hydrogen Bond Donor. Phys. Chem. Chem. Phys. 2017, 19, 3297-3306.

193. Migliorati, V.; Sessa, F.; D'Angelo, P. Deep Eutectic Solvents: A Structural Point of View on the Role of the Cation. Chemical Physics Letters: X 2019, 2, 100001.

194. Sun, H.; Li, Y.; Wu, X.; Li, G. Theoretical Study on the Structures and Properties of Mixtures of Urea and Choline Chloride. Journal of Molecular Modeling 2013, 19, 2433-2441. 
195. Kaur, S.; Malik, A.; Kashyap, H.K. Anatomy of Microscopic Structure of Ethaline Deep Eutectic Solvent Decoded through Molecular Dynamics Simulations. J. Phys. Chem. B 2019, 123, 8291-8299.

196. Ferreira, E.S.C.; Voroshylova, I.V.; Pereira, C.M.; D S Cordeiro, M.N. Improved Force Field Model for the Deep Eutectic Solvent Ethaline: Reliable Physicochemical Properties. J. Phys. Chem. B 2016, 120, 10124-10137.

197. Bonomo, M.; Gontrani, L.; Capocefalo, A.; Sarra, A.; Nucara, A.; Carbone, M.; Postorino, P.; Dini, D. A Combined Electrochemical, Infrared and EDXD Tool to Disclose Deep Eutectic Solvents Formation When One Precursor Is Liquid: Glyceline as Case Study. J. Mol. Liq. 2020, 319, 114292.

198. Ferreira, E.S.C.; Voroshylova, I.V.; Figueiredo, N.M.; Pereira, C.M.; Cordeiro, M.N.D.S. Computational and Experimental Study of Propeline: A Choline Chloride Based Deep Eutectic Solvent. J. Mol. Liq. 2020, 298, 111978.

199. Ferreira, E.S.C.; Voroshylova, I.V.; Figueiredo, N.M.; Cordeiro, M.N.D.S. Molecular Dynamic Study of Alcohol-Based Deep Eutectic Solvents. J. Chem. Phys. 2021, 155, 064506.

200. Paul, N.; Naik, P.K.; Ribeiro, B.D.; Gooh Pattader, P.S.; Marrucho, I.M.; Banerjee, T. Molecular Dynamics Insights and Water Stability of Hydrophobic Deep Eutectic Solvents Aided Extraction of Nitenpyram from an Aqueous Environment. J. Phys. Chem. B 2020, 124, 7405-7420.

201. Fu, N.; Li, L.; Liu, K.; Kim, C.K.; Li, J.; Zhu, T.; Li, J.; Tang, B. A Choline Chloride-Acrylic Acid Deep Eutectic Solvent Polymer Based on Fe3O4 Particles and MoS2 Sheets (poly(ChCl-AA DES)@Fe3O4@MoS2) with Specific Recognition and Good Antibacterial Properties for $\beta$-Lactoglobulin in Milk. Talanta 2019, 197, 567-577.

202. Gontrani, L.; Plechkova, N.V.; Bonomo, M. In-Depth Physico-Chemical and Structural Investigation of a Dicarboxylic Acid/Choline Chloride Natural Deep Eutectic Solvent (NADES): A Spotlight on the Importance of a Rigorous Preparation Procedure. ACS Sustainable Chem. Eng. 2019, 7, 12536-12543.

203. Saha, M.; Rahman, M.S.; Hossain, M.N.; Raynie, D.E.; Halim, M.A. Molecular and Spectroscopic Insights of a Choline Chloride Based Therapeutic Deep Eutectic Solvent. J. Phys. Chem. A 2020, 124, 4690-4699.

204. Bonab, P.J.; Esrafili, M.D.; Ebrahimzadeh, A.R.; Sardroodi, J.J. Molecular Dynamics Simulations of Choline Chloride and Phenyl Propionic Acid Deep Eutectic Solvents: Investigation of Structural and Dynamics Properties. J. Mol. Graph. Model. 2021, 106, 107908.

205. Jahanbakhsh Bonab, P.; Rastkar Ebrahimzadeh, A.; Jahanbin Sardroodi, J. Insights into the Interactions and Dynamics of a DES Formed by Phenyl Propionic Acid and Choline Chloride. Sci. Rep. 2021, 11, 6384.

206. Stott, P.W.; Williams, A.C.; Barry, B.W. Transdermal Delivery from Eutectic Systems: Enhanced Permeation of a Model Drug, Ibuprofen. J. Control. Release 1998, 50, 297-308.

207. Aroso, I.M.; Silva, J.C.; Mano, F.; Ferreira, A.S.D.; Dionísio, M.; Sá-Nogueira, I.; Barreiros, S.; Reis, R.L.; Paiva, A.; Duarte, A.R.C. Dissolution Enhancement of Active Pharmaceutical Ingredients by Therapeutic Deep Eutectic Systems. Eur. J. Pharm. Biopharm. 2016, 98, 57-66.

208. Korneev, S.M. Hydrocinnamic Acids: Application and Strategy of Synthesis. Synthesis 2013, 45, 1000-1015.

209. Perkins, S.L.; Painter, P.; Colina, C.M. Molecular Dynamic Simulations and Vibrational Analysis of an Ionic Liquid Analogue. J. Phys. Chem. B 2013, 117, 10250-10260.

210. van den Bruinhorst, A.; Spyriouni, T.; Hill, J.-R.; Kroon, M.C. Experimental and Molecular Modeling Evaluation of the Physicochemical Properties of Proline-Based Deep Eutectic Solvents. J. Phys. Chem. B 2018, 122, 369-379.

211. Migliorati, V.; D'Angelo, P. Deep Eutectic Solvents: A Structural Point of View on the Role of the Anion. Chem. Phys. Lett. 2021, $777,138702$.

212. Cerajewski, U.; Träger, J.; Henkel, S.; Roos, A.H.; Brehm, M.; Hinderberger, D. Nanoscopic Structures and Molecular Interactions Leading to a Dystectic and Two Eutectic Points in [EMIm] [Cl]/urea Mixtures. Phys. Chem. Chem. Phys. 2018, 20, 29591-29600. 
213. Naik, P.K.; Paul, S.; Banerjee, T. Physiochemical Properties and Molecular Dynamics Simulations of Phosphonium and Ammonium Based Deep Eutectic Solvents. J. Solution Chem. 2019, 48, 1046-1065.

214. Kussainova, D.; Shah, D. Structure of Monoethanolamine Based Type III DESs: Insights from Molecular Dynamics Simulations. Fluid Phase Equilib. 2019, 482, 112-117.

215. van Osch, D.J.G.P.; Zubeir, L.F.; van den Bruinhorst, A.; Rocha, M.A.A.; Kroon, M.C. Hydrophobic Deep Eutectic Solvents as Water-Immiscible Extractants. Green Chem. 2015, 17, 4518-4521.

216. Ribeiro, B.D.; Florindo, C.; Iff, L.C.; Coelho, M.A.Z.; Marrucho, I.M. Menthol-Based Eutectic Mixtures: Hydrophobic Low Viscosity Solvents. ACS Sustainable Chem. Eng. 2015, 3, 2469-2477.

217. van Osch, D.J.G.P.; Dietz, C.H.J.T.; Warrag, S.E.E.; Kroon, M.C. The Curious Case of Hydrophobic Deep Eutectic Solvents: A Story on the Discovery, Design, and Applications. ACS Sustain. Chem. Eng. 2020, doi:10.1021/acssuschemeng.0c00559.

218. S Salehi, H.; Celebi, A.T.; Vlugt, T.J.H.; Moultos, O.A. Thermodynamic, Transport, and Structural Properties of Hydrophobic Deep Eutectic Solvents Composed of Tetraalkylammonium Chloride and Decanoic Acid. J. Chem. Phys. 2021, $154,144502$.

219. Abbas, U.L.; Qiao, Q.; Nguyen, M.T.; Shi, J.; Shao, Q. Molecular Dynamics Simulations of Heterogeneous Hydrogen Bond Environment in Hydrophobic Deep Eutectic Solvents. AIChE J. 2021, doi:10.1002/aic.17382.

220. Alizadeh, V.; Geller, D.; Malberg, F.; Sánchez, P.B.; Padua, A.; Kirchner, B. Strong Microheterogeneity in Novel Deep Eutectic Solvents. Chemphyschem 2019, 20, 1786-1792.

221. Cui, Y.; Kuroda, D.G. Evidence of Molecular Heterogeneities in Amide-Based Deep Eutectic Solvents. J. Phys. Chem. A 2018, 122, 1185-1193.

222. Kaur, S.; Gupta, A.; Kashyap, H.K. Nanoscale Spatial Heterogeneity in Deep Eutectic Solvents. J. Phys. Chem. B 2016, 120, 67126720.

223. Kaur, S.; Kashyap, H.K. Unusual Temperature Dependence of Nanoscale Structural Organization in Deep Eutectic Solvents. J. Phys. Chem. B 2018, 122, 5242-5250.

224. Das, S.; Mukherjee, B.; Biswas, R. Microstructures and Their Lifetimes in Acetamide/electrolyte Deep Eutectics: Anion Dependence. J. Chem. Sci. 2017, 129, 939-951.

225. Banerjee, S.; Ghorai, P.K.; Das, S.; Rajbangshi, J.; Biswas, R. Heterogeneous Dynamics, Correlated Time and Length Scales in Ionic Deep Eutectics: Anion and Temperature Dependence. J. Chem. Phys. 2020, 153, 234502.

226. Ogawa, H.; Mori, H. Lithium Salt/amide-Based Deep Eutectic Electrolytes for Lithium-Ion Batteries: Electrochemical, Thermal and Computational Study. Phys. Chem. Chem. Phys. 2020, 22, 8853-8863.

227. Li, Y.; Ali, M.C.; Yang, Q.; Zhang, Z.; Bao, Z.; Su, B.; Xing, H.; Ren, Q. Hybrid Deep Eutectic Solvents with Flexible HydrogenBonded Supramolecular Networks for Highly Efficient Uptake of NH3. ChemSusChem 2017, 10, 3368-3377.

228. Jangir, A.K.; Nain, A.K.; Kuperkar, K. Insight into Structural Properties and Molecular Interactions of Maline (choline Chloride + Malonic Acid) and 1, 4- Butanediol Based Pseudo-Binary Mixture: A Thermophysical, Spectral, and Simulation Portrayal. J. Mol. Liq. 2021, 334, 116050.

229. Srinivasan, H.; Sharma, V.K.; Mitra, S.; Biswas, R.; Mukhopadhyay, R. Dynamics in Acetamide+LiNO3 Deep Eutectic Solvents. Physica B Condens. Matter 2019, 562, 13-16.

230. Srinivasan, H.; Sharma, V.K.; Mukhopadhyay, R.; Mitra, S. Solvation and Transport of Lithium Ions in Deep Eutectic Solvents. J. Chem. Phys. 2020, 153, 104505.

231. Srinivasan, H.; Sharma, V.K.; Sakai, V.G.; Embs, J.P.; Mukhopadhyay, R.; Mitra, S. Transport Mechanism of Acetamide in Deep Eutectic Solvents. J. Phys. Chem. B 2020, 124, 1509-1520.

232. Das, A.; Das, S.; Biswas, R. Fast Fluctuations in Deep Eutectic Melts: Multi-Probe Fluorescence Measurements and All-Atom Molecular Dynamics Simulation Study. Chem. Phys. Lett. 2013, 581, 47-51. 
233. Guchhait, B.; Das, S.; Daschakraborty, S.; Biswas, R. Interaction and Dynamics of (alkylamide + Electrolyte) Deep Eutectics: Dependence on Alkyl Chain-Length, Temperature, and Anion Identity. J. Chem. Phys. 2014, 140, 104514.

234. Das, S.; Biswas, R.; Mukherjee, B. Orientational Jumps in (acetamide + Electrolyte) Deep Eutectics: Anion Dependence. J. Phys. Chem. B 2015, 119, 11157-11168.

235. Das, A.; Das, S.; Biswas, R. Density Relaxation and Particle Motion Characteristics in a Non-Ionic Deep Eutectic Solvent (acetamide + Urea): Time-Resolved Fluorescence Measurements and All-Atom Molecular Dynamics Simulations. J. Chem. Phys. 2015, 142, 034505.

236. Mukherjee, K.; Das, S.; Tarif, E.; Barman, A.; Biswas, R. Dielectric Relaxation in Acetamide + Urea Deep Eutectics and Neat Molten Urea: Origin of Time Scales via Temperature Dependent Measurements and Computer Simulations. J. Chem. Phys. 2018, $149,124501$.

237. Rajbangshi, J.; Mukherjee, K.; Biswas, R. Heterogeneous Orientational Relaxations and Translation-Rotation Decoupling in (choline Chloride + Urea) Deep Eutectic Solvents: Investigation through Molecular Dynamics Simulations and Dielectric Relaxation Measurements. J. Phys. Chem. B 2021, 125, 5920-5936.

238. Laage, D.; Hynes, J.T. A Molecular Jump Mechanism of Water Reorientation. Science 2006, 311, 832-835.

239. Titantah, J.T.; Karttunen, M. Long-Time Correlations and Hydrophobe-Modified Hydrogen-Bonding Dynamics in Hydrophobic Hydration. J. Am. Chem. Soc. 2012, 134, 9362-9368.

240. MacKerell, A.D.; Wiorkiewicz-Kuczera, J.; Karplus, M. An All-Atom Empirical Energy Function for the Simulation of Nucleic Acids. J. Am. Chem. Soc. 1995, 117, 11946-11975.

241. Best, R.B.; Zhu, X.; Shim, J.; Lopes, P.E.M.; Mittal, J.; Feig, M.; MacKerell, A.D. Optimization of the Additive CHARMM AllAtom Protein Force Field Targeting Improved Sampling of the Backbone $\phi, \psi$ and Side-Chain $\chi 1$ and $\chi 2$ Dihedral Angles. J. Chem. Theory Comput. 2012, 8, 3257-3273.

242. Jensen, K.P.; Jorgensen, W.L. Halide, Ammonium, and Alkali Metal Ion Parameters for Modeling Aqueous Solutions. J. Chem. Theory Comput. 2006, 2, 1499-1509.

243. Cadena, C.; Maginn, E.J. Molecular Simulation Study of Some Thermophysical and Transport Properties of Triazolium-Based Ionic Liquids. J. Phys. Chem. B 2006, 110, 18026-18039.

244. Papoyan, G.; Gu, K.-J.; Wiorkiewicz-Kuczera, J.; Kuczera, K.; Bowman-James, K. Molecular Dynamics Simulations of Nitrate Complexes with Polyammonium Macrocycles: Insight on Phosphoryl Transfer Catalysis. J. Am. Chem. Soc. 1996, 118, 1354-1364.

245. Smith, L.J.; Berendsen, H.J.C.; van Gunsteren, W.F. Computer Simulation of Urea-Water Mixtures: A Test of Force Field Parameters for Use in Biomolecular Simulation. The Journal of Physical Chemistry B 2004, 108, 1065-1071.

246. Mardani, A.; Streimikiene, D.; Cavallaro, F.; Loganathan, N.; Khoshnoudi, M. Carbon Dioxide (CO2) Emissions and Economic Growth: A Systematic Review of Two Decades of Research from 1995 to 2017. Sci. Total Environ. 2019, 649, 31-49.

247. Kumar, M.; Sundaram, S.; Gnansounou, E.; Larroche, C.; Thakur, I.S. Carbon Dioxide Capture, Storage and Production of Biofuel and Biomaterials by Bacteria: A Review. Bioresour. Technol. 2018, 247, 1059-1068.

248. Mukherjee, A.; Okolie, J.A.; Abdelrasoul, A.; Niu, C.; Dalai, A.K. Review of Post-Combustion Carbon Dioxide Capture Technologies Using Activated Carbon. Journal of Environmental Sciences 2019, 83, 46-63.

249. García, G.; Atilhan, M.; Aparicio, S. Interfacial Properties of Deep Eutectic Solvents Regarding to CO2 Capture. J. Phys. Chem. C 2015, 119, 21413-21425.

250. Taghizadeh, M.; Taghizadeh, A.; Vatanpour, V.; Ganjali, M.R.; Saeb, M.R. Deep Eutectic Solvents in Membrane Science and Technology: Fundamental, Preparation, Application, and Future Perspective. Sep. Purif. Technol. 2021, $258,118015$.

251. Karadas, F.; Atilhan, M.; Aparicio, S. Review on the Use of Ionic Liquids (ILs) as Alternative Fluids for CO2 Capture and Natural Gas Sweetening. Energy Fuels 2010, 24, 5817-5828. 
252. Peters, L.; Hussain, A.; Follmann, M.; Melin, T.; Hägg, M.-B. CO2 Removal from Natural Gas by Employing Amine Absorption and Membrane technology-A Technical and Economical Analysis. Chem. Eng. J. 2011, 172, 952-960.

253. Kussainova, D.; Shah, D. Monoethanolamine Based DESs for CO2 Absorption: Insights from Molecular Dynamics Simulations. Sep. Purif. Technol. 2020, 231, 115931.

254. Haider, M.B.; Jha, D.; Marriyappan Sivagnanam, B.; Kumar, R. Modelling and Simulation of CO2 Removal from Shale Gas Using Deep Eutectic Solvents. Journal of Environmental Chemical Engineering 2019, 7, 102747.

255. Lin, H.; Gong, K.; Ying, W.; Chen, D.; Zhang, J.; Yan, Y.; Peng, X. CO2 -Philic Separation Membrane: Deep Eutectic Solvent Filled Graphene Oxide Nanoslits. Small 2019, 15, e1904145.

256. Shen, Y.; Abedin, R.; Hung, F.R. On the Performance of Confined Deep Eutectic Solvents and Ionic Liquids for Separations of Carbon Dioxide from Methane: Molecular Dynamics Simulations. Langmuir 2019, 35, 3658-3671.

257. Lin, H.; Gong, K.; Hykys, P.; Chen, D.; Ying, W.; Sofer, Z.; Yan, Y.; Li, Z.; Peng, X. Nanoconfined Deep Eutectic Solvent in Laminated MXene for Efficient CO2 Separation. Chem. Eng. J. 2021, 405, 126961.

258. Alioui, O.; Benguerba, Y.; Alnashef, I.M. Investigation of the CO2-Solubility in Deep Eutectic Solvents Using COSMO-RS and Molecular Dynamics Methods. J. Mol. Liq. 2020, 307, 113005.

259. Wang, J.; Cheng, H.; Song, Z.; Chen, L.; Deng, L.; Qi, Z. Carbon Dioxide Solubility in Phosphonium-Based Deep Eutectic Solvents: An Experimental and Molecular Dynamics Study. Ind. Eng. Chem. Res. 2019, 58, 17514-17523.

260. Li, C.; Zhang, J.; Li, Z.; Yin, J.; Cui, Y.; Liu, Y.; Yang, G. Extraction Desulfurization of Fuels with "metal Ions" Based Deep Eutectic Solvents (MDESs). Green Chem. 2016, 18, 3789-3795.

261. El-hoshoudy, A.N.; Soliman, F.S.; Abd El-Aty, D.M. Extractive Desulfurization Using Choline Chloride-Based DES/molybdate Nanofluids; Experimental and Theoretical Investigation. J. Mol. Liq. 2020, 318, 114307.

262. Shah, D.; Gapeyenko, D.; Urakpayev, A.; Torkmahalleh, M. Molecular Dynamics Simulations on Extractive Desulfurization of Fuels by Tetrabutylammonium Chloride Based Deep Eutectic Solvents. J. Mol. Liq. 2019, 274, 254-260.

263. Kumar, N.; Naik, P.K.; Banerjee, T. Molecular Modeling Insights in the Extraction of Benzene from Hydrocarbon Stream Using Deep Eutectic Solvent. J. Mol. Liq. 2020, 317, 113909.

264. Naik, P.K.; Mohan, M.; Banerjee, T.; Paul, S.; Goud, V.V. Molecular Dynamic Simulations for the Extraction of Quinoline from Heptane in the Presence of a Low-Cost Phosphonium-Based Deep Eutectic Solvent. J. Phys. Chem. B 2018, 122, $4006-4015$.

265. Zhang, Z.; Liu, X.; Yao, D.; Ma, Z.; Zhao, J.; Zhang, W.; Cui, P.; Ma, Y.; Zhu, Z.; Wang, Y. Molecular Kinetic Extraction Mechanism Analysis of 1-Butanol from N-Heptane-1-Butanol by Choline-Based DESs as Extractants. J. Mol. Liq. 2021, 322, 114665.

266. Kumari, P.; Shobhna; Kaur, S.; Kashyap, H.K. Influence of Hydration on the Structure of Reline Deep Eutectic Solvent: A Molecular Dynamics Study. ACS Omega 2018, 3, 15246-15255.

267. Weng, L.; Toner, M. Janus-Faced Role of Water in Defining Nanostructure of Choline Chloride/glycerol Deep Eutectic Solvent. Phys. Chem. Chem. Phys. 2018, 20, 22455-22462.

268. Huang, L.; Bittner, J.P.; Domínguez de María, P.; Jakobtorweihen, S.; Kara, S. Modeling Alcohol Dehydrogenase Catalysis in Deep Eutectic Solvent/Water Mixtures. Chembiochem 2020, 21, 811-817.

269. Dai, Y.; Witkamp, G.-J.; Verpoorte, R.; Choi, Y.H. Tailoring Properties of Natural Deep Eutectic Solvents with Water to Facilitate Their Applications. Food Chem. 2015, 187, 14-19.

270. Yadav, A.; Pandey, S. Densities and Viscosities of (choline Chloride+ Urea) Deep Eutectic Solvent and Its Aqueous Mixtures in the Temperature Range 293.15 K to 363.15 K. J. Chem. Eng. Data 2014.

271. Kumari, P.; Kumari, M.; Kashyap, H.K. How Pure and Hydrated Reline Deep Eutectic Solvents Affect the Conformation and Stability of Lysozyme: Insights from Atomistic Molecular Dynamics Simulations. J. Phys. Chem. B 2020, 124, 11919-11927. 
272. Sapir, L.; Harries, D. Restructuring a Deep Eutectic Solvent by Water: The Nanostructure of Hydrated Choline Chloride/Urea. J. Chem. Theory Comput. 2020, 16, 3335-3342.

273. Aryafard, M.; Karimi, A.; Harifi-Mood, A.R.; Minofar, B. Molecular Dynamics Simulations, Solvatochromic Parameters, and Preferential Solvation in Aqueous Solutions of Ethaline, Ethylene Glycol, and Choline Chloride. J. Chem. Eng. Data 2020, 65, 4556-4566.

274. Alizadeh, V.; Malberg, F.; Pádua, A.A.H.; Kirchner, B. Are There Magic Compositions in Deep Eutectic Solvents? Effects of Composition and Water Content in Choline Chloride/Ethylene Glycol from Ab Initio Molecular Dynamics. J. Phys. Chem. B 2020, 124, 7433-7443.

275. Bezerra-Neto, J.R.; Bezerra, L.L.; Sousa, N.G.; Dos Santos, L.P.M.; Marinho, E.S.; Monteiro, N.K.V.; Correia, A.N.; de Lima-Neto, P. Molecular Approach about the Effect of Water on the Electrochemical Behaviour of Ag+ Ions in Urea-Choline Chloride-Water Mixture. J. Mol. Model. 2020, 26, 339.

276. Busato, M.; Di Lisio, V.; Del Giudice, A.; Tomai, P.; Migliorati, V.; Galantini, L.; Gentili, A.; Martinelli, A.; D’ Angelo, P. Transition from Molecular- to Nano-Scale Segregation in a Deep Eutectic Solvent - Water Mixture. J. Mol. Liq. 2021, $331,115747$.

277. Ghorpade, U.V.; Suryawanshi, M.P.; Shin, S.W.; Wang, X.; Jo, E.; Bae, H.; Park, K.; Ha, J.-S.; Kolekar, S.S.; Kim, J.H. Eutectic Solvent-Mediated Selective Synthesis of Cu-Sb-S-Based Nanocrystals: Combined Experimental and Theoretical Studies toward Highly Efficient Water Splitting. J. Mater. Chem. A Mater. Energy Sustain. 2018, 6, 19798-19809.

278. Celebi, A.T.; Vlugt, T.J.H.; Moultos, O.A. Structural, Thermodynamic, and Transport Properties of Aqueous Reline and Ethaline Solutions from Molecular Dynamics Simulations. J. Phys. Chem. B 2019, 123, 11014-11025.

279. Celebi, A.T.; Vlugt, T.J.H.; Moultos, O.A. Thermal Conductivity of Aqueous Solutions of Reline, Ethaline, and Glyceline Deep Eutectic Solvents; a Molecular Dynamics Simulation Study. Mol. Phys. 2021, e1876263.

280. Bezerra-Neto, J.R.; Sousa, N.G.; Dos Santos, L.P.M.; Correia, A.N.; de Lima-Neto, P. The Effect of Water on the Physicochemical Properties of an Ethylene Glycol and Choline Chloride Mixture Containing Cu2+ Ions: Electrochemical Results and Dynamic Molecular Simulation Approach. Phys. Chem. Chem. Phys. 2018, 20, 9321-9327.

281. Lukaczynska-Anderson, M.; Mamme, M.H.; Ceglia, A.; Van den Bergh, K.; De Strycker, J.; De Proft, F.; Terryn, H.; Ustarroz, J. The Role of Hydrogen Bond Donor and Water Content on the Electrochemical Reduction of Ni2+ from Solvents - an Experimental and Modelling Study. Phys. Chem. Chem. Phys. 2020, 22, 16125-16135.

282. Baz, J.; Held, C.; Pleiss, J.; Hansen, N. Thermophysical Properties of Glyceline-Water Mixtures Investigated by Molecular Modelling. Phys. Chem. Chem. Phys. 2019, 21, 6467-6476.

283. Shehata, M.; Unlu, A.; Sezerman, U.; Timucin, E. Lipase and Water in a Deep Eutectic Solvent: Molecular Dynamics and Experimental Studies of the Effects of Water-In-Deep Eutectic Solvents on Lipase Stability. J. Phys. Chem. B 2020, 124, 8801-8810.

284. Paul, R.; Mitra, A.; Paul, S. Phase Separation Property of a Hydrophobic Deep Eutectic Solvent-Water Binary Mixture: A Molecular Dynamics Simulation Study. J. Chem. Phys. 2021, 154, 244504.

285. Salehi, H.S.; Moultos, O.A.; Vlugt, T.J.H. Interfacial Properties of Hydrophobic Deep Eutectic Solvents with Water. J. Phys. Chem. B 2021, doi:10.1021/acs.jpcb.1c07796.

286. Atilhan, M.; Costa, L.T.; Aparicio, S. Elucidating the Properties of Graphene-Deep Eutectic Solvents Interface. Langmuir 2017, $33,5154-5165$.

287. Shen, Y.; He, X.; Hung, F.R. Structural and Dynamical Properties of a Deep Eutectic Solvent Confined Inside a Slit Pore. J. Phys. Chem. C 2015, 119, 24489-24500.

288. Mamme, M.H.; Moors, S.L.C.; Terryn, H.; Deconinck, J.; Ustarroz, J.; De Proft, F. Atomistic Insight into the Electrochemical Double Layer of Choline Chloride-Urea Deep Eutectic Solvents: Clustered Interfacial Structuring. J. Phys. Chem. Lett. 2018, 9, 6296-6304. 
289. Shen, Y.; Hung, F.R. A Molecular Simulation Study of Carbon Dioxide Uptake by a Deep Eutectic Solvent Confined in Slit Nanopores. J. Phys. Chem. C 2017, 121, 24562-24575.

290. Safavi, A.; Shekarnoush, M.; Ajamian, M.; Zolghadr, A.R. High-Yield Synthesis, Characterization, Self-Assembly of Extremely Thin Gold Nanosheets in Sugar Based Deep Eutectic Solvents and Their High Electrocatalytic Activity. J. Mol. Liq. 2019, 279, 208-223.

291. Rozas, S.; Atilhan, M.; Aparicio, S. Deep Eutectic Solvent Reline at 2D Nanomaterial Interfaces. J. Phys. Chem. B 2020, 124, 11971206.

292. Shakourian-Fard, M.; Taimoory, S.M.; Ghenaatian, H.R.; Kamath, G.; Trant, J.F. A DFT Study of the Adsorption of Deep Eutectic Solvents onto Graphene and Defective Graphene Nanoflakes. J. Mol. Liq. 2021, 327, 114850.

293. Zec, N.; Mangiapia, G.; Zheludkevich, M.L.; Busch, S.; Moulin, J.-F. Revealing the Interfacial Nanostructure of a Deep Eutectic Solvent at a Solid Electrode. Phys. Chem. Chem. Phys. 2020, 22, 12104-12112.

294. Patidar, P.; Kanoje, B.; Bahadur, A.; Kuperkar, K.; Ray, D.; Aswal, V.K.; Wang, M.; Chen, L.-J.; Bahadur, P. Micellar Characteristics of an Amphiphilic Star-Block Copolymer in DES-Water Mixture. Colloid Polym. Sci. 2021, 299, 117-128.

295. Elbourne, A.; Meftahi, N.; Greaves, T.L.; McConville, C.F.; Bryant, G.; Bryant, S.J.; Christofferson, A.J. Nanostructure of a Deep Eutectic Solvent at Solid Interfaces. J. Colloid Interface Sci. 2021, 591, 38-51.

296. Atilhan, M.; Aparicio, S. Deep Eutectic Solvents on the Surface of Face Centered Cubic Metals. J. Phys. Chem. C 2016, 120, 1040010409.

297. Atilhan, M.; Aparicio, S. Molecular Dynamics Simulations of Metal Nanoparticles in Deep Eutectic Solvents. J. Phys. Chem. C 2018, 122, 18029-18039.

298. Gao, Q.; Wu, N.; Qin, Y.; Laaksonen, A.; Zhu, Y.; Ji, X.; Lu, X. Molecular Insight into Wetting Behavior of Deep Eutectic Solvent Droplets on Ionic Substrates: A Molecular Dynamics Study. J. Mol. Liq. 2020, 319, 114298.

299. Atilhan, M.; Aparicio, S. Molecular Dynamics Simulations of Mixed Deep Eutectic Solvents and Their Interaction with Nanomaterials. J. Mol. Liq. 2019, 283, 147-154.

300. Kaur, S.; Sharma, S.; Kashyap, H.K. Bulk and Interfacial Structures of Reline Deep Eutectic Solvent: A Molecular Dynamics Study. J. Chem. Phys. 2017, 147, 194507.

301. Malik, A.; Dhattarwal, H.S.; Kashyap, H.K. Molecular Dynamics Investigation of Wetting-Dewetting Behavior of Reline DES Nanodroplet at Model Carbon Material. J. Chem. Phys. 2020, 153, 164704.

302. Rozas, S.; Atilhan, M.; Aparicio, S. Insights on (C, BN, Si, Ge, MoS2) Nanotubes in Reline Deep Eutectic Solvent. J. Phys. Chem. B 2020, 124, 3556-3567.

303. Castro, V.I.B.; Craveiro, R.; Silva, J.M.; Reis, R.L.; Paiva, A.; C Duarte, A.R. Natural Deep Eutectic Systems as Alternative Nontoxic Cryoprotective Agents. Cryobiology 2018, 83, 15-26.

304. Das, A.; Mukhopadhyay, C. Urea-Mediated Protein Denaturation: A Consensus View. The Journal of Physical Chemistry B 2009, $113,12816-12824$.

305. Lim, W.K.; Rösgen, J.; Englander, S.W. Urea, but Not Guanidinium, Destabilizes Proteins by Forming Hydrogen Bonds to the Peptide Group. Proc. Natl. Acad. Sci. U. S. A. 2009, 106, 2595-2600.

306. Rossky, P.J. Protein Denaturation by Urea: Slash and Bond. Proc. Natl. Acad. Sci. U. S. A. 2008, 105, 16825-16826.

307. Gorke, J.T.; Srienc, F.; Kazlauskas, R.J. Hydrolase-Catalyzed Biotransformations in Deep Eutectic Solvents. Chem. Commun. 2008, 1235-1237.

308. Monhemi, H.; Housaindokht, M.R.; Moosavi-Movahedi, A.A.; Bozorgmehr, M.R. How a Protein Can Remain Stable in a Solvent with High Content of Urea: Insights from Molecular Dynamics Simulation of Candida Antarctica Lipase B in Urea : Choline Chloride Deep Eutectic Solvent. Phys. Chem. Chem. Phys. 2014, 16, 14882-14893. 
309. Sarkar, S.; Ghosh, S.; Chakrabarti, R. Ammonium Based Stabilizers Effectively Counteract Urea-Induced Denaturation in a Small Protein: Insights from Molecular Dynamics Simulations. RSC Adv. 2017, 7, 52888-52906.

310. Maity, A.; Sarkar, S.; Theeyancheri, L.; Chakrabarti, R. Choline Chloride as a Nano-Crowder Protects HP-36 from Urea-Induced Denaturation: Insights from Solvent Dynamics and Protein-Solvent Interactions. Chemphyschem 2020, 21, 552-567.

311. Pal, S.; Roy, R.; Paul, S. Potential of a Natural Deep Eutectic Solvent, Glyceline, in the Thermal Stability of the Trp-Cage MiniProtein. J. Phys. Chem. B 2020, 124, 7598-7610.

312. Pal, S.; Paul, S. Effect of Hydrated and Nonhydrated Choline Chloride-Urea Deep Eutectic Solvent (Reline) on ThrombinBinding G-Quadruplex Aptamer (TBA): A Classical Molecular Dynamics Simulation Study. J. Phys. Chem. C 2019, 123, 1168611698.

313. Pal, S.; Paul, S. Understanding The Role of Reline, a Natural DES, on Temperature-Induced Conformational Changes of C-Kit G-Quadruplex DNA: A Molecular Dynamics Study. J. Phys. Chem. B 2020, 124, 3123-3136.

314. Atilhan, M.; Costa, L.T.; Aparicio, S. On the Behaviour of Aqueous Solutions of Deep Eutectic Solvents at Lipid Biomembranes. J. Mol. Liq. 2017, 247, 116-125.

315. Chen, Y.; Mu, T. Application of Deep Eutectic Solvents in Biomass Pretreatment and Conversion. Green Energy E Environment 2019, 4, 95-115.

316. Mohan, M.; Naik, P.K.; Banerjee, T.; Goud, V.V.; Paul, S. Solubility of Glucose in Tetrabutylammonium Bromide Based Deep Eutectic Solvents: Experimental and Molecular Dynamic Simulations. Fluid Phase Equilib. 2017, 448, 168-177.

317. Fu, H.; Wang, X.; Sang, H.; Hou, Y.; Chen, X.; Feng, X. Dissolution Behavior of Microcrystalline Cellulose in DBU-Based Deep Eutectic Solvents: Insights from Spectroscopic Investigation and Quantum Chemical Calculations. J. Mol. Liq. 2020, 299 , 112140.

318. Sánchez-Badillo, J.A.; Gallo, M.; Rutiaga-Quiñones, J.G.; López-Albarrán, P. Solvent Behavior of an Ionic Liquid Set around a Cellulose I $\beta$ Crystallite Model through Molecular Dynamics Simulations. Cellulose 2021, 28, 6767-6795.

319. Muley, P.D.; Mobley, J.K.; Tong, X.; Novak, B.; Stevens, J.; Moldovan, D.; Shi, J.; Boldor, D. Rapid Microwave-Assisted Biomass Delignification and Lignin Depolymerization in Deep Eutectic Solvents. Energy Convers. Manage. 2019, 196, $1080-1088$.

320. Provatas, N.; Elder, K. Phase-Field Methods in Materials Science and Engineering; Wiley-VCH Verlag GmbH \& Co. KGaA, 2010;.

321. Steinbach, I. Phase-Field Models in Materials Science. Modell. Simul. Mater. Sci. Eng. 2009, 17, 073001.

322. Boettinger, W.J.; Warren, J.A.; Beckermann, C.; Karma, A. Phase-Field Simulation of Solidification. Annu. Rev. Mater. Res. 2002, $32,163 ? 194$.

323. Humadi, H.; Ofori-Opoku, N.; Provatas, N.; Hoyt, J.J. Atomistic Modeling of Solidification Phenomena Using the Phase-FieldCrystal Model. JOM 2013, 65, 1103-1110.

324. Grossmann, B.; Elder, K.R.; Grant, M.; Kosterlitz, J.M. Directional Solidification in Two and Three Dimensions. Phys. Rev. Lett. 1993, 71, 3323-3326.

325. Elder, K.R.; Katakowski, M.; Haataja, M.; Grant, M. Modeling Elasticity in Crystal Growth. Phys. Rev. Lett. $2002,88,245701$.

326. Alster, E.; Elder, K.R.; Voorhees, P.W. Displacive Phase-Field Crystal Model. Physical Review Materials 2020, 4, doi:10.1103/physrevmaterials.4.013802.

327. Courtemanche, M. Complex Spiral Wave Dynamics in a Spatially Distributed Ionic Model of Cardiac Electrical Activity. Chaos 1996, 6, 579-600.

328. Efimov, I.R.; Krinsky, V.I.; Jalife, J. Dynamics of Rotating Vortices in the Beeler-Reuter Model of Cardiac Tissue. Chaos Solitons Fractals 1995, 5, 513-526.

329. Elder, K.; Grant, M. Modeling Elastic and Plastic Deformations in Nonequilibrium Processing Using Phase Field Crystals. Physical Review E 2004, 70, doi:10.1103/PhysRevE.70.051605.

330. Wang, Q.; Zhang, G.; Li, Y.; Hong, Z.; Wang, D.; Shi, S. Application of Phase-Field Method in Rechargeable Batteries. npj Computational Materials 2020, 6, 176. 
331. Wheeler, D.; Keller, T.; DeWitt, S.J.; Jokisaari, A.M.; Schwen, D.; Guyer, J.E.; Aagesen, L.K.; Heinonen, O.G.; Tonks, M.R.; Voorhees, P.W.; et al. PFHub: The Phase-Field Community Hub. J. Open Res. Softw. 2019, 7, doi:10.5334/jors.276.

332. DeWitt, S.; Rudraraju, S.; Montiel, D.; Andrews, W.B.; Thornton, K. PRISMS-PF: A General Framework for Phase-Field Modeling with a Matrix-Free Finite Element Method. npj Computational Materials 2020, 6, 1-12.

333. Permann, C.J.; Gaston, D.R.; Andrš, D.; Carlsen, R.W.; Kong, F.; Lindsay, A.D.; Miller, J.M.; Peterson, J.W.; Slaughter, A.E.; Stogner, R.H.; et al. MOOSE: Enabling Massively Parallel Multiphysics Simulation. SoftwareX 2020, 11, 100430.

334. Cimrman, R.; Lukeš, V.; Rohan, E. Multiscale Finite Element Calculations in Python Using SfePy. Adv. Comput. Math. 2019, 45, 1897-1921.

335. Guyer, J.E.; Wheeler, D.; Warren, J.A. FiPy: Partial Differential Equations with Python. Computing in Science Engineering 2009, 11, 6-15.

336. Silber, S.A.; Karttunen, M. SymPhas --General Purpose Software for Phase-Field, Phase-Field Crystal and Reaction-Diffusion Simulations. Adv. Theory Sim. 2021, accepted.

337. Wheeler, A.A.; Boettinger, W.J.; McFadden, G.B. Phase-Field Model for Isothermal Phase Transitions in Binary Alloys. Phys. Rev. A 1992, 45, 7424-7439.

338. Elder, K.R.; Drolet, F.; Kosterlitz, J.M.; Grant, M. Stochastic Eutectic Growth. Phys. Rev. Lett. 1994, 72, 677-680.

339. Karma, A. Phase-Field Model of Eutectic Growth. Phys. Rev. E Stat. Phys. Plasmas Fluids Relat. Interdiscip. Topics 1994, 49, 22452250 .

340. Wheeler, A.A.; McFadden, G.B.; Boettinger, W.J. Phase-Field Model for Solidification of a Eutectic Alloy. Proceedings of the Royal Society of London. Series A: Mathematical, Physical and Engineering Sciences 1996, 452, 495-525.

341. Gyoon Kim, S.; Tae Kim, W.; Suzuki, T.; Ode, M. Phase-Field Modeling of Eutectic Solidification. J. Cryst. Growth 2004, 261, 135158.

342. Choudhury, A.N. Quantitative Phase-Field Model for Phase Transformations in Multi-Component Alloys 2012.

343. Choudhury, A.; Nestler, B. Grand-Potential Formulation for Multicomponent Phase Transformations Combined with ThinInterface Asymptotics of the Double-Obstacle Potential. Phys. Rev. E Stat. Nonlin. Soft Matter Phys. 2012, 85, 021602.

344. Plapp, M. Unified Derivation of Phase-Field Models for Alloy Solidification from a Grand-Potential Functional. Phys. Rev. E Stat. Nonlin. Soft Matter Phys. 2011, 84, 031601.

345. Nestler, B.; Garcke, H.; Stinner, B. Multicomponent Alloy Solidification: Phase-Field Modeling and Simulations. Phys. Rev. E Stat. Nonlin. Soft Matter Phys. 2005, 71, 041609.

346. Steinmetz, P.; Hötzer, J.; Kellner, M.; Genau, A.; Nestler, B. Study of Pattern Selection in 3D Phase-Field Simulations during the Directional Solidification of Ternary Eutectic Al-Ag-Cu. Comput. Mater. Sci. 2018, 148, 131-140.

347. Kollau, L.J.B.M.; Vis, M.; van den Bruinhorst, A.; Tuinier, R.; de With, G. Entropy Models for the Description of the Solid-liquid Regime of Deep Eutectic Solutions. J. Mol. Liq. 2020, 302, 112155.

348. Cosby, T.; Kapoor, U.; Shah, J.K.; Sangoro, J. Mesoscale Organization and Dynamics in Binary Ionic Liquid Mixtures. J. Phys. Chem. Lett. 2019, 10, 6274-6280.

349. Ding, Y.; Zhang, C.; Zhang, L.; Wei, H.; Li, Y.; Yu, G. Insights into Hydrotropic Solubilization for Hybrid Ion Redox Flow Batteries. ACS Energy Lett. 2018, 3, 2641-2648.

350. Zahrina, I.; Nasikin, M.; Mulia, K.; Prajanto, M.; Yanuar, A. Molecular Interactions between Betaine Monohydrate-Glycerol Deep Eutectic Solvents and Palmitic Acid: Computational and Experimental Studies. J. Mol. Liq. 2018, 251, 28-34.

351. Zahrina, I.; Mulia, K.; Yanuar, A.; Nasikin, M. Molecular Interactions in the Betaine Monohydrate-Polyol Deep Eutectic Solvents: Experimental and Computational Studies. J. Mol. Struct. 2018, 1158, 133-138. 
352. Pauric, A.D.; Halalay, I.C.; Goward, G.R. Combined NMR and Molecular Dynamics Modeling Study of Transport Properties in Sulfonamide Based Deep Eutectic Lithium Electrolytes: LiTFSI Based Binary Systems. Phys. Chem. Chem. Phys. 2016, 18, 66576667.

353. Karibayev, M.; Shah, D. Comprehensive Computational Analysis Exploring the Formation of Caprolactam-Based Deep Eutectic Solvents and Their Applications in Natural Gas Desulfurization. Energy Fuels 2020, 34, 9894-9902.

354. Chatterjee, S.; Ghosh, D.; Haldar, T.; Deb, P.; Sakpal, S.S.; Deshmukh, S.H.; Kashid, S.M.; Bagchi, S. Hydrocarbon Chain-Length Dependence of Solvation Dynamics in Alcohol-Based Deep Eutectic Solvents: A Two-Dimensional Infrared Spectroscopic Investigation. J. Phys. Chem. B 2019, 123, 9355-9363.

355. Chatterjee, S.; Haldar, T.; Ghosh, D.; Bagchi, S. Electrostatic Manifestation of Micro-Heterogeneous Solvation Structures in Deep-Eutectic Solvents: A Spectroscopic Approach. J. Phys. Chem. B 2020, 124, 3709-3715.

356. Cui, Y.; Fulfer, K.D.; Ma, J.; Weldeghiorghis, T.K.; Kuroda, D.G. Solvation Dynamics of an Ionic Probe in Choline ChlorideBased Deep Eutectic Solvents. Phys. Chem. Chem. Phys. 2016, 18, 31471-31479.

357. Liu, C.; Fang, H.; Liu, X.; Xu, B.; Rao, Z. Novel Silica Filled Deep Eutectic Solvent Based Nanofluids for Energy Transportation. ACS Sustainable Chem. Eng. 2019, 7, 20159-20169.

358. Barani Pour, S.; Jahanbin Sardroodi, J.; Rastkar Ebrahimzadeh, A. The Study of Structure and Interactions of Glucose-Based Natural Deep Eutectic Solvents by Molecular Dynamics Simulation. J. Mol. Liq. 2021, 334, 115956.

359. Mamashli, F.; Badraghi, J.; Delavari, B.; Lanjanian, H.; Sabbaghian, M.; Hosseini, M.; Saboury, A.A. Improvement of Versatile Peroxidase Activity and Stability by a Cholinium-Based Ionic Liquid. J. Mol. Liq. 2018, 272, 597-608.

360. Lehmann, C.; Bocola, M.; Streit, W.R.; Martinez, R.; Schwaneberg, U. Ionic Liquid and Deep Eutectic Solvent-Activated CelA2 Variants Generated by Directed Evolution. Appl. Microbiol. Biotechnol. 2014, 98, 5775-5785.

361. Bittner, J.P.; Huang, L.; Zhang, N.; Kara, S.; Jakobtorweihen, S. Comparison and Validation of Force Fields for Deep Eutectic Solvents in Combination with Water and Alcohol Dehydrogenase. J. Chem. Theory Comput. 2021, 17, 5322-5341.

362. Ji, H.; Lv, P. Mechanistic Insights into the Lignin Dissolution Behaviors of a Recyclable Acid Hydrotrope, Deep Eutectic Solvent (DES), and Ionic Liquid (IL). Green Chem. 2020, 22, 1378-1387.

363. Yan, W.-W.; Zong, Z.-M.; Li, Z.-X.; Li, J.; Liu, G.-H.; Ma, Z.-H.; Zhang, Y.-Y.; Xu, M.-L.; Liu, F.-J.; Wei, X.-Y. Effective Separation and Purification of Nitrogen-Containing Aromatics from the Light Portion of a High-Temperature Coal Tar Using Choline Chloride and Malonic Acid: Experimental and Molecular Dynamics Simulation. ACS Sustainable Chem. Eng. 2020, 8, $9464-9471$.

364. Triolo, A.; Lo Celso, F.; Russina, O. Structural Features of $\beta$-Cyclodextrin Solvation in the Deep Eutectic Solvent, Reline. J. Phys. Chem. B 2020, 124, 2652-2660.

365. Hammond, O.S.; Bowron, D.T.; Edler, K.J. Liquid Structure of the Choline Chloride-Urea Deep Eutectic Solvent (reline) from Neutron Diffraction and Atomistic Modelling. Green Chem. 2016, 18, 2736-2744.

366. Gupta, R.; Vats, B.; Pandey, A.K.; Sharma, M.K.; Sahu, P.; Yadav, A.K.; Ali, S.M.; Kannan, S. Insight into Speciation and Electrochemistry of Uranyl Ions in Deep Eutectic Solvents. J. Phys. Chem. B 2020, 124, 181-189.

367. Zhang, Y.; You, Y.; Gao, Q.; Zhang, C.; Wang, S.; Qin, Y.; Zhu, Y.; Lu, X. Molecular Insight into Flow Resistance of Choline Chloride/urea Confined in Ionic Model Nanoslits. Fluid Phase Equilib. 2021, 533, 112934.

368. Sarkar, S.; Maity, A.; Chakrabarti, R. Microscopic Structural Features of Water in Aqueous-Reline Mixtures of Varying Compositions. Phys. Chem. Chem. Phys. 2021, 23, 3779-3793.

369. Shah, D.; Mansurov, U.; Mjalli, F.S. Intermolecular Interactions and Solvation Effects of Dimethylsulfoxide on Type III Deep Eutectic Solvents. Phys. Chem. Chem. Phys. 2019, 21, 17200-17208.

370. Abedin, R.; Heidarian, S.; Flake, J.C.; Hung, F.R. Computational Evaluation of Mixtures of Hydrofluorocarbons and Deep Eutectic Solvents for Absorption Refrigeration Systems. Langmuir 2017, 33, 11611-11625. 
371. Zhekenov, T.; Toksanbayev, N.; Kazakbayeva, Z.; Shah, D.; Mjalli, F.S. Formation of Type III Deep Eutectic Solvents and Effect of Water on Their Intermolecular Interactions. Fluid Phase Equilib. 2017, 441, 43-48.

372. Aryafard, M.; Abbasi, M.; Řeha, D.; Harifi-Mood, A.R.; Minofar, B. Experimental and Theoretical Investigation of Solvatochromic Properties and Ion Solvation Structure in DESs of Reline, Glyceline, Ethaline and Their Mixtures with PEG 400. J. Mol. Liq. 2019, 284, 59-67.

373. Harifi-Mood, A.R.; Ghobadi, R.; Matić, S.; Minofar, B.; Řeha, D. Solvation Analysis of Some Solvatochromic Probes in Binary Mixtures of Reline, Ethaline, and Glyceline with DMSO. J. Mol. Liq. 2016, 222, 845-853.

374. Salehi, H.S.; Ramdin, M.; Moultos, O.A.; Vlugt, T.J.H. Computing Solubility Parameters of Deep Eutectic Solvents from Molecular Dynamics Simulations. Fluid Phase Equilib. 2019, 497, 10-18.

375. Atilhan, M.; Aparicio, S. Behavior of Deep Eutectic Solvents under External Electric Fields: A Molecular Dynamics Approach. J. Phys. Chem. B 2017, 121, 221-232.

376. Vraneš, M.; Tot, A.; Papović, S.; Panić, J.; Gadžurić, S. Is Choline Kosmotrope or Chaotrope? J. Chem. Thermodyn. 2018, 124, 6573.

377. Triolo, A.; Lo Celso, F.; Brehm, M.; Di Lisio, V.; Russina, O. Liquid Structure of a Choline Chloride-Water Natural Deep Eutectic Solvent: A Molecular Dynamics Characterization. J. Mol. Liq. 2021, 331, 115750.

378. Malik, A.; Kashyap, H.K. Multiple Evidences of Dynamic Heterogeneity in Hydrophobic Deep Eutectic Solvents. J. Chem. Phys. 2021, 155, 044502.

379. Mjalli, F.S.; Shah, D. Simulation Based Insight into Solvation Properties of Ferric Chloride Based Eutectic Solvent., doi:10.3303/CET1543308.

380. Srinivasan, H.; Sharma, V.K.; Mitra, S. Water Accelerates the Hydrogen-Bond Dynamics and Abates Heterogeneity in Deep Eutectic Solvent Based on Acetamide and Lithium Perchlorate. J. Chem. Phys. 2021, 155, 024505.

381. Lesch, V.; Heuer, A.; Rad, B.R.; Winter, M.; Smiatek, J. Atomistic Insights into Deep Eutectic Electrolytes: The Influence of Urea on the Electrolyte Salt LiTFSI in View of Electrochemical Applications. Phys. Chem. Chem. Phys. 2016, 18, 28403-28408.

382. Nandy, A.; Smiatek, J. Mixtures of LiTFSI and Urea: Ideal Thermodynamic Behavior as Key to the Formation of Deep Eutectic Solvents? Phys. Chem. Chem. Phys. 2019, 21, 12279-12287.

383. Ahmad, N.; Lin, X.; Wang, X.; Xu, J.; Xu, X. Understanding the CO2 Capture Performance by MDEA-Based Deep Eutectics Solvents with Excellent Cyclic Capacity. Fuel 2021, 293, 120466.

384. Sanam; Bux, K.; al-Rashida, M.; Alharthy, R.D.; Moin, S.T.; Hameed, A. Morpholinium and Piperidinium Based Deep Eutectic Solvents for Synthesis of pyrazole-5-carbonitriles, Indoles and Tetrazoles: Bulk PropertiesviaMolecular Dynamics Simulations. ChemistrySelect 2018, 3, 12907-12917.

385. Panda, D.K.; Bhargava, B.L. Intermolecular Interactions in Tetrabutylammonium Chloride Based Deep Eutectic Solvents: Classical Molecular Dynamics Studies. J. Mol. Liq. 2021, 335, 116139.

386. Lima, F.; Dietz, C.H.J.T.; Silvestre, A.J.D.; Branco, L.C.; Canongia Lopes, J.; Gallucci, F.; Shimizu, K.; Held, C.; Marrucho, I.M. Vapor Pressure Assessment of Sulfolane-Based Eutectic Solvents: Experimental, PC-SAFT, and Molecular Dynamics. J. Phys. Chem. B 2020, 124, 10386-10397.

387. Gapeyenko, D.; Jamwal, P.; Shah, D. Molecular Dynamics Simulations to Design Novel Solvents for Deep Desulfurization. In Proceedings of the Advanced Materials; Springer International Publishing, 2018; pp. 119-124.

388. Wu, X.; Cheng, N.-N.; Jiang, H.; Zheng, W.-T.; Chen, Y.; Huang, K.; Liu, F. 1-Ethyl-3-Methylimidazolium Chloride plus Imidazole Deep Eutectic Solvents as Physical Solvents for Remarkable Separation of H2S from CO2. Sep. Purif. Technol. 2021, $276,119313$.

389. Altamash, T.; Amhamed, A.I.; Aparicio, S.; Atilhan, M. Combined Experimental and Theoretical Study on High Pressure Methane Solubility in Natural Deep Eutectic Solvents. Ind. Eng. Chem. Res. 2019, 58, 8097-8111. 
390. Kalhor, P.; Yarivand, O.; Seifpanahi-Shabani, K. Quantum Chemical Calculations on Dissolution of Dimethylformamide in Ethaline. J. Mol. Graph. Model. 2021, 107, 107966.

391. Zhong, F.-Y.; Zhou, L.; Shen, J.; Liu, Y.; Fan, J.-P.; Huang, K. Rational Design of Azole-Based Deep Eutectic Solvents for Highly Efficient and Reversible Capture of Ammonia. ACS Sustainable Chem. Eng. 2019, 7, 14170-14179.

392. Jangir, A.K.; Lad, B.; Dani, U.; Shah, N.; Kuperkar, K. In Vitro Toxicity Assessment and Enhanced Drug Solubility Profile of Green Deep Eutectic Solvent Derivatives (DESDs) Combined with Theoretical Validation. RSC Adv. 2020, 10, $24063-24072$.

393. Ghenaatian, H.R.; Shakourian-Fard, M.; Kamath, G. Interaction of Cun, Agn and Aun (n=1-4) Nanoparticles with ChCl:Urea Deep Eutectic Solvent. J. Mol. Graph. Model. 2021, 105, 107866.

394. El-hoshoudy, A.N.; Soliman, F.S.; Mansour, E.M.; Zaki, T.; Desouky, S.M. Experimental and Theoretical Investigation of Quaternary Ammonium-Based Deep Eutectic Solvent for Secondary Water Flooding. J. Mol. Liq. 2019, 294, 111621. 